\title{
OECD MCCI-2 Project Final Report
}

\author{
Rev. 1-Final
}

November 2010

by:

M. T. Farmer, S. Lomperski, D. J. Kilsdonk, and R. W. Aeschlimann

Nuclear Engineering Division

Argonne National Laboratory

9700 S. Cass Avenue

Argonne, IL 60439 USA 


\section{Table of Contents}

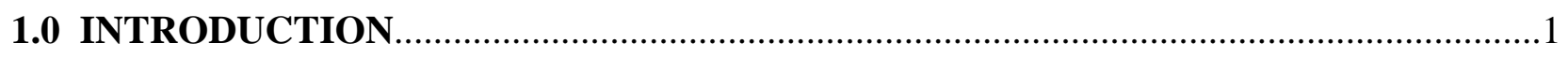

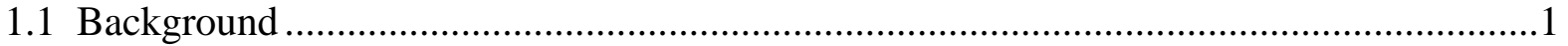

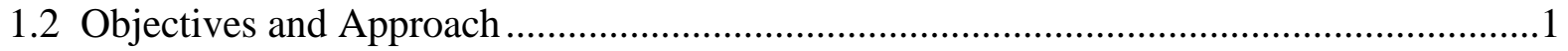

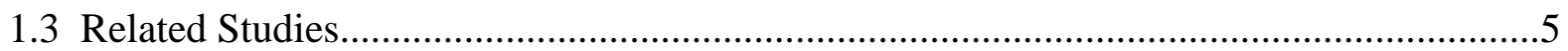

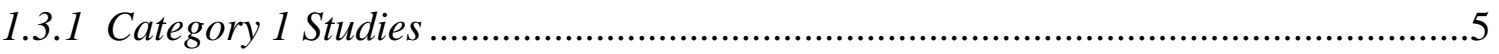

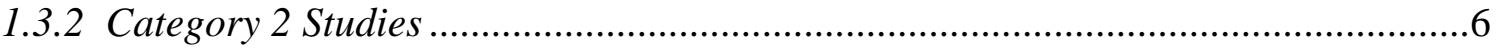

1.3.3 Category 3 Studies .......................................................................................

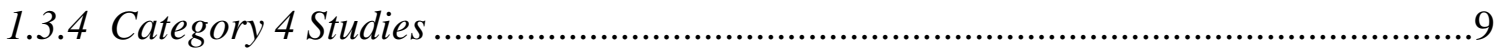

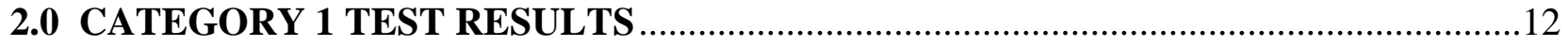

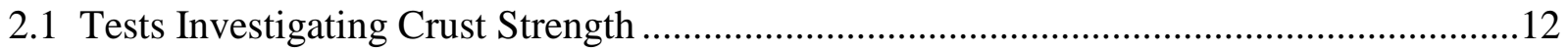

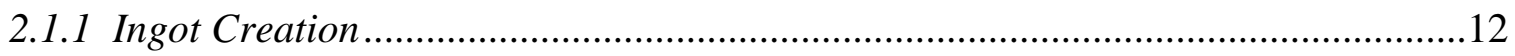

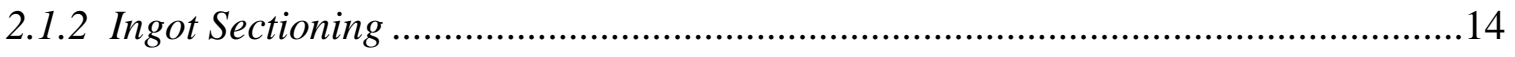

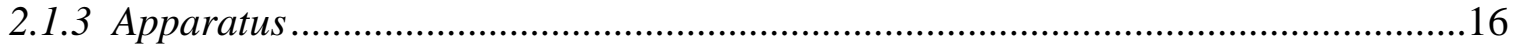

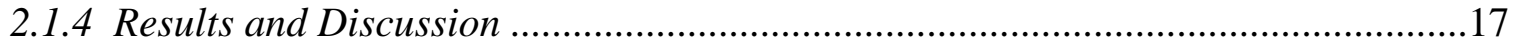

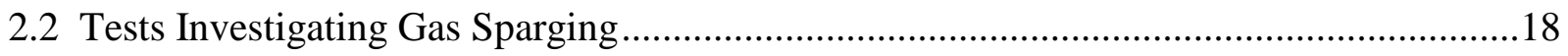

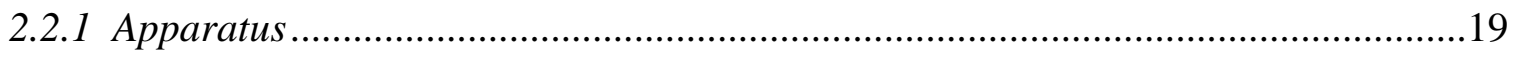

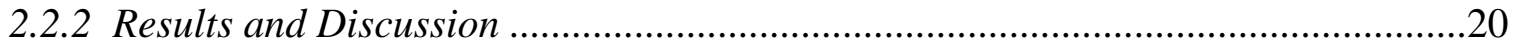

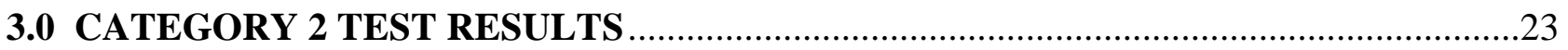

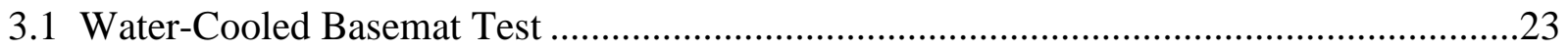

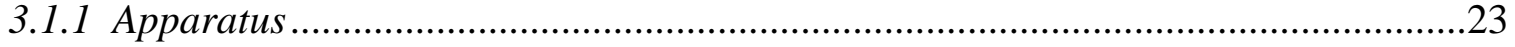

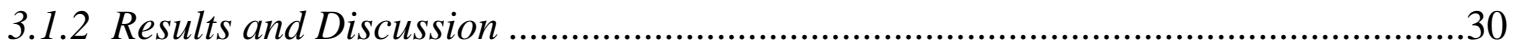

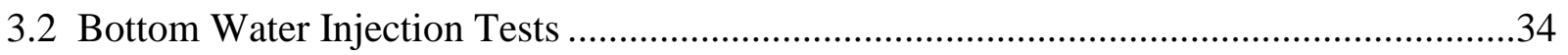

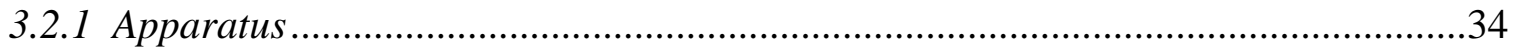

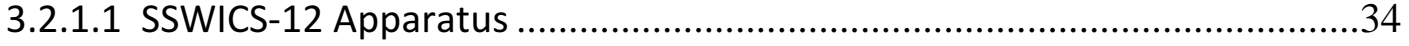

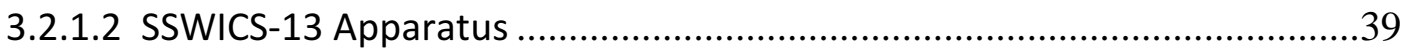

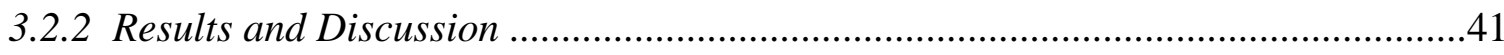




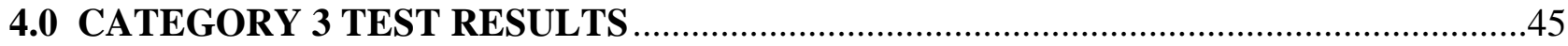

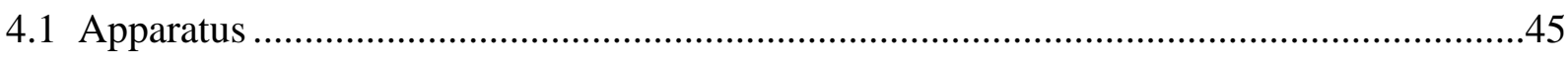

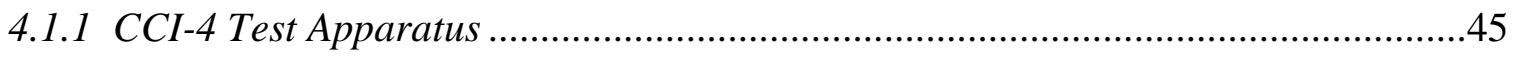

4.1.2 CCI-5 Test Apparatus .............................................................................49

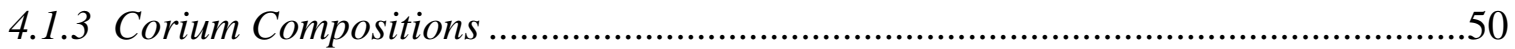

4.1.4 Concrete Compositions ............................................................................51

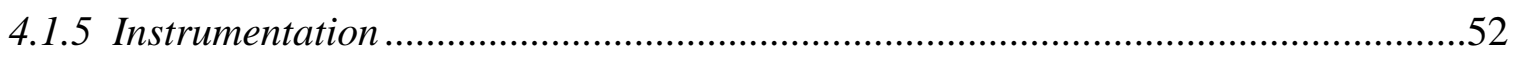

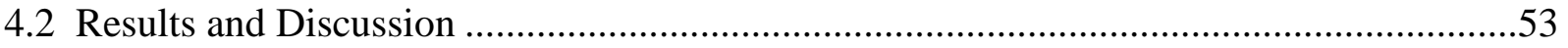

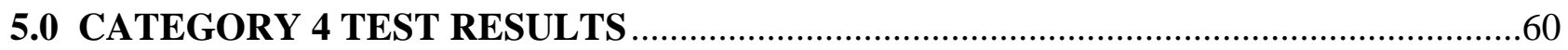

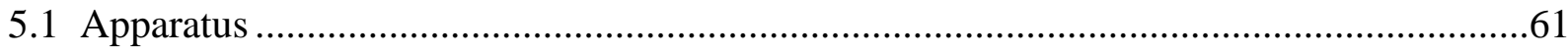

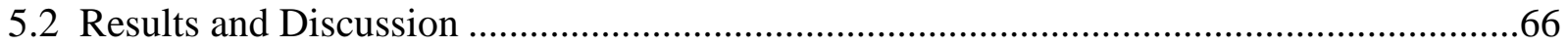

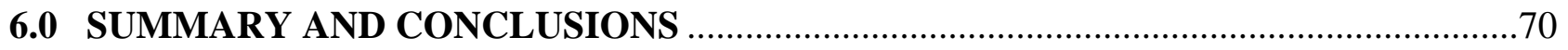

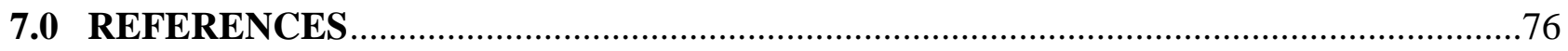

APPENDIX A: BIBLIOGRAPHY OF MCCI-2 PROJECT REPORTS ..............................82 


\section{List of Figures}

Figure

Page

2-1 Crust Anchoring with Thermal Decoupling from Melt

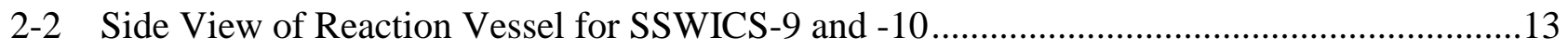

2-3 Middle Section of Ingot 6 after Cutting .......................................................................... 15

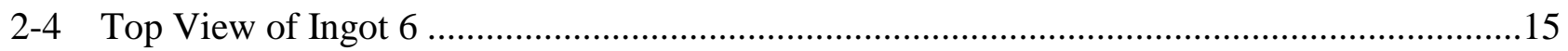

2-5 Bottom View of Ingot 10, which was not Sectioned .................................................15

2-6 Apparatus for Applying Mechanical Loads to Corium Sections at Room

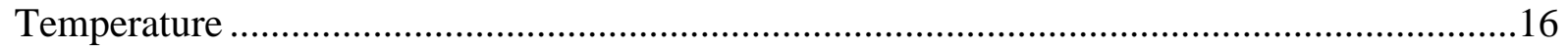

2-7 Load Test Data for the Bottom Section of Ingot 6........................................................ 17

2-8 Maximum Centerline Stress before Fracture for Ingot Sections under Point Load at Room Temperature

2-9 Comparison between Measured Section Strength and Calculated Peak Stress in a 6 m Diameter, Self Supported Crust.

2-10 SSWICS-11 Tungsten Tube Layout with Capillaries Extending 50 mm Above 19 the Basemat.

2-11 SSWICS-11 Tungsten Tube Layout with Capillaries Extending 50 mm Above the Basemat..... .21

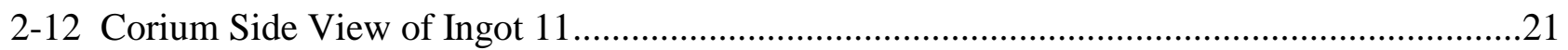

2-13 Corium at Level of Top of Tungsten Thermowell after Removal of Upper Layers

2-14 (a) Heat Flux for Tests with Sparging (11) and Without (8 \& 6); Melt Composition and Quench Conditions are Identical for the Three Tests. (b) Calculated Heat Flux for all Nine Quench Tests....

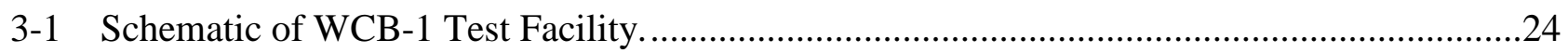

3-2 (a) Electrode and (b) Non-Electrode Sidewall Views of WCB-1 Lower Test Section. ...........26

3-3 (a) Design Details and (b) Instrument Feed Through Locations for Water-Cooled Basemat Plate.

3-4 (a) Plan View of Basemat Instrumentation and (b) Elevation View of Type C Instrument Locations

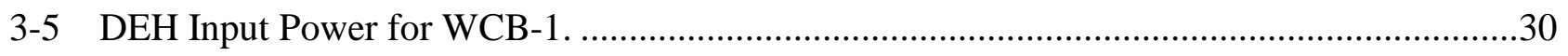

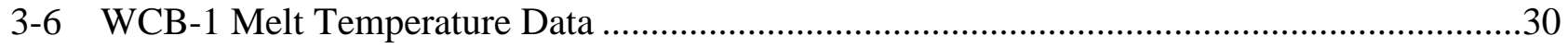

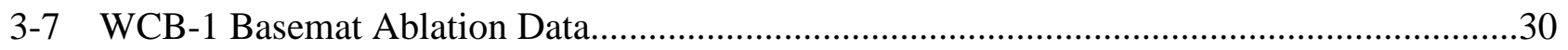




\section{List of Figures (Contd.)}

Figure

Page

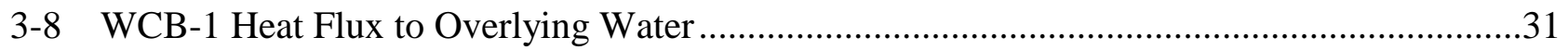

3-9 Data from All Water-Cooled Basemat Heat Flux Meters ....................................................31

3-10 Water-Cooled Basemat Upper Surface Temperatures ...................................................31

3-11 (a) Rendering of WCB-1 Posttest Debris; (b) Photo of Top Surface of Water-Cooled Plate after Debris Removal...................................................................... 32

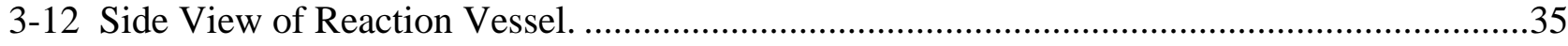

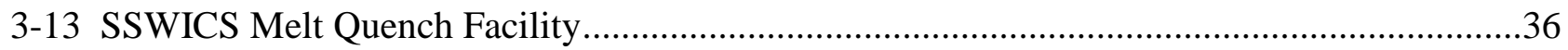

3-14 (a) Design Details and (b) Photograph of SSWICS-12 Lower Plenum................................37

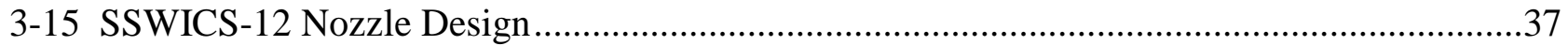

3-16 (a) Design Details and (b) Photograph of SSWICS-13 Lower Plenum................................40

3-17 Details of Nozzle Design with Gas Injection .............................................................40

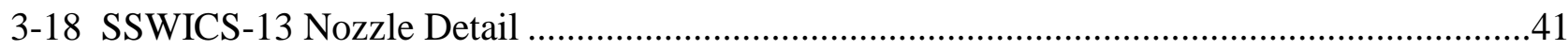

3-19 SSWICS-12 Melt Temperatures in Quadrants with (a) 0.1 and (b) 0.2 Bar Static Water Head

3-20 SSWICS-13 Melt Temperatures in Partitions with (a) Water Only and

(b) Gas-Water Nozzles ......................................................................................42

3-21 Debris-Water Heat Fluxes for (a) SSWICS-12 and (b) SSWICS-13 ................................43

3-22 Posttest Debris Distributions for (a) SSWICS-12 and (b) SSWICS-13 ..............................43

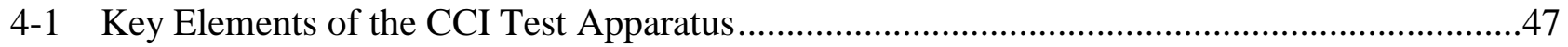

4-2 Side View of CCI-4 Lower Test Section Showing Concrete Sidewall Sections ....................47

4-3 Top View of CCI-4 Lower Test Section........................................................................48

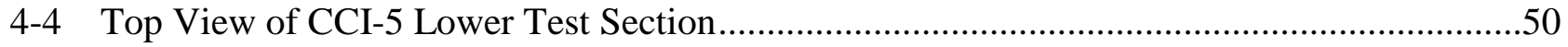

4-5 Side View of CCI-5 Lower Test Section Showing Concrete Sidewall ................................50

4-6 Plan View of CCI-4 Basemat Instrument Locations......................................................52

4-7 Plan View of CCI-5 Basemat Instrument Locations.........................................................53

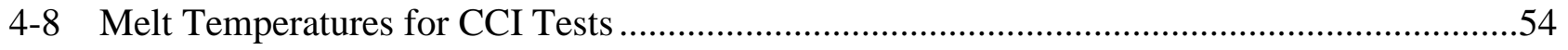

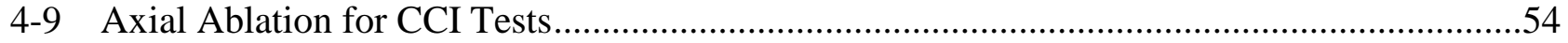

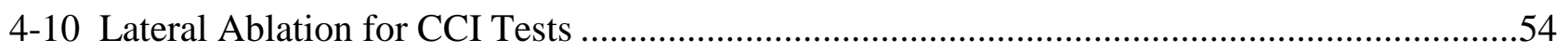




\section{List of Figures (Contd.)}

Figure

4-11 Axial Debris Morphology for Siliceous Concrete Tests (a) CCI-1, (b) CCI-3, and

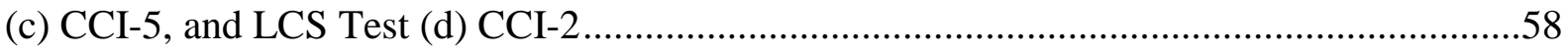

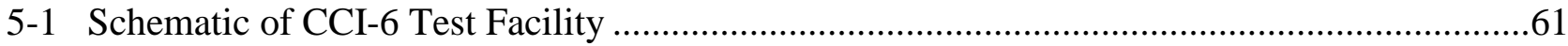

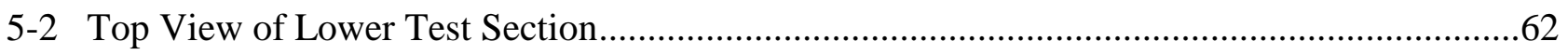

5-3 Side View of CCI-6 Lower Test Section ....................................................................62

5-4 Plan View of CCI-6 Basemat Instrumentation ...........................................................65

5-5 CCI-6 DEH Input Power.......................................................................................6

5-6 CCI-6 Axial and Radial Ablation Depth Data vs. Time ...................................................66

5-7 CCI-6 Top Flooding Debris-Water Heat Flux .............................................................66

5-8 Melt Temperatures Measured (a) Radially Near North Concrete Wall, (b) Axially Near Test Section Centerline, and (c) Radially Near South Concrete Wall ..........................67

5-9 Rendering of CCI-6 Posttest Debris Configuration ...................................................68

5-10 Photographs of (a) Particle Bed and (b) Fractured Crust Debris Regions ..............................69 


\section{List of Tables}

Table Page

1-1 Summary of Coolability Mechanisms Observed in Integral Tests [1]. ...............................2

1-2 Summary of Tests Completed as Part of the MCCI-2 Program ...........................................2

2-1 Specifications for SSWICS Quench Experiments that Produced the Ingots .........................14

2-2 Source Data for Calculation of Section Strength.......................................................... 16

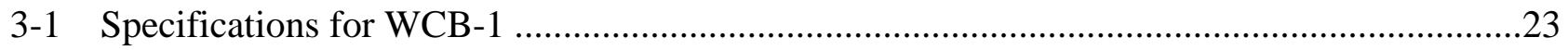

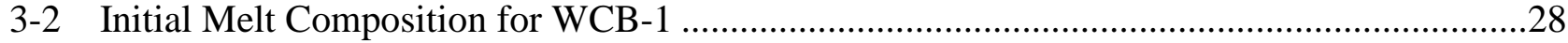

3-3 Composition of WCB-1 Siliceous Concrete.....................................................................28

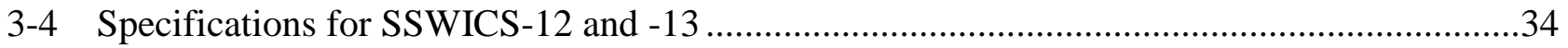

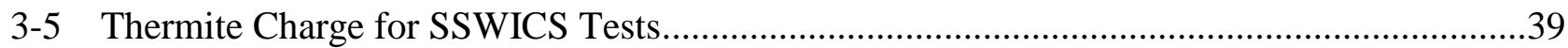

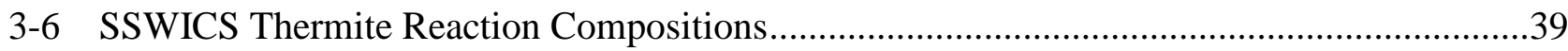

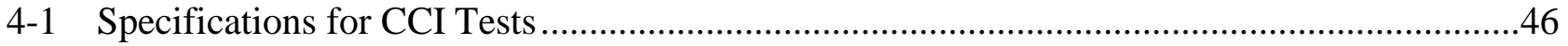

4-2 Chemical Composition of Concretes ...........................................................................51

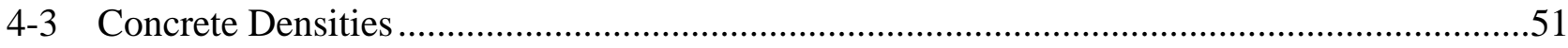

4-4 Detailed Melt Compositions at the Start of Basemat Ablation .............................................52

4-5 Lateral/Axial Ablation Rate and Power Split Estimates for CCI Tests .................................56

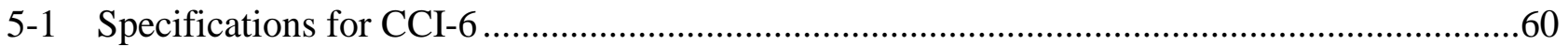

5-2 Chemical Composition of CCI-6 Siliceous Concrete......................................................64

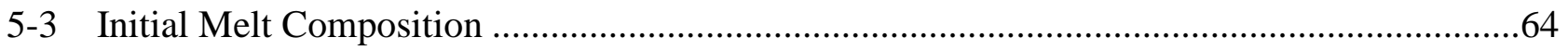




\subsection{INTRODUCTION}

\subsection{Background}

Ex-vessel debris coolability is an important light water reactor (LWR) technical challenge. For existing plants, resolution of this challenge will confirm the technical basis for severe accident management guidelines (SAMGs). For new reactors, understanding this challenge will help confirm the effectiveness of the design and implementation of new accident mitigation features and severe accident management design alternatives (SAMDAs). The first OECD-MCCI program (MCCI-1) [1] conducted reactor material experiments focused on achieving the following technical objectives: i) provide confirmatory evidence and data for various cooling mechanisms through separate effect tests for severe accident model development, and ii) provide long-term 2-D core-concrete interaction data for code assessment and improvement. Debris cooling mechanisms investigated as part of this program included: i) water ingression through cracks/fissures in the core debris, ii) melt eruptions caused by gas sparging, and iii) large-scale crust mechanical failure leading to renewed bulk cooling. Additional descriptions of these mechanisms are provided in Table 1-1. The results of testing and associated analysis provided an envelope (principally determined by melt depth) for debris coolability. However, this envelope did not encompass the full range of potential melt depths for all plant accident sequences. Cooling augmentation by additional means may be needed at the late stage to assure coolability for new reactor designs as well as for various accident sequences for existing reactors. In addition, the results of the CCI tests showed that lateral/axial power split is a function of concrete type. However, the first program produced limited data sets for code assessment. In light of significant differences in ablation behavior for different concrete types, additional data would be useful in reducing uncertainties and gaining confidence in code predictions.

Based on these findings, a broad workscope was defined for the follow-on MCCI-2 program. The workscope was divided into the following four categories:

1. Combined effect tests to investigate the interplay of different cooling mechanisms, and to provide data for model development and code assessment purposes.

2. Tests to investigate new design features to enhance coolability, applicable particularly to new reactor designs.

3. Tests to generate two-dimensional core-concrete interaction data.

4. Integral tests to validate severe accident codes.

In addition to the experimental work, an analysis task was defined to develop and validate coolability models to form the basis for extrapolating the experiment findings to plant conditions.

\subsection{Objectives and Approach}

As part of the steps to satisfy these objectives, a total of 10 successful reactor material experiments were carried out across the four test categories described above; these tests are summarized in Table 1-2, along with a description of key findings from each test category. 
Table 1-1. Summary of Coolability Mechanisms Observed in Integral Tests [1].

\begin{tabular}{|c|l|l|}
\hline Mechanism & \multicolumn{1}{|c|}{ Description } & \multicolumn{1}{c|}{ Experimental Evidence } \\
\hline $\begin{array}{c}\text { Bulk } \\
\text { Cooling }\end{array}$ & $\begin{array}{l}\text { Melt sparging rate is initially high enough to } \\
\text { preclude stable crust formation at melt/water } \\
\text { interface, resulting in high heat transfer rates due } \\
\text { to conduction and radiation across the agitated } \\
\text { (area enhanced) interface. Phase terminated } \\
\text { when a stable interfacial crust forms. }\end{array}$ & $\begin{array}{l}\text { High heat transfer rates measured during } \\
\text { early phase of the melt-water interaction. } \\
\text { Data indicates that a coherent crust cannot } \\
\text { form; rather, crust segments are broken up } \\
\text { and mixed into melt. Validated models } \\
\text { have been developed for this mechanism. }\end{array}$ \\
$\begin{array}{c}\text { Melt } \\
\text { Eruptions }\end{array}$ & $\begin{array}{l}\text { Melt dispersal occurs by an entrainment } \\
\text { mechanism where sparging gas carries melt } \\
\text { through defects in the crust into the overlying } \\
\text { coolant. The dispersed material is quenched as a } \\
\text { coolable bed of particles and high surface area } \\
\text { volcanic formations. }\end{array}$ & $\begin{array}{l}\text { Eruptions have been observed in all tests } \\
\text { conducted with limestone-common sand } \\
\text { concrete after crust formation. The } \\
\text { particle beds are characterized by high } \\
\text { porosity and large particle size. }\end{array}$ \\
Water & $\begin{array}{l}\text { Corium shrinkage during quench is 18 vol\%. } \\
\text { This causes voids/defects to appear in the frozen } \\
\text { Ingterial. Water penetrates down through the } \\
\text { voids/defects, augmenting the otherwise } \\
\text { conduction-limited heat transfer process. }\end{array}$ & $\begin{array}{l}\text { Melt/water heat flux far exceeds that } \\
\text { which could by transferred by conduction } \\
\text { across the (up to 10 cm) thick crusts } \\
\text { formed during the tests. Posttest } \\
\text { measurements indicate that crusts are } \\
\text { permeable. }\end{array}$ \\
\hline $\begin{array}{c}\text { Crust } \\
\text { Breach }\end{array}$ & $\begin{array}{l}\text { Due to water ingression, thick crusts form and } \\
\text { bond to the cavity walls. These crusts will not } \\
\text { stable in the typical span of most plants. Thus, } \\
\text { they will fail, leading to renewed cooling by the } \\
\text { above mechanisms. }\end{array}$ & $\begin{array}{l}\text { Partial crust failures observed in MACE } \\
\text { integral effects tests. Various structural - } \\
\text { mechanical analyses have shown that } \\
\text { crusts will not be stable at reactor scale. }\end{array}$ \\
\hline
\end{tabular}

Table 1-2. Summary of Tests Completed as Part of the MCCI-2 Program.

\begin{tabular}{|c|c|c|c|c|}
\hline $\begin{array}{l}\text { Cat. } \\
\text { No. }\end{array}$ & Task Description & $\begin{array}{c}\text { No. of } \\
\text { Tests } \\
\text { Proposed }\end{array}$ & $\begin{array}{l}\text { No. of Tests } \\
\text { Completed }\end{array}$ & Summary of Findings \\
\hline 1 & $\begin{array}{l}\text { Combined effect tests } \\
\text { to investigate the } \\
\text { interplay of different } \\
\text { cooling mechanisms }\end{array}$ & up to 4 & $\begin{array}{c}4: \\
\text { SSWICS-8 to } 11\end{array}$ & $\begin{array}{l}\text { 1) Confirmed prototypicality of crust strength } \\
\text { measurements made in MCCI-1. } \\
\text { 2) Demonstrated that gas sparging during CCI } \\
\text { can enhance crust water ingression cooling. }\end{array}$ \\
\hline 2 & $\begin{array}{l}\text { Tests to investigate } \\
\text { new design features } \\
\text { to enhance coolability }\end{array}$ & $\begin{array}{l}\text { up to } 4 \\
\text { small } \\
\text { scale or } \\
1-2 \text { large } \\
\text { scale }\end{array}$ & $\begin{array}{l}2 \text { small scale: } \\
\text { SSWICS-12, } 13 \\
1 \text { large scale: } \\
\text { WCB-1 }\end{array}$ & $\begin{array}{l}\text { 1) Provided data on the effects of water head } \\
\text { and concurrent NC gas injection on the } \\
\text { efficacy of bottom water injection cooling } \\
\text { 2) Demonstrated transient evolution and } \\
\text { stabilization of a core melt over a water- } \\
\text { cooled steel plate. }\end{array}$ \\
\hline 3 & $\begin{array}{l}\text { Tests to provide } \\
\text { additional 2-D core- } \\
\text { concrete interaction } \\
\text { data }\end{array}$ & $1-2$ & $\begin{array}{c}2: \\
\text { CCI-4, CCI-5 }\end{array}$ & $\begin{array}{l}\text { 1) Provided data on the effect of cladding } \\
\text { oxidation state on long-term CCI. } \\
\text { 2) Demonstrated that test scale did not } \\
\text { influence rad/ax power split for SIL concrete }\end{array}$ \\
\hline 4 & $\begin{array}{l}\text { Integral tests to } \\
\text { validate severe } \\
\text { accident codes }\end{array}$ & $1-2$ & $\begin{array}{c}1: \\
\text { CCI-6 }\end{array}$ & $\begin{array}{l}\text { 1) Demonstrated that early cavity flooding } \\
\text { significantly enhances debris coolability, } \\
\text { even for siliceous concrete. } \\
\text { 2) Demonstrated that eruptions are a viable } \\
\text { cooling mechanism for siliceous concrete }\end{array}$ \\
\hline
\end{tabular}


In Category 1, four separate effects tests were completed [2] in the SSWICS test facility that was developed as part of the MCCI-1 program to investigate water ingression cooling under inert basemat conditions [3], as well as crust strength [4]. The effect of gas sparging on the water ingression cooling was investigated in two tests (i.e. SSWICS-8 and SSWICS-11) by injecting argon through capillaries embedded within the basemat. Gases generated at the bottom of the melt rose up through the corium due to buoyancy and this had the potential to create melt porosity, which may supplement the fissures induced by thermal stress cracking and enhance water ingression cooling. Conversely, two other tests (i.e. SSWICS-9 and SSWICS-10) were carried out to address the possibility that cutting ingots into thinner sections contributes to the existing crack structure and weakens samples before load testing. Ingots produced by the first seven tests in MCCI-1 were sectioned because, at a height of $15 \mathrm{~cm}$, they were too thick to fail in the desired mode when loaded with the apparatus designed to measure sample strength. This uncertainty was eliminated for the new tests by reducing the corium charge to $25 \mathrm{~kg}$ so that the quench process produced a $5 \mathrm{~cm}$ high ingot that could be load tested without first experiencing the sectioning process.

The Project Review Group (PRG) convened a subcommittee in order to guide the planning process for Category 2 experiments. Based on the committee deliberations, two general approaches for stabilizing ex-vessel core melts were defined; i.e.

1) a cold-crucible method in which decay heat from the corium is removed by cooling of the crucible exterior boundary with water, and

2) a melt fragmentation method in which water is introduced at the bottom of the melt pool at a slight overpressure, and the ensuing steam formation acts to cool and solidify the melt in a highly porous configuration that is readily permeable by water.

As shown in Table 1-2, one large scale water-cooled basemat integral effect test was conducted in this area to provide data on the cold-crucible method for melt stabilization, and two separate effect tests that utilized the SSWICS test facility were conducted to provide data on the melt fragmentation method for melt stabilization [5]. The specific objective of the Water-Cooled Basemat (WCB-1) test was to provide prototypic data on the transient evolution and stabilization of a core melt in a generic water-cooled core catcher design for advanced plant applications. The experiment approach was to incorporate a water-cooled basemat into the test apparatus used for the CCI tests [1]. Due to the longer timeframe associated with this type of experiment, it was necessary to Direct Electrically Heat (DEH) the melt to provide sufficient time for the melt to come to thermal equilibrium. The objective of the first test bottom water injection test (viz. SSWICS-12) was to evaluate the effect of pressure head on the debris cooling rate using a porous concrete nozzle design. The approach was to install four nozzles into the inert $\mathrm{MgO}$ basemat of the SSWICS apparatus; each nozzle was fed by a different header tank, and the four tanks were positioned at different elevations in the test cell in order to vary the water head to each nozzle. The test section was divided into four quadrants using a tungsten cruciform, with one nozzle in each quadrant, which basically allowed four tests to be conducted simultaneously. The objective of the second test (viz. SSWICS-13) was to examine the influence of concurrent noncondensable (i.e., $\mathrm{N}_{2}$ ) gas injection on the local debris cooling rate, since the presence of non-condensable gas 
during melt-water interaction is postulated to suppress the possibility of an energetic interaction. Four stainless steel tube nozzles were incorporated into the basemat for this test; two were fed with water only, while the other two were fed with a gas-water mixture. A tungsten cruciform was used to separate the test section into two sectors; the first side contained the water-fed nozzles, while the second contained the water-gas mixture nozzles. This approach thus allowed two tests to be conducted simultaneously. Note that DEH was not used in these tests since the heat removal rate by bottom injection significantly exceeds decay heat, and so the absence of sustained heating did not constitute a significant experiment distortion.

In Category 3, two additional large scale CCI experiments were completed [6] that were focused on broadening the database that was developed as part of the MCCI-1 program [1]. The overall objective of this test series was to provide information in the following areas: i) lateral vs. axial power split during dry core-concrete interaction, ii) integral debris coolability data following late phase flooding, and iii) data regarding the nature and extent of the cooling transient following breach of the crust formed at the melt-water interface. The experiment approach was to investigate the interaction of prototypic core melts with specially-designed 2-D concrete test sections. The initial phase of the tests was conducted under dry cavity conditions. After a predetermined time interval and/or ablation depth was reached, the cavities were flooded with water to obtain data on the coolability of core melts after core-concrete interaction had progressed for some time. Tests CCI-1 through CCI-3 in MCCI-1 [1] principally addressed the effect of concrete type on 2-D cavity erosion behavior and late phase debris coolability. Test CCI-4 expanded the parameter base addressed in the test series by examining the influence of core melt composition on cavity erosion behavior and coolability. The specific objectives were to: i) increase the metal content of the melt to the highest practical level to more accurately mock up a BWR core melt composition, and ii) modify the apparatus design to increase the duration of the dry core-concrete interaction phase. The first objective was met by placing a metal-bearing concrete insert on top of the concrete basemat that was ablated into the melt prior to onset of basemat ablation, thereby increasing the metal content to the target level. ${ }^{1}$ The second objective was met by reducing the inside dimension of the concrete crucible (i.e., $50 \mathrm{~cm}$ to $40 \mathrm{~cm}$ ) to provide more concrete for ablation, in addition to allowing the ablation to proceed to a greater depth into the crucible relative to the limits imposed in the original test series. Conversely, Test CCI-5 focused on examining the influence of melt pool aspect ratio on the radial/axial power split under dry cavity conditions. The specific objective was to increase the test section aspect ratio (i.e., test section width/melt depth) to the greatest extent possible to more accurately mock up prototypic conditions. The approach was to modify the test section design to include a single concrete sidewall that would undergo ablation, whereas the opposing sidewall was made from refractory $\mathrm{MgO}$ that essentially created an adiabatic boundary condition. The initial distance between the sidewalls was also increased from $50 \mathrm{~cm}$ to $79 \mathrm{~cm}$ to maximize the aspect ratio at the start of the experiment.

Finally, in Category 4 a single large scale integral test [8] was conducted to provide a database for validation of severe accident codes under the conditions of early cavity flooding. In

\footnotetext{
${ }^{1}$ This technique was originally developed as part of the Advanced Containment Experiment Molten Core Concrete Interaction (ACE/MCCI) test series [7] that focused on quantifying fission product source term due to core-concrete interaction.
} 
the event that the core melt was not quenched and stabilized in the early phase, an array of water injection nozzles was cast into the basemat so additional data on Category 2 bottom water injection cooling could be obtained during the late phase of the test. The experiment approach was to enlarge the test section to include a $70 \mathrm{~cm}$ x $70 \mathrm{~cm}$ basemat, and the initial melt depth was increased to $28 \mathrm{~cm}$, which corresponds to a melt mass of $900 \mathrm{~kg}$. To better reflect early flooding conditions, the thermite charge was redesigned to include a reduced amount of concrete decomposition products (i.e., $6 \mathrm{wt} \%$ ) relative to the previously performed CCI tests. In contrast to previous tests, the core melt was flooded soon after the melt was produced and before significant cavity erosion had occurred.

The purposes of this final report are to: i) summarize key results from the various test categories, and ii) evaluate the results in terms of satisfying the overall program objectives described above. To that end, a summary of related studies is provided immediately below, followed by a description of key results and findings from each of the four test categories. Additional information regarding the apparatuses, procedures, and results are provided in the final reports that were prepared for each test Category. A bibliography of all technical reports prepared as part of the MCCI-2 program is provided in Appendix A.

\subsection{Related Studies}

The purpose of this section is to identify and briefly discuss findings from related studies in the various test categories that have been addressed as part of this work. For consistency, the literature review is organized along the same lines.

\subsubsection{Category 1 Studies}

This area generally consists of separate effect and simulant material tests to provide phenomenological insights and test data to support model development and code validation activities. Areas of investigation relevant to debris coolability have included the quench rate of of melt pools and particle beds by water ingression, and the strength of crust material formed by contact with water. As discussed by Sehgal [9], the coolability of particle beds in the containment is similar to that in beds formed inside the lower head, with the primary difference being the presence of noncondensable gases sparging through the bed from concrete decomposition. The effect of countercurrent inert gas flow on the quenching process was evaluated in the POMECO test facility for beds with varying porosities [10,11]. The data indicated that for gas flowrates that are characteristic of core-concrete interactions, countercurrent gas flow reduced the quenching rate for low porosity (i.e. $26 \%$ ) particle beds, but the gases had little effect on quench rate for high porosity (i.e. $40 \%$ ) beds. In general, the effect of non-condensable gas sparging on the dry out heat flux did not appear to be large. These tests $[10,11]$ were predominately $1-\mathrm{D}$, and the POMECO facility was subsequently upgraded to examine multi-dimensional bed quenching effects [12]. These tests indicated that lateral injection of water did not significantly increase the cooling rate relative to top-down quenching scenarios. 
Aside from the heat transfer data, the SSWICS tests also provided valuable information on the mechanical strength of corium crusts that form during quench [14]. These measurements showed that the crust is quite weak, and would be unlikely to anchor to the cavity sidewalls at plant scale during an ex-vessel severe accident. The results of the MACE test series [15] clearly showed that in relatively small test sections, the crusts could anchor, eventually leading to meltcrust separation as the core-concrete interaction proceeded downward. Formation of this gap was found to effectively terminate the melt eruption and water ingression cooling processes [15]. Thus, the finding [14] that the crust will not anchor at plant scale is important since sustained melt-crust contact in a plant accident will allow these cooling mechanisms to proceed.

\subsubsection{Category 2 Studies}

The primary objective of research and development efforts in the area of ex-vessel corium coolability has been to demonstrate through a combination of experiments and analysis that core melt interacting with concrete can be quenched and rendered coolable over a wide range of conditions. Unfortunately, this has been a difficult objective to achieve. Results to date [1,1516] indicate that modestly deep (i.e., $<40 \mathrm{~cm}$ ) core melt pools interacting with LCS concrete should be coolable. However, for deeper melts, or for melts interacting with siliceous concrete, the same conclusion cannot be drawn.

For new Generation 3+ plants, the focus has been on achieving long term coolability and melt stabilization as a key design objective. Vendors have taken note of the results coming out of the debris coolability R\&D programs and decided that engineering features to enhance coolability would need to be built into new plant designs. As described by Sehgal [9], two approaches have been taken: i) in-vessel melt stabilization and retention, and ii) ex-vessel coolability and melt retention. In-vessel melt retention relies on flooding of the reactor pit and submerging the vessel lower head with water. The design challenge in this case is to ensure that the thermal load to the water pool through the head does not exceed the CHF limit with sufficient margin. This approach has been adopted for the AP600 [17] and AP1000 [18] plant designs.

As noted earlier, for ex-vessel conditions, two approaches for stabilizing the melt have been either proposed or adopted, viz., i) the cold crucible technique, and ii) melt fragmentation. The cold crucible technique has been adopted for the $\mathrm{EPR}^{\mathrm{TM}}$ [19] that features a spreading room adjacent to the reactor pit in which the melt is cooled by water from the bottom and top after spreading is completed. An extensive series of full scale experiments were performed in order characterize the heat removal capabilities of this cooling structure [20]. The VVER-1000 also utilizes a crucible technique, but in this design the crucible is located directly below the reactor vessel [21].

The melt fragmentation technique, denoted COMET, was pioneered by Forschungszentrum Karlsruhe (FZK). Both simulant and a limited number of reactor material tests have shown that this is a very effective means for quenching and stabilizing core melt [2224]. However, to the best of the author's knowledge, this concept has not been deployed in any current reactor design. Another concept that has been developed by Sehgal and coworkers [2526] are downcomers that provide a pathway to channel water from the top of the melt pool to the 
bottom, where the water is introduced into the debris thereby achieving the same beneficial results as those observed for COMET. This technique may be useful as a simple backfit to existing plants to improve the chances of cooling and stabilizing the core melt in the event of a severe accident.

\subsubsection{Category 3 Studies}

This section covers previous studies that have been carried out to investigate coreconcrete interaction under dry cavity conditions. Other studies addressing these interactions under wet cavity conditions are described in the next section.

Early transient high temperature steel simulant experiments were conducted under dry cavity conditions by Powers et al. [27,28] at Sandia National Laboratories to identify basic phenomenology associated with core-concrete interaction. These early transient tests were followed by additional sustained heating experiments using metallic melts at different power levels by Copus et al. [29,30] and Tarbell et al. [31] at Sandia, as well as Alsmeyer et al. [32,33] at Karlsruhe Institute of Technology (KIT; formerly Forschungszentrum Karlsruhe) in Germany. Recently, Sevón et al. at VTT in Finland [34] conducted transient metal tests focused on quantifying the ablation characteristics for hematite concrete, which is the type used as sacrificial material in the EPR reactor pit. In terms of reactor material testing, a series of 1-D experiments addressing thermal-hydraulic behavior and fission product release were conducted by Thompson et al. [7,35] and Fink et al. [36] at Argonne National Laboratory. In addition to these tests, several large scale 1-D core melt tests were carried out at Sandia under both transient [37] and sustained heating [38-40] conditions. Finally, 2-D core-concrete interaction experiments under dry cavity conditions have been carried out at the VULCANO test facility at CEA in France $[41,42]$. Results from both the simulant and reactor material testing programs are summarized below.

Powers et al. [27,28] conducted early exploratory tests at Sandia that investigated the transient interaction of superheated steel melts (up to $200 \mathrm{~kg}$ ) with basaltic and limestone/common sand concretes. These tests revealed that concrete erosion is primarily a melting process as opposed to a mechanical spallation process, and that water vapor and $\mathrm{CO}_{2}$ released by concrete decomposition are reduced to hydrogen and $\mathrm{CO}$. The results also showed that the heat transfer rate to the concrete was influenced by the gas generation rate and the crucible geometry.

These tests were followed by additional SURC-series experiments by Copus et al. [29,30] that featured enhanced instrumentation to monitor the melt and concrete temperatures during the interaction and to quantify aerosol release, as well as induction heating of the metal melt in order to mock up decay heat. A key element of these experiments was the addition of zirconium to the melt after the interaction was underway. The experiments exhibited large increases in melt temperature, erosion rate, concurrent gas release, and aerosol production following zirconium addition. Another phenomenon that was identified was the extensive production of low density oxide foam. 
In addition to the high temperature sustained heating tests, Tarbell et al. [31] conducted the FRAG test series to investigate the long-term interaction of solidified core debris with various concrete types. During cooldown of the metallic phase during long-term core-concrete interaction, partial or complete solidification of the metal phase may occur, leading to sustained concrete attack by an overlying solid mass. The results showed that low-temperature debris is capable of eroding both basalt and limestone/common sand concrete types; typical erosion rates were of the order of 3-4 cm/hour for the input power levels applied during the tests.

Aside from the metal tests conducted within the U.S., the BETA test series [32] at KIT provided early valuable data on multi-dimensional core-concrete interaction using metallic melt. A total of 19 experiments were conducted in the series; most tests (i.e., 16) utilized siliceous concrete, although three experiments utilized limestone/common sand concrete. The metal melts were also inductively heated using a cylindrical, annular induction coil to simulate decay heat, and different input power levels were used to mock up different stages of the accident sequence. Early, rapid cooling of the metal phase was observed in these tests. For siliceous concrete, axial erosion was found to be more significant than radial. The limestone/common sand tests exhibited a more uniform radial/axial power split.

Motivated by the findings of the SURC metal test series [29,30], additional experiments were carried out in the BETA test facility [33] to evaluate the effect of cladding oxidation on ablation behavior. The results confirmed the strong influence of the $\mathrm{Zr}$ oxidation process during the early cavity ablation phase with siliceous concrete, which was attributed to the exothermic reduction of $\mathrm{SiO}_{2}$ by the $\mathrm{Zr}$ to form $\mathrm{Si}$ metal that was later oxidized by $\mathrm{CO}_{2}$ and $\mathrm{H}_{2} \mathrm{O}$ concrete decomposition gases.

More recently, the transient interaction between metallic melt and concrete was investigated by Sevon et al. in the HECLA program [34] by pouring melt streams into concrete crucibles and observing the cavity ablation behavior as the melt cooled. Five experiments were conducted in this test series; the first two used ordinary siliceous concrete, while the last three used hematite concrete typical of that used in the reactor pit of the Olkiluoto 3 EPR plant in Finland. The main objectives of these tests were to: i) investigate the ablation characteristics of this special concrete type in comparison to ordinary siliceous concrete, and ii) obtain thermophysical property data for the concrete as little information was available in the open literature at the time. Based on the experiment results, it was estimated that $\sim 83 \mathrm{~mm}$ of sacrificial concrete would be ablated during the initial interaction in the Olkiluoto 3 reactor pit, which is much less than the $500 \mathrm{~mm}$ of material provided in the plant design.

In terms of reactor material tests, six large scale reactor material experiments addressing thermal-hydraulic behavior and fission product release during core-concrete interaction were conducted by Thompson et al. [7,35] and Fink et al. [36] at Argonne National Laboratory. These tests were carried out in a one dimensional test section that examined axial erosion behavior. Direct Electrical Heating (DEH) of the melt was used to simulate fission product decay heat. The melt was doped with non-radioactive isotopes of key fission product species to mock up fission products in the melt. The results showed that the concrete erosion process is closely 
linked to concrete type, and that fission product release during core-concrete interaction is actually quite low [36].

In addition to the 1-D core melt experiments conducted at ANL, several large scale 1-D tests were carried out at Sandia under both transient [37] and sustained heating [38-40] conditions. The initial TURC experiment series [37] consisted of pouring suboxidized $\left[(\mathrm{U}, \mathrm{Zr}) \mathrm{O}_{2-\mathrm{x}}\right]$ core melts into limestone/common sand crucibles and observing the extent of concrete ablation and aerosol release as the melts cooled. The results indicated very rapid crust formation on the concrete surfaces upon initial contact, which resulted in no detectable concrete ablation over the course of either test. The subsequent SURC test series [38-40] investigated the longer term interaction of suboxidized core melts interacting with limestone/common sand and basaltic concrete crucibles by inductively heating tungsten susceptors that were positioned in the crucible. Consistent with findings from the other programs, the results of these tests showed an initial rapid period of erosion and melt temperature escalation during the $\mathrm{Zr}$ oxidation phase, followed by a reduced erosion rate and declining melt temperature after the cladding was fully oxidized.

Aside from U.S. programs, studies of multi-dimensional core-concrete interaction under dry cavity conditions have also been carried out at the VULCANO test facility at CEA [41,42]. The main experimental objectives of this program are to investigate long-term 2-D core concrete interaction using either purely oxidic core melt, or stratified configurations consisting of metal and oxide layers, which is the expected condition at plant scale. The major finding from these tests is the ablation is non-isotropic for siliceous concrete, which is consistent with the findings from the OECD/MCCI-1 core-concrete interaction test series [1,43].

\subsubsection{Category 4 Studies}

In terms of wet cavity core-concrete interactions, low temperature simulant experiments have been conducted by Theofanous et al. [44] to identify phenomena associated with melt coolability, while high temperature simulant experiments have been conducted at Sandia by Blose et al. [45,46], as well as Sdouz et al. [47] and Alsmeyer et al. [48] at KIT, to investigate coolability with concurrent concrete erosion. In terms of reactor material testing, the COTELS $[49,50]$ and MACE $[15,51]$ experiment programs have been carried out to investigate coolability mechanisms under prototypic MCCI conditions. Results from both the simulant and reactor material testing programs are summarized below; more thorough discussions of the findings in this area are provided by Farmer et al. [15] and Sehgal [52].

To investigate fundamental phenomena associated with melt coolability, simulant material experiments were conducted by Theofanous, Liu, and Yuen [44]. In these tests, glycerin and liquid nitrogen were used to simulate the melt and overlying coolant, respectively. Gas sparging from MCCI was simulated by purging air through a porous plate located at the bottom of the apparatus. Fission product decay heat was simulated by the sensible energy deposited in the glycerin due to cooling of the purged gas from the inlet temperature to the melt pool temperature. Experiments were conducted in two different geometries; namely, cylindrical and square test sections. In the cylindrical tests, the diameters of the two test sections were 15 and $45 \mathrm{~cm}$. For 
the rectilinear test sections, three different scales were investigated: $70 \mathrm{~cm} \mathrm{x} 70 \mathrm{~cm}, 100 \mathrm{~cm} \times 100$ $\mathrm{cm}$, and $120 \mathrm{~cm} \mathrm{x} 120 \mathrm{~cm}$. For the small scale tests conducted in the circular geometry, quench was not achieved due to the formation of wall-anchored crusts which inhibited the melt-coolant interaction. However, for the larger scale tests, quench was generally achieved. In particular, the data indicates that the time to quench increases with initial melt depth and decreases with increasing sparging rate. The principal mechanism leading to coolability in these experiments was volcanic eruptions. These eruptions lead to enhanced debris surface area available for contact with the overlying coolant. The same phenomenon was first identified through reactor material experiments under MCCI conditions [51].

Three melt coolability experiments were conducted at Sandia using high temperature simulants with sustained heating and concurrent concrete erosion. These experiments include the SWISS tests [45], conducted with stainless steel melts interacting with limestone/common sand concrete, and the WETCOR test [46] that utilized an oxide simulant interacting with Basaltic concrete. These tests also provided valuable data on debris coolability, but complete quench was not obtained in any of these experiments due in part to the formation of crusts that anchored to the test section sidewalls, eventually leading to decoupling of the melt pool from the crust as the coreconcrete interaction proceeded downwards. However, these tests were quite valuable as they provided information on the effect of an overlying water pool on aerosol scrubbing during coreconcrete interaction, since these data are sparse in the literature.

Other simulant material debris coolability data under top flooding conditions was obtained at KIT by Sdouz et al. [47] and Alsmeyer et al. [48] as part of the COMET test program. These were large scale multi-component (metal - oxide) mixture tests that focused on examining twodimensional cavity erosion behavior using siliceous concrete in a stratified configuration. Consistent with the dry cavity metal test results, these experiments exhibited ablation behavior that was biased downwards. In these experiments, the simulant oxide phase was on top the metal phase that was heated and therefore driving the axial erosion. This oxide material showed little evidence of coolability following top flooding.

In terms of prototypic experiments, a total of 10 reactor material tests that investigated Fuel Coolant Interaction (FCI) and debris coolability were carried out within the framework of a joint study between NUPEC and the National Nuclear Center (NNC) in Kazakhstan [49,50]. Each experiment was conducted in two phases; i.e., test series "B" investigated FCI aspects of the initial water injection onto molten corium, while the follow-on series " $C$ " tests investigated the long-term aspects of MCCI under the conditions of continual water injection.

For these tests, based on the rate of steam transport to the condensation system, the steadystate melt/water heat flux was reported to range from 0.2 to $0.7 \mathrm{MW} / \mathrm{m}^{2}$. In all cases, both the concrete sidewalls and base of the crucible were found to be eroded. In addition, an interstitial pebble bed formed at the interface of the core material and the concrete; the bed was composed of concrete decomposition products (presumably the aggregate). The depth of this pebble bed was found to increase with increasing ablation depth. The depth of the discolored concrete region surrounding the decomposed pebble bed was also found to increase with ablation depth. Posttest examinations revealed the important finding that crust anchoring to the concrete sidewalls with 
subsequent melt/crust separation did not occur for any of these tests. The absence of anchoring was presumably attributable to the sidewall decomposition that occurred.

The tests were classified in terms of the debris mass that was rendered in the form of a particle bed above the remaining corium layer. In particular, Case (1) corresponded to formation of a particle bed containing 20-40 wt \% of the total debris mass, Case (2) corresponded to 70-80 wt $\%$ of the debris mass in the particle bed, while Case (3) corresponded to no particle bed formation. For experiments in which particle bed formation occurred (i.e., Cases (1)-(2)), the depth of the bed was found to increase with increasing basemat erosion depth, and with increasing melt specific power density. Particle bed depths ranged from 7 to $12 \mathrm{~cm}$. In the Case (3) tests, no bed formation occurred; these experiments were characterized by comparatively low power density. The mechanism by which these beds formed (e.g., entrainment by concrete decomposition gases) was not identified as part of this work. The coherent solidified corium layer remaining over the basemat was always found to contain cracks and crevices which axially spanned the depth of the layer. The test results indicate that water was able to penetrate into these cracks and crevices during the test, in addition to penetrating into the intervening gap formed at the sidewall corium-concrete interface due to sidewall erosion. In fact, for these tests the cooling mechanisms of water ingression through interstitial porosity and particle bed formation over the solidifying core material were of sufficient magnitude to effectively quench the core material and terminate the MCCI, as evidenced by thermocouple measurements in the basemat.

A series of melt coolability experiments were conducted at Argonne National Laboratory as part of the Melt Attack and Coolability Experiment (MACE) program [15,51]. The specific objective of these tests was to explore the possible benefits of massive addition of water to an MCCI already in progress insofar as: i) quenching and stabilizing the heat generating core melt, and ii) arresting or even terminating basemat ablation. Early tests M0 and M1b were conducted with $70 \%$ oxidized PWR melt compositions, while the later tests M3b and M4 were conducted with fully oxidized core melts. Three tests in the matrix were conducted with limestone/common sand (LCS) concrete, while the fourth test was conducted with siliceous concrete. A principal parameter in the experiment matrix was test section lateral span, which varied from $30 \mathrm{~cm} \times 30$ $\mathrm{cm}$ up to $120 \mathrm{~cm} \mathrm{x} 120 \mathrm{~cm}$. Melt masses in these tests ranged from 100 to $1800 \mathrm{~kg}$.

The M0 experiment was conducted with a purely concrete test section, thereby allowing both axial and radial cavity ablation data to be obtained. This test provided early data on the effectiveness of the melt eruption cooling mechanism, with a substantial fraction of the initial core melt mass rendered in the form of a coolable bed by eruptions. Unfortunately, the crust anchored to the test section electrodes located along two opposing walls of the test section, and this eventually led to a configuration in which the melt had separated from the crust by the end of the experiment. Researchers thought that this experiment distortion may have precluded complete quench of the core debris. On this basis, the facility was redesigned to incorporate inert $\mathrm{MgO}$ sidewalls, thereby making it one dimensional, and the electrodes were recessed into the $\mathrm{MgO}$ sidewalls to reduce the surface area available for the crust to bond to. The balance of the integral experiments in the program (i.e., M1b, M3b, and M4) was conducted with this test configuration. Unfortunately, crust anchoring with subsequent melt-crust separation occurred in all these tests, and so a definitive demonstration of debris coolability was not obtained as a part of this program. 


\subsection{CATEGORY 1 TEST RESULTS}

\subsection{Tests Investigating Crust Strength}

One element of the SSWICS separate effects experiments involved measurements of corium crust strength. The purpose of collecting such data was to aid in the assessment of the potential stability of an anchored corium crust within a power plant. The crust, rather than floating on top of the melt and moving downward as the basemat is eroded, could attach to structures and become fixed in space (Figure 2-1). Melt movement downward is caused by a reduction in concrete volume as $\mathrm{CO}_{2}$ and $\mathrm{H}_{2} \mathrm{O}$ are lost through concrete decomposition. Anchoring of the crust to containment walls potentially allows a gas gap to form between crust and melt, which would hinder heat transfer between an overlying water layer and the melt. The gap is expected to reduce the melt cooling rate below that of the non-anchored configuration and to prolong the MCCI. Containment integrity is not assured for such a scenario.

For the crust to remain anchored, it must be strong enough to support itself and the water above it. The stability of the anchored crust configuration can be assessed if the strength of the crust is known. Measurements of the structural strength of corium can be useful in gauging the strength of a plant-scale crust, but specimens must be large enough to contain a representative sampling of the cracks and voids one would expect in an actual corium crust since a crust with few flaws is likely to be more stable than one permeated with cracks.

The strength of a corium crust depends upon its thickness, temperature, chemical composition, and morphology. Crust morphology is itself a strong function of melt composition and cooling rate, and so strength testing ideally involves a sample with the expected melt constituents that has been quenched by water. These conditions were met for the ingots (crust samples) generated by the SSWICS quench tests, which were conceived with the primary aim of measuring corium cooling rate for various melt compositions and system pressures. A total of thirteen SSWICS tests were carried out over the course of the MCCI1 and -2 programs, with eight of the tests producing ingots suitable for strength measurements. The following sections describe the origination of the ingots, ingot sectioning, the apparatus used to measure strength, and test results.

\subsubsection{Ingot Creation}

Eight corium ingots were used for the load tests and all but one were byproducts of quench experiments intended to quantify the

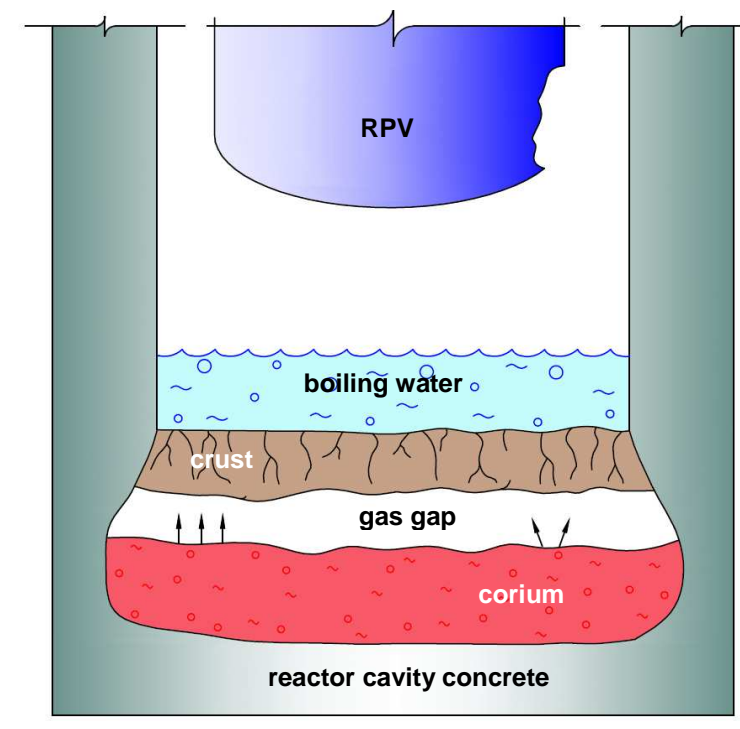

Figure 2-1. Crust Anchoring with Thermal Decoupling from Melt (heat transfer limited by radiation across gap). 
influence of melt composition on its cooling rate [14]. The exception is a quench test with the sole purpose of creating an ingot thin enough for strength testing without the need for sectioning. All melts were composed of mixtures of $\mathrm{UO}_{2}, \mathrm{ZrO}_{2}$ and chemical constituents of concrete. A melt was created within an inert $\mathrm{MgO}$ crucible using a short-lived exothermic chemical reaction that raised the temperature of the constituents to $\sim 2000^{\circ} \mathrm{C}$ in less than one minute. Water was then poured over the melt to quench it, which produced steam that was collected and condensed. Figure 2-2 provides a schematic of the quench apparatus and corium level for the test used to generate the thin ingot. Five of the melts were quenched at ambient pressure while three were quenched at 4 bar. The tests incorporated neither heating to simulate fission product decay heat nor sparging to simulate gas production from concrete ablation. Though these tests provided no possibility of gas-generated voids within the corium, the shortcoming is not critical as it can only increase sample strength producing a more conservative assessment of the stability of an

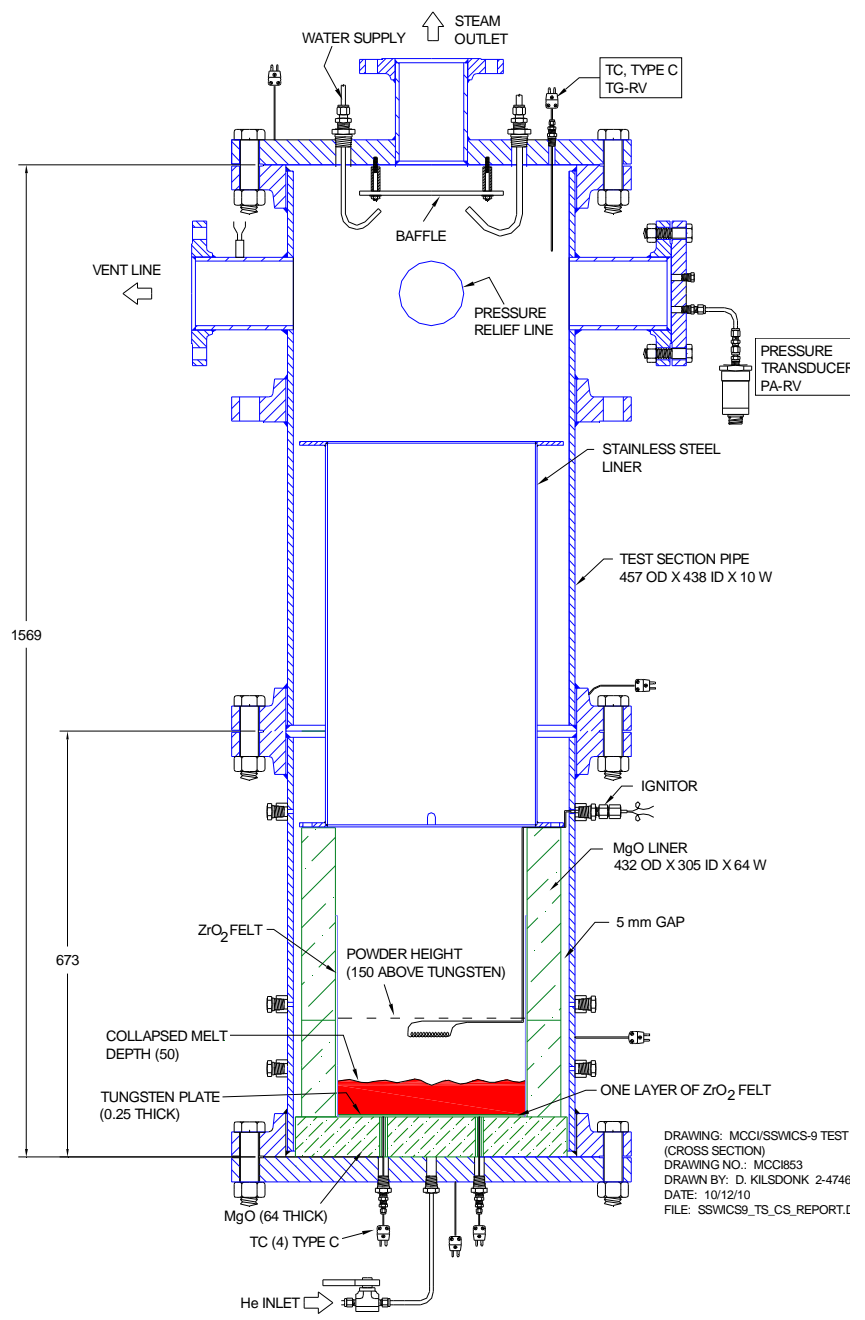

Figure 2-2. Side View of Reaction Vessel for SSWICS-9 and -10. anchored crust.

The final product of each test was a $30 \mathrm{~cm}$ diameter ingot. Table 2-1 shows melt composition, mass, initial temperature, and system pressure during the quench. The chemical constituents of a melt included oxides of elements found in concrete such as silicon, aluminum, magnesium, and calcium. The quantity was varied depending on the desired type and mass fraction of concrete to be simulated. The melts contained either 8, 14, or $23 \mathrm{wt} \%$ siliceous or limestone common sand concrete. The range represents different phases of a core-concrete interaction in which concrete is accrued by the melt over time as it attacks the basemat. The melts were formulated to have a core-to-cladding oxide mass ratio of 2.44 , which is typical of pressurized water reactors.

The melt compositions listed in the table are known to better than $1 \mathrm{wt} \%$ and the melt mass better than $10 \mathrm{~g}$. The depth is a nominal value calculated from the melt mass and theoretical density neglecting potential porosity. Varying amounts of melt are lost to upper parts 
Table 2-1. Specifications for SSWICS Quench Experiments that Produced the Ingots.

\begin{tabular}{|l|c|c|c|c|c|c|c|c|}
\hline Parameter & $\mathbf{1}$ & $\mathbf{2}$ & $\mathbf{3}$ & $\mathbf{4}$ & $\mathbf{5}$ & $\mathbf{6}$ & $\mathbf{8}$ & $\mathbf{1 0}$ \\
\hline $\begin{array}{l}\text { Melt composition (wt\% } \\
\mathrm{UO}_{2} / \mathrm{ZrO}_{2} / \mathrm{Cr} / \text { Concrete) }\end{array}$ & $\begin{array}{c}61 / 25 / 6 / \\
8\end{array}$ & $\begin{array}{c}61 / 25 / 6 / \\
8\end{array}$ & $\begin{array}{c}61 / 25 / 6 / \\
8\end{array}$ & $\begin{array}{c}48 / 20 / 9 / 2 \\
3\end{array}$ & $\begin{array}{c}56 / 23 / 7 / 1 \\
4\end{array}$ & $\begin{array}{c}56 / 23 / 6 / 1 \\
4\end{array}$ & $\begin{array}{c}56 / 23 / 6 / 1 \\
4\end{array}$ & $61 / 25 / 6 / 8$ \\
\hline Concrete type & LCS & SIL & LCS & LCS & LCS & SIL & SIL & SIL \\
\hline Melt mass (kg) & 75 & 75 & 75 & 60 & 68 & 68 & 68 & 25 \\
\hline Melt depth (cm) & 15 & 15 & 15 & 15 & 15 & 15 & 15 & 5 \\
\hline $\begin{array}{l}\text { Initial Melt } \\
\text { Temperature ( }{ }^{\circ} \text { C) }\end{array}$ & 2300 & $\sim 2100$ & $\sim 2100$ & $\sim 2100$ & $\sim 2100$ & $\sim 1950$ & $\sim 1900$ & - \\
\hline System pressure (bar) & 1 & 1 & 4 & 4 & 4 & 1 & 1 & 1 \\
\hline $\begin{array}{l}\text { Water injection flowrate } \\
\text { (lpm) }\end{array}$ & 4 & 4 & 12 & 13 & 6 & 14 & 10 & 9 \\
\hline Water injected (liters) & 33 & 39 & 34 & 40 & 61 & 47 & 41 & 29 \\
\hline Test duration (hours) & 2.2 & 1.2 & 1.8 & 2.4 & 2.6 & 3.9 & 4.3 & 0.4 \\
\hline Test date (day/mo/year) & $30 / 08 / 02$ & $17 / 09 / 02$ & $30 / 01 / 03$ & $13 / 03 / 03$ & $15 / 10 / 03$ & $24 / 02 / 04$ & $25 / 01 / 07$ & $5 / 03 / 08$ \\
\hline
\end{tabular}

of the crucible (above the ingot) and so actual melt depths may vary by a few centimeters from the nominal value. Initial melt temperatures are based on the peak temperature measured within a thermowell within the bottom quarter of the melt and should be considered only as a general indication of initial temperature of the melt as a whole. Coolant injection temperatures varied by as much as $\pm 5^{\circ} \mathrm{C}$ and the system pressure for high pressure tests was regulated to within 0.1 bar of the 4 bar set point.

\subsubsection{Ingot Sectioning}

A key requirement for the load tests is that they reproduce the failure mode expected for the anchored plant-scale crust. For a full-scale MCCI in a power plant, the crust may be thought of as a large flat plate fixed around its perimeter to the containment wall. The failure mode for a flat plate will depend upon its aspect ratio, which is defined as the ratio of the plate diameter and thickness $(\mathrm{D} / \mathrm{t})$. The aspect ratio at the plant scale would be $\sim 30$ for a postulated $20 \mathrm{~cm}$ thick crust within the typical $6 \mathrm{~m}$ cavity span of most operating plants. The maximum stress in a plate under these conditions would be tensile and at the centerline. The load tests should be designed to produce a similar stress distribution in the ingot.

The most practical device for testing the ingots was considered to be one that applies a centered point load to the top while the bottom edge is simply supported. Calculations showed that the ingot aspect ratio should be greater than four to assure the desired failure mode. The $30 \mathrm{~cm}$ diameter, $15 \mathrm{~cm}$ high ingots produced by the quench tests have an aspect ratio of only two and so it was decided that they would be sectioned to increase the aspect ratio. 
Ingots were cut in the radial direction using a large band saw. Each was cut either once or twice to produce between one and three serviceable samples per ingot. Figure 23 is a photo of Ingot 6 after sectioning. The liner was cut along with the ingot because the two bond together and could not be separated without damaging the ingot. The extensive crack structure seen in the photo is typical. The scale of crack spacing is $\sim 1 \mathrm{~cm}$ and so the $30 \mathrm{~cm}$-diameter sections should be sufficiently large to reflect the effective mechanical properties of the plant-scale crust. Figure 2-4 is included to illustrate that though cracking is always evident on the bottom, it is not evident on the top. It is emphasized that there are indeed cracks within the ingots before they are cut. A bottom view of Ingot 10 is shown in Figure 2-5 for comparison. The photo shows several large cracks but not the denser network seen in the cut ingot. Dimensions of each corium section are listed in Table 2-2.

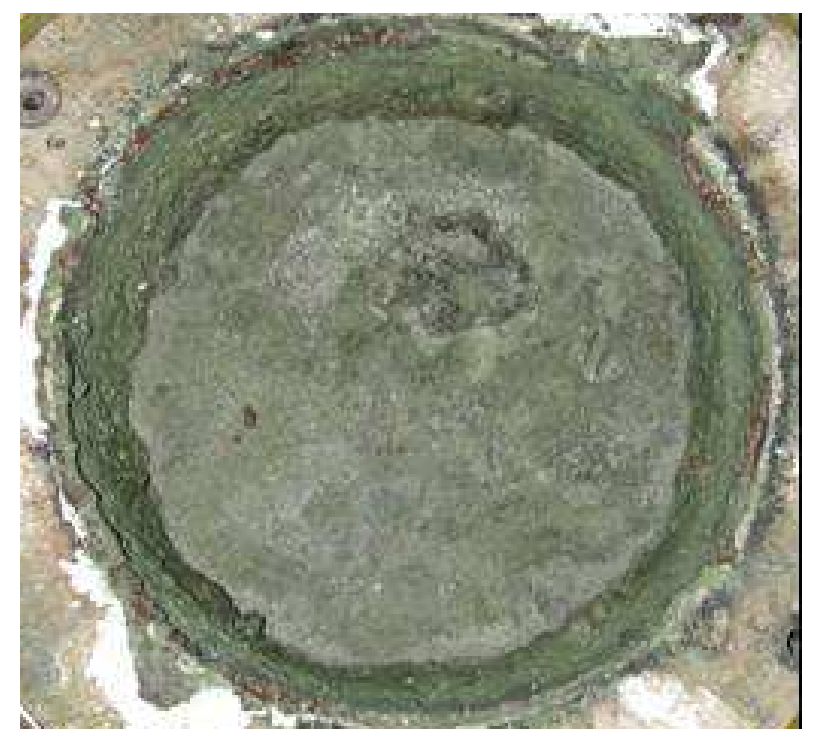

Figure 2-4. Top View of Ingot 6. (Ingot surface $\sim 15 \mathrm{~cm}$ from top of crucible. The green tint is a thin layer of $\mathrm{Cr}_{2} \mathrm{O}_{3}$, a byproduct of the reaction producing the melt)

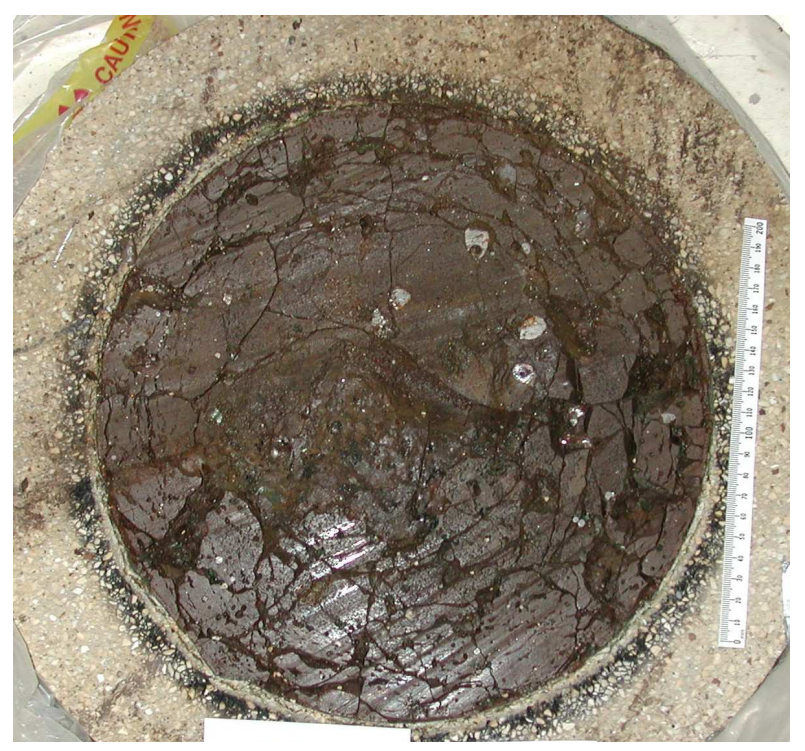

Figure 2-3. Middle Section of Ingot 6 after Cutting. (Silver inclusions are metallic $\mathrm{Cr}$ ).

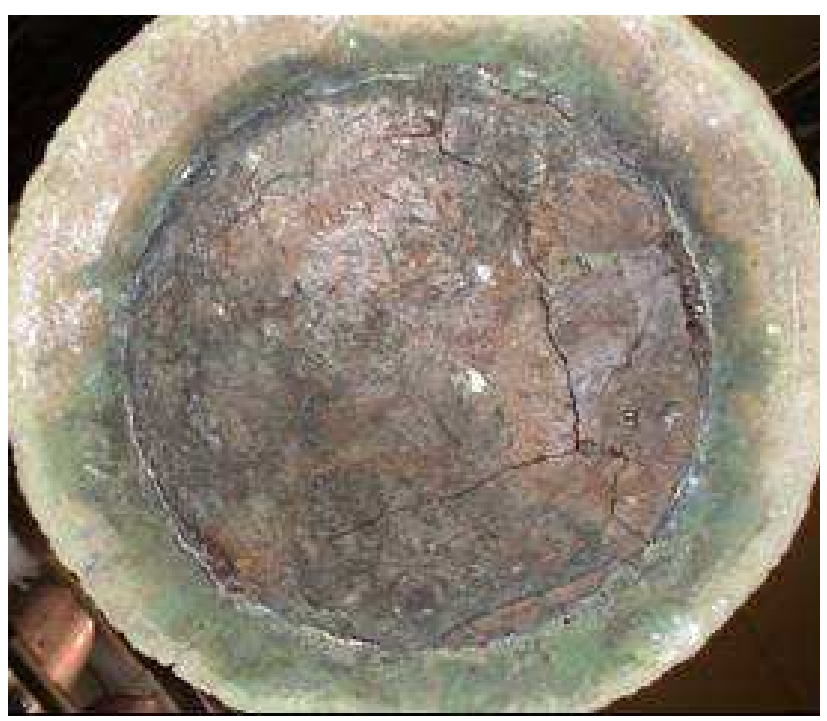

Figure 2-5. Bottom View of Ingot 10, which was not Sectioned. 
Table 2-2. Source Data for Calculation of Section Strength.

\begin{tabular}{|l|c|c|c|c|c|c|c|c|c|c|c|c|}
\hline Ingot number & $\mathbf{1}$ & $\mathbf{2}$ & $\mathbf{3}$ & \multicolumn{2}{|c|}{$\mathbf{4}$} & \multicolumn{2}{|c|}{$\mathbf{5}$} & \multicolumn{3}{|c|}{$\mathbf{6}$} & $\mathbf{8}$ & $\mathbf{1 0}$ \\
\hline Slab thickness $(\mathrm{mm})$ & 100 & 100 & 90 & $55-60$ & $55-60$ & 55 & 45 & 50 & 55 & 40 & 50 & 50 \\
\hline Aspect ratio & 3 & 3 & 3.3 & 5 & 5 & 5.4 & 6.7 & 6 & 5.4 & 7.5 & 6 & 6 \\
\hline Region of ingot & $\mathrm{T}$ & $\mathrm{T}$ & $\mathrm{T}$ & $\mathrm{M}$ & $\mathrm{B}$ & $\mathrm{M}$ & $\mathrm{B}$ & $\mathrm{T}$ & $\mathrm{M}$ & $\mathrm{B}$ & $\mathrm{M}$ & - \\
\hline Concrete content $(\%)$ & 8 & 8 & 8 & 23 & 23 & 14 & 14 & 14 & 14 & 14 & 14 & 8 \\
\hline Peak load $(\mathrm{kN})$ & 8.2 & 8.2 & 15.3 & 3.2 & 2.7 & 3.6 & 4.4 & 4.5 & 4.1 & 3.0 & 2.4 & 1.4 \\
\hline$\sigma_{\max }$ & 1.1 & 1.1 & 2.7 & 1.6 & 1.3 & 2.0 & 3.6 & 3.0 & 2.2 & 3.2 & 1.6 & 1.0 \\
\hline Stress uncertainty $(\mathrm{MPa})$ & 0.2 & 0.2 & 0.4 & 0.3 & 0.3 & 1.0 & 0.8 & 1.0 & 0.5 & 0.7 & 0.4 & 0.3 \\
\hline $\begin{array}{l}\text { Top surface } \Delta \mathrm{z} \text { at peak } \\
\text { load }(\mathrm{mm})\end{array}$ & 10.0 & 9.1 & 8.2 & 2.4 & 5.3 & 2.3 & 2.4 & 5.0 & 3.8 & 4.8 & - & 5.9 \\
\hline $\begin{array}{l}\text { Bottom surface } \Delta \mathrm{z} \text { at peak } \\
\text { load }(\mathrm{mm})\end{array}$ & - & - & - & - & - & 2.1 & 2.2 & 8.9 & 3.2 & 3.8 & - & 3.9 \\
\hline
\end{tabular}

* $\mathrm{T}=$ top; $\mathrm{M}=$ middle; $\mathrm{B}$ = bottom segment.

\subsubsection{Apparatus}

An apparatus was constructed for the purpose of applying a point load to the center of a corium section. Figure 2-6 shows the loading apparatus along with a section in testing position. A load was applied to the sample via a $35 \mathrm{~mm}$-diameter steel piston. The surface area of the ingot was therefore $\sim 73$ times that of the piston. The load was generated using an air-operated device that pressurized a hydraulic line connected to the piston. The sample was supported around the bottom edge by a steel ring having an outer diameter of $302 \mathrm{~mm}$ and wall thickness of $7 \mathrm{~mm}$. Corium sections were centered over the ring so that the outer edge of the ring lied below the joint. A displacement sensor tracked piston movement as a surrogate for deflection of the section's top surface. A second displacement sensor was positioned on the underside of the corium directly below the piston. This sensor was used to verify that the piston deflected the entire section rather than merely crushing a small region near the surface. The load was increased stepwise until the section failed. The applied load at the time of failure was used to calculate the effective tensile strength of the section.

The load testing apparatus provides a reasonable facsimile of the idealized point load on a simply supported circular plate. This particular test geometry was chosen for ease of implementation and because it allows one to calculate peak tensile stress using a simple analytical expression [53].

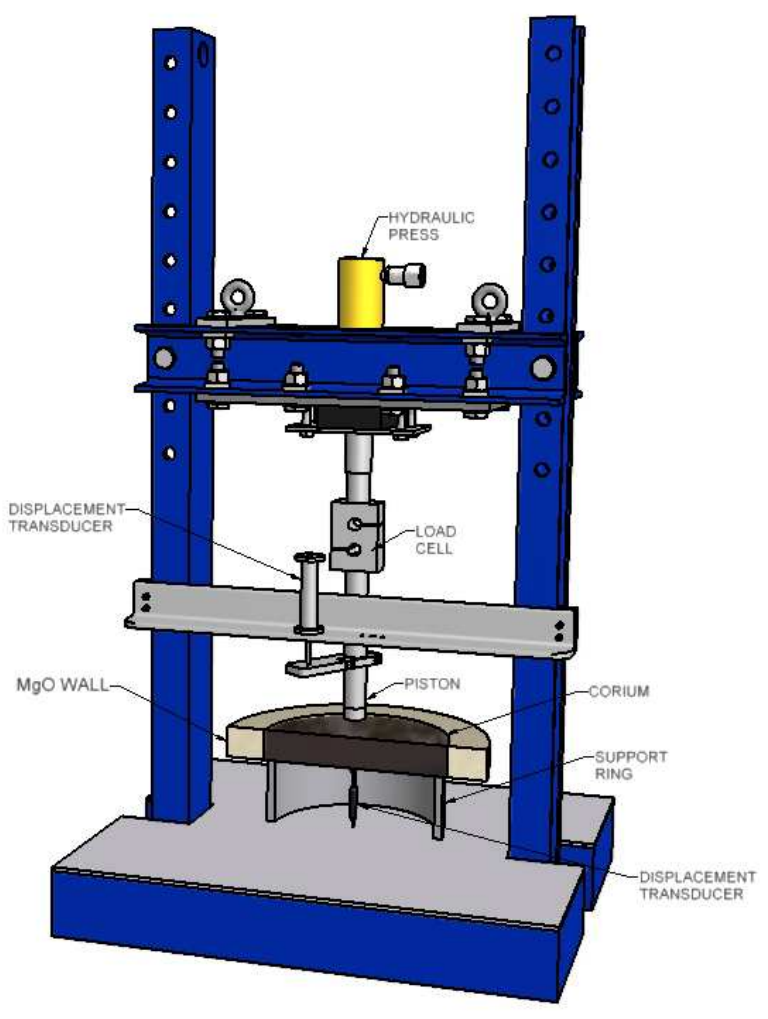

Figure 2-6. Apparatus for Applying Mechanical Loads to Corium Sections at Room Temperature. 


\subsubsection{Results and Discussion}

Figure 2-7 shows force and displacement measurements made during the load test of a section cut from the middle of Ingot 6. The results are typical for the twelve sections. Loads were increased stepwise with brief pauses between steps. Each load increase was accompanied by piston displacement that was roughly proportional to the magnitude of the increase. Sections were loaded until failure, which was often accompanied by audible cracking and, on occasion, fracture of the $\mathrm{MgO}$ liner. Failure was always marked by pronounced buckling that brought stress relief as indicated by a drop in applied force. Such a drop is evident in the figure. Also evident are slight dips in the load in the seconds following each step increase. This relaxation phenomenon is associated with the pneumatic device used to generate the load. It was also observed during trial loading of an aluminum plate and does not reflect any particularities of the corium section.

The peak measured load was used to calculate the maximum stress generated in a section. The maximum centerline stresses for the ten tested sections are plotted in Figure 2-8. Each was loaded until it fractured and so there is a single data point per section. The data points in the plot are labeled with the number of the originating ingot. The plot shows the relationship between the strength of the section and its concrete content. Chemical analyses of each section indicated that the corium constituents were distributed homogenously within the ingots. Therefore the composition of each section is equivalent to that of the originating melt as given in Table 2-1. There is no dependence of strength on concrete content apparent in the data plot. Similarly, there is no consistent difference between sections containing limestone common sand concrete (Ingots 1 and 3-5) and those with siliceous concrete (Ingots 2, 6 and 10). Section strength falls in the range of 1-4 $\mathrm{MPa}$. The measured section strength is considerably lower than that of sintered $\mathrm{UO}_{2}, \sim 150 \mathrm{MPa}$ [54] and comparable to that of conventional concrete, $2-5 \mathrm{MPa}$ [55]. The error bars in the plot are based on the largest quantifiable source of uncertainty, which is variance in the section thickness. The cutting process produced sections that varied in thickness by roughly $\pm 5 \mathrm{~mm}$. Uncertainty in the other parameters, namely the applied load, crust diameter, and Poisson's ratio, are comparatively small.

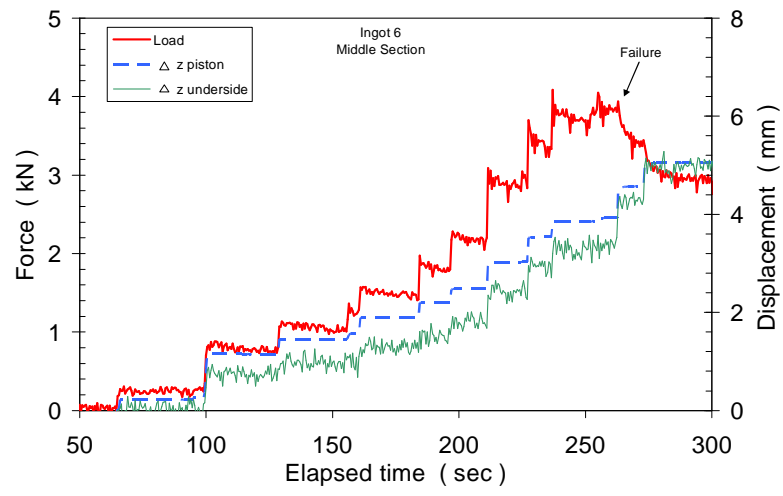

Figure 2-7. Load Test Data for the Bottom Section of Ingot 6.

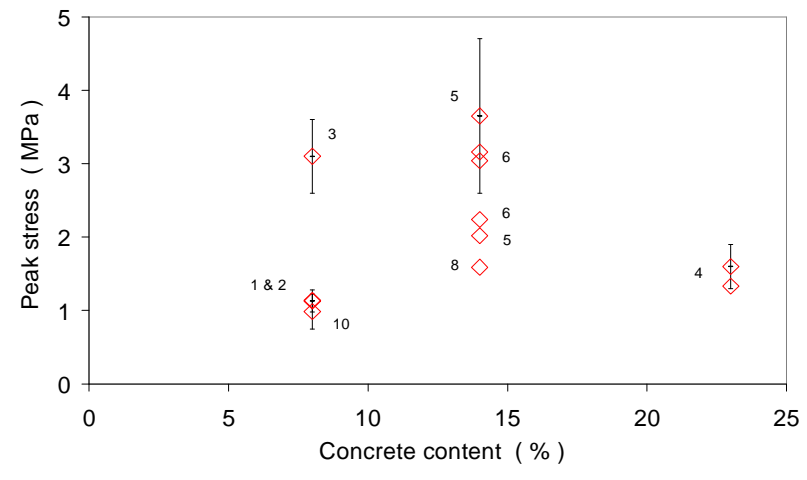

Figure 2-8. Maximum Centerline Stress before Fracture for Ingot Sections under Point Load at Room Temperature. 
Section thickness ranged from 40 to $100 \mathrm{~mm}$, which corresponds to aspect ratios of 7.5 to 3. Three of the sections had aspect ratios below the target minimum of four. These thicker sections could have failed in a manner different from that of the thinner ones, potentially giving rise to a much different measure of strength. Such an effect should be evident in a plot of strength versus section thickness like that of Figure 2-9. However, the plot shows measured strength to be independent of section thickness, indicating either invariance in the failure mode or a weak relationship between strength and failure mode for an aspect ratio between 3 and 7.5.

Figure 2-9 includes curves representing the peak centerline stress within a $6 \mathrm{~m}$ diameter, self-supported corium crust. Stress was calculated using the same stress equation [53] for simply-supported flat plates employed for the corium samples. The lower curve corresponds to a dry crust and the upper curve to a crust covered by a $50 \mathrm{~cm}$ deep water pool. The crust is presumed to be anchored at the perimeter and subjected to a distributed load equal to the weight of the crust itself (and water in the second case). Crust density was assumed to be $7000 \mathrm{~kg} / \mathrm{m}^{3}$. The peak stress can be compared with the strength data for an indication of the thickness required of a stable, selfsupporting crust. The plot shows that the required thickness of a dry crust is 200$300 \mathrm{~mm}$ while a crust with an overlying water layer must be $>300 \mathrm{~mm}$ thick.

The expected melt depth at the outset of an MCCI depends upon the accident scenario and plant design. One can say, however, that $300 \mathrm{~mm}$ is generally regarded as rather deep for a melt pool. This bolsters the notion that crust anchoring is unlikely to play a role in prolonging an MCCI. Firstly, thin crusts

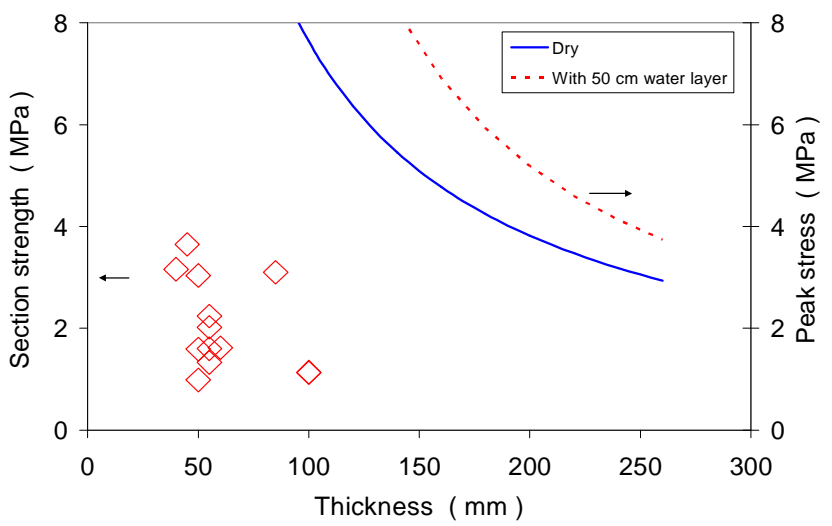

Figure 2-9. Comparison between Measured Section Strength and Calculated Peak Stress in a 6 m Diameter, Self Supported Crust. can be expected to break and fall back into the melt so that a gas gap like that shown in Figure 2-1 cannot persist. Secondly, a crust thick enough to be self-supporting is likely to embody the majority of the corium involved in the MCCI, leaving relatively little to continue the concrete erosion that potentially threatens containment integrity. Reference [14] presents a comprehensive case for a weak crust by examining MACE testing of small corium blocks, the SSWICS data presented here, and measured loads on high temperature crusts during CCI tests.

\subsection{Tests Investigating Gas Sparging}

One aim of the MCCI-2 program was to investigate the role of gas sparging on the corium cooling rate. The gases are a byproduct of the decomposition of concrete, which occurs when the material overheats. Gases generated near the corium/concrete interaction zone at the bottom of the melt are propelled up through the corium by buoyancy forces and the resultant gas flow has the potential to create melt porosity. This porosity is expected to supplement the fissures induced 
by thermal stress cracking. These extra pathways could enhance the amount of water ingression cooling and quench the melt more rapidly than cases lacking sparging gases. Alternatively, the upward movement of noncondensable gas could hinder the downward flow of water into cracks with the result being degradation in cooling rate.

All seven quench tests conducted during the previous program [3] utilized an inert $\mathrm{MgO}$ basemat and excluded sparging gases to better isolate the effects of melt composition on cooling rate. Sparging gases were included for two tests in the MCCI-2 program,

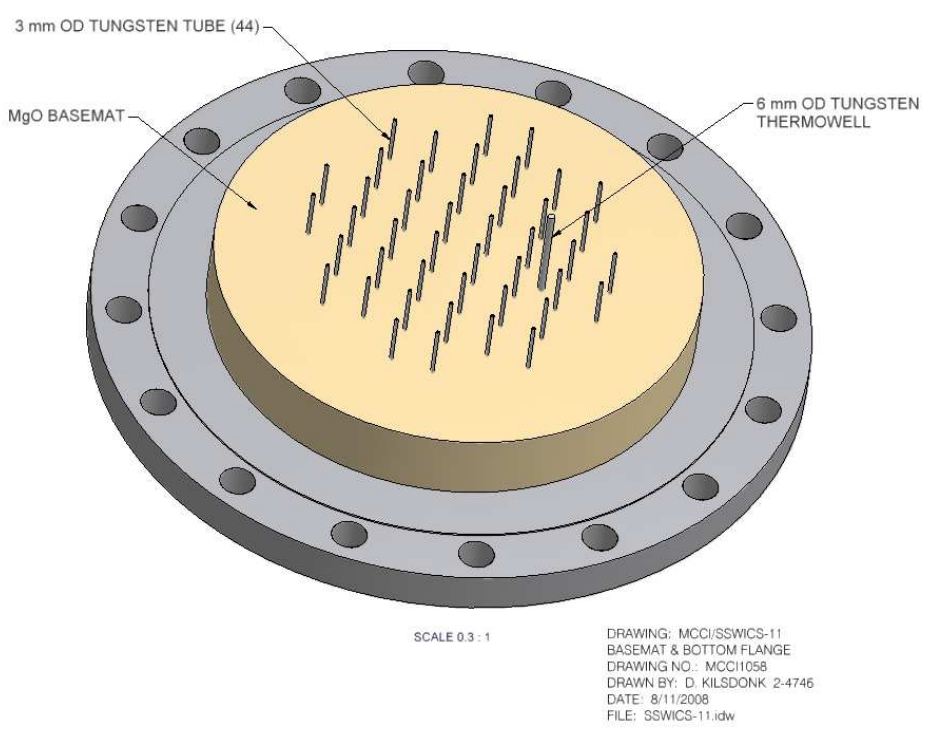

Figure 2-10. SSWICS-11 Tungsten Tube Layout with Capillaries Extending 50 mm Above the Basemat.

SSWICS-8 and -11. The melt composition and quench conditions were matched to those of SSWICS-6 $\left(56 \% \mathrm{UO}_{2}, 23 \% \mathrm{ZrO}_{2}, 7 \% \mathrm{Cr}\right.$, and $14 \%$ siliceous concrete, 1 bar pressure [3]) to allow a direct determination of the influence of gas on morphology and cooling rate. The SSWICS facility was not equipped to heat the melt to simulate fission product decay heat and so replacement of the $\mathrm{MgO}$ basemat with a concrete basemat would not be useful in generating a continuing supply of gas from decomposing concrete. Instead, the facility was outfitted with a system to inject gas through a network of capillaries in the basemat, allowing precise control of the injection rate. The system configuration for these tests and results are described below.

\subsubsection{Apparatus}

The MACE MSET-1 injector pitch was deemed suitable for the SSWICS injector since the distance is less than the expected bubble diameter [56]. The MSET-1 injector was a plate with $1 \mathrm{~mm}$ ID holes arranged on a square pitch of $38 \mathrm{~mm}$, which produced a hole density of $\sim 7$ holes $/ 100 \mathrm{~cm}^{2}$. Figure $2-10$ provides an isometric view of the basemat capillary layout for SSWICS-11. A total of 44 capillaries were used, each having an inner and outer diameter of 0.57 and $1.5 \mathrm{~mm}$, respectively. The capillaries were all linked to a common plenum. This system generates the desired flow rate with an even distribution across the capillaries.

For SSWICS-8, the tips of the capillaries were made flush with the basemat surface as it was considered pointless to extend them above the basemat and into the melt since the initial thermite temperature is $2000^{\circ} \mathrm{C}$ and steel melts at $1400^{\circ} \mathrm{C}$. Unfortunately, this geometry allowed the sparging gases to move laterally across the basemat under the melt and escape without passing through the melt. It is thought that shortly after thermite ignition a thin crust quickly formed between the melt and the basemat, preventing gas flow up through the melt [57]. No gas travelled through the melt during SSWICS-8 and so it was effectively a repeat of SSWICS-6 and 
unable to provide information on the effects of sparging. The remainder of this section covers SSWICS-11, which was equipped with a modified injection system that proved successful.

The SSWICS-11 configuration introduced tungsten tubes extending $50 \mathrm{~mm}$ above the basemat. The tubes had an outer diameter of $3 \mathrm{~mm}$, which was the smallest available for tubes of sufficient length to extend down through the basemat, the flange, and the compression fitting. The inner diameter was $1.6 \mathrm{~mm}$. Figure 2-11 shows a side view of the reaction vessel and injection system. A compression fitting connected each tungsten tube to a stainless steel capillary.

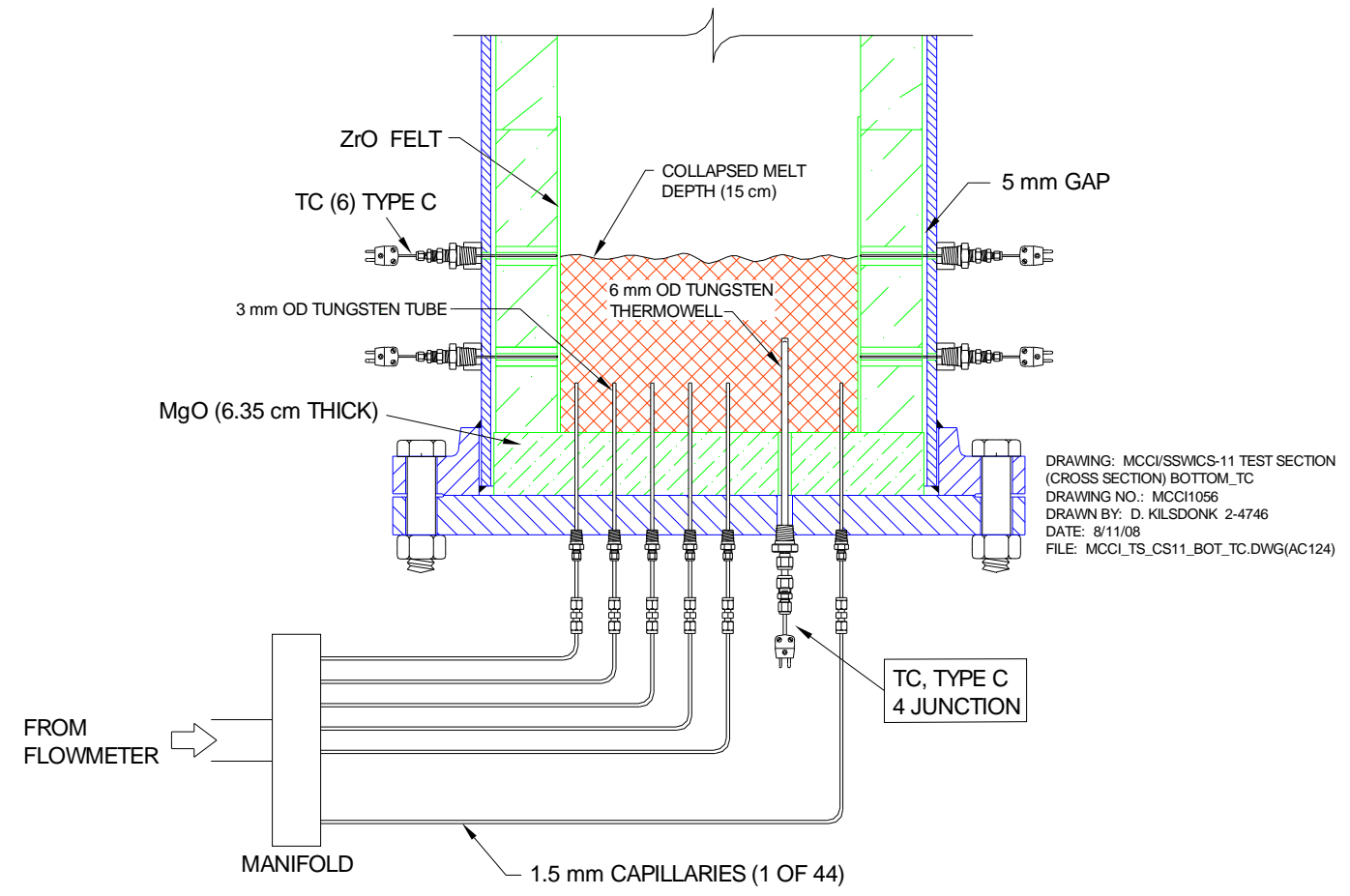

Figure 2-11. SSWICS-11 Tungsten Tube Layout with Capillaries Extending $50 \mathrm{~mm}$ Above the Basemat.

\subsubsection{Results and Discussion}

The revised injector design with tungsten capillaries extending up into the melt succeeded in preventing the gas bypass observed in SSWICS-8. Post test examinations revealed an ingot morphology that differed from all other SSWICS tests. The ingot did not bond to the MgO liner as usual, but instead bonded strongly to the basemat. This permitted removal of the liner by simply lifting it up from the basemat so that the perimeter of the ingot could be examined. The ingot is shown in Figure 2-12. The smooth white-green material around the outer surface is the remains of the zirconia felt used to cover the inside of the liner. The felt is normally white and most of it was scraped away to reveal the corium below.

The ingot proved to be a solid mass without the coarse crack network present in earlier specimens. It also had an unusually porous appearance that can be seen upon close examination 
of Figure 2-13. The extensive array of dimples/holes was unique among the SSWICS ingots. The ingot mass was $\sim 61.8 \mathrm{~kg}$, which was calculated by subtracting the $6.2 \mathrm{~kg}$ of corium attached to the liner walls above the ingot from the initial thermite mass of $68 \mathrm{~kg}$. The porosity was estimated to be roughly $37 \%$, which was calculated from the ingot mass, a density of $6000 \mathrm{~kg} / \mathrm{m}^{3}$, and an approximate average height of $23 \mathrm{~cm}$. The SSWICS-6 and -8 ingots were about $15 \mathrm{~cm}$ high though they had the same composition and mass.

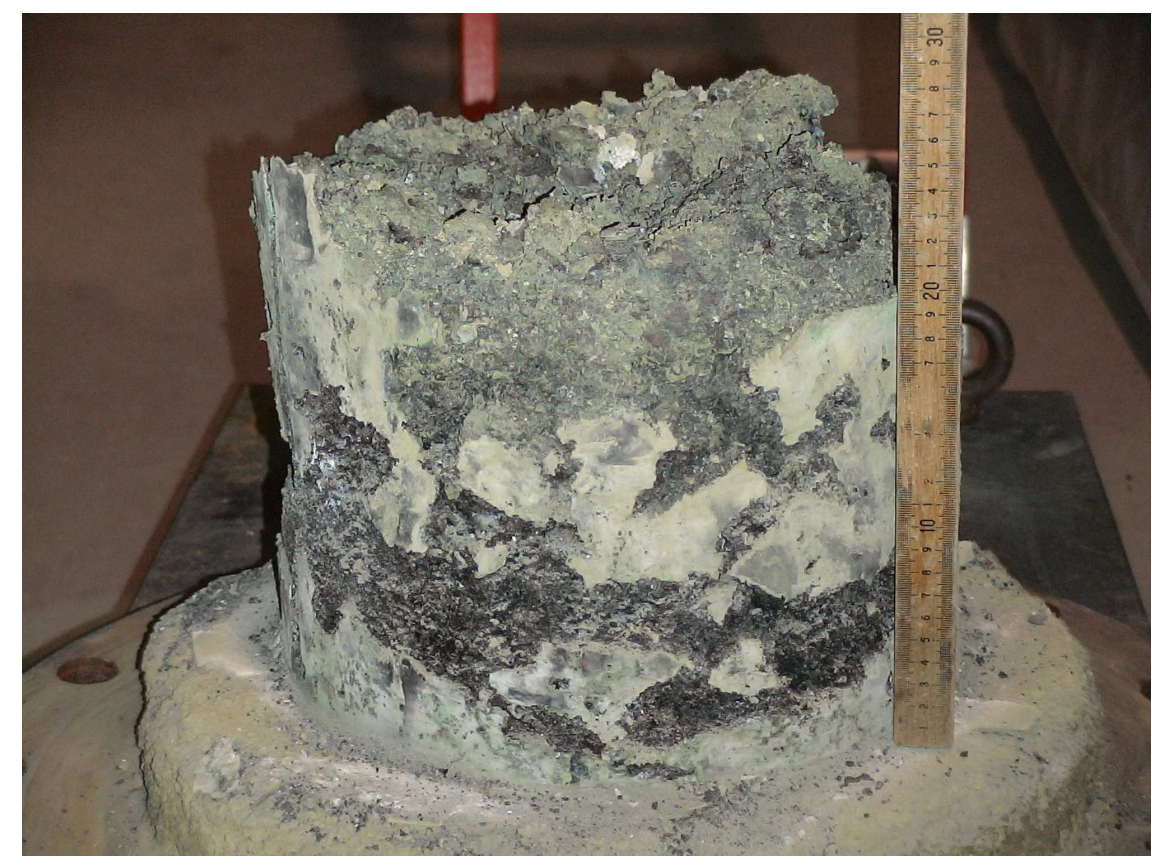

Figure 2-12. Corium Side View of Ingot 11.

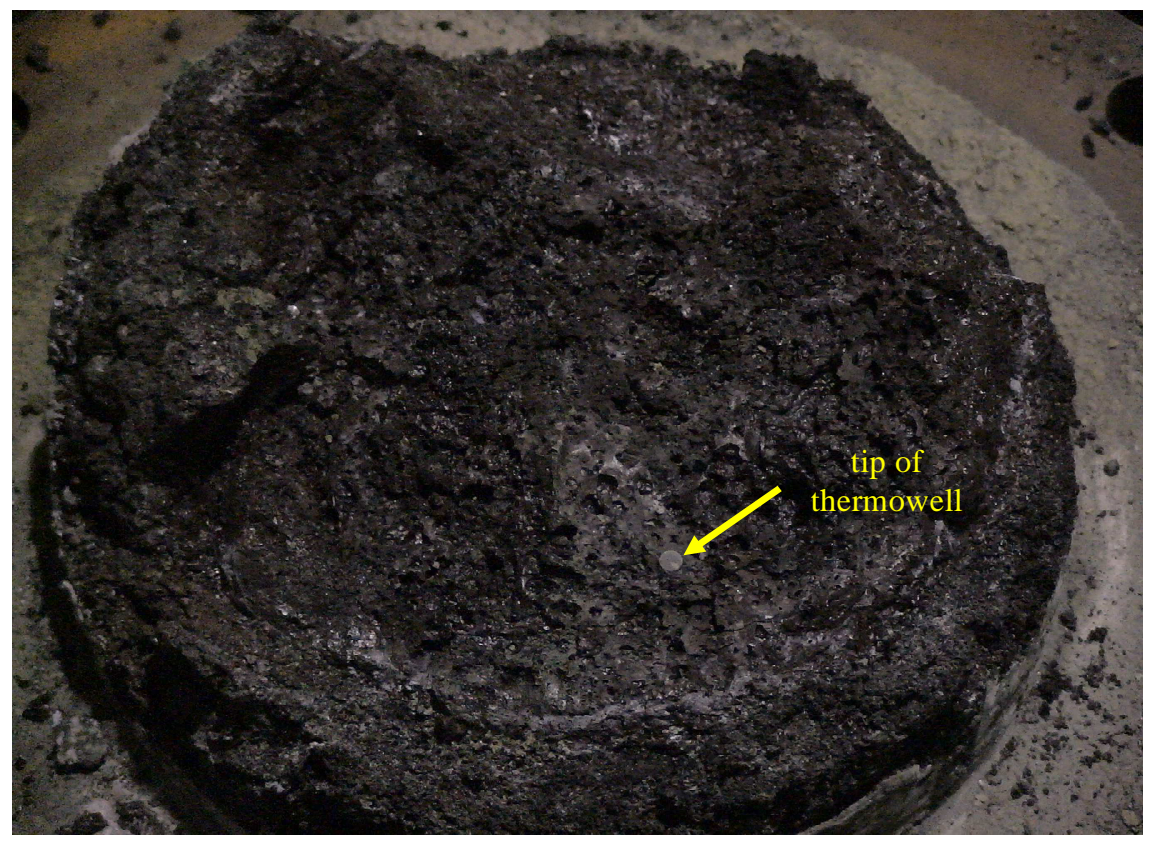

Figure 2-13. Corium at Level of Top of Tungsten Thermowell after Removal of Upper Layers (Ingot 11). 
Figure 2-14 compares the cooling rates during SSWICS-6, -8, and -11. As noted earlier, the injected argon circumvented the melt in SSWICS-8 and so it was effectively a repeat of SSWICS-6. The plot shows that the cooling rates correspond well for the two tests. The figure also shows the cooling rates for all of the $\sim 70 \mathrm{~kg}$ quench tests (SSWICS-9 and -10 were $25 \mathrm{~kg}$ ). It can be seen that SSWICS-11, with its comparatively high concrete content, cooled at a rate more comparable to the low concrete melts. Only SSWICS-7, with the lowest tested concrete content, quenched more quickly. Note also that melts with high cooling rates seem to plateau early in the transient, which was associated with a dryout limit. SSWICS-11 did not exhibit a plateau, which may be because this porous melt had a dryout limit far higher than the other melts. Without internal heating, the melt would be unable to sustain an extremely high heat flux and so one might see the monotonic decline exhibited in the plot.

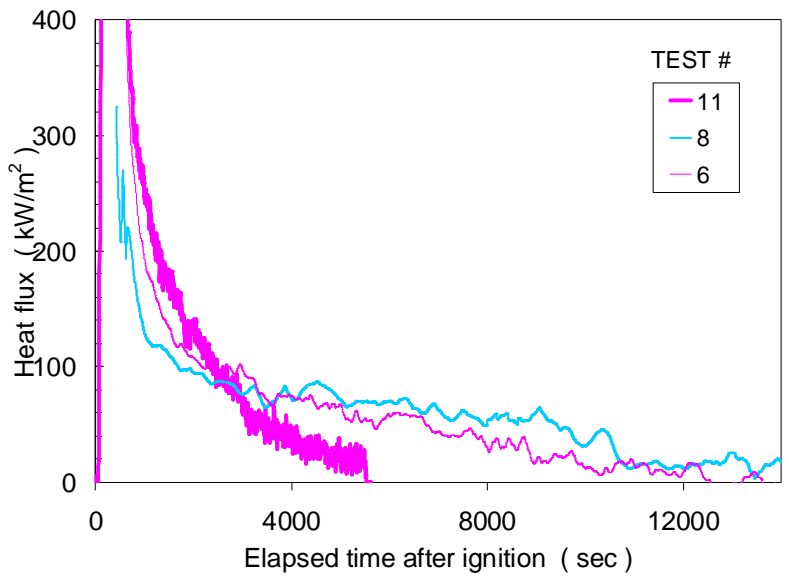

(a)

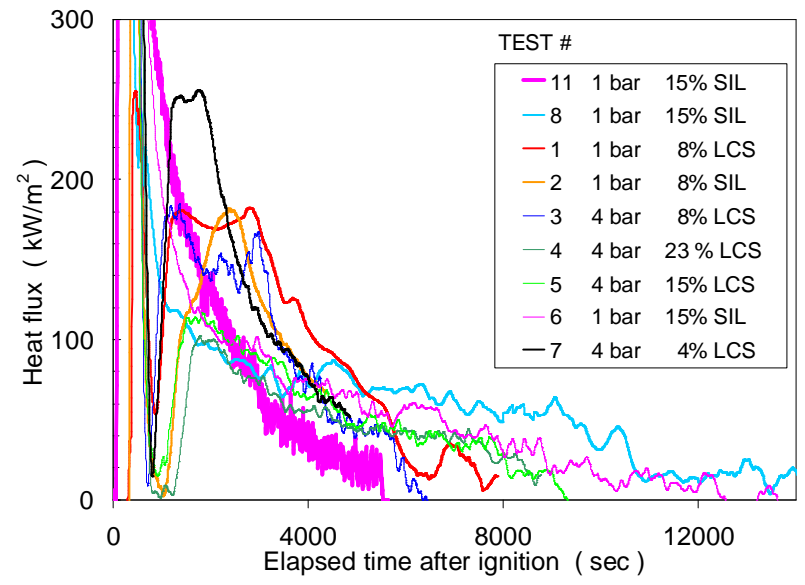

(b)

Figure 2-14. (a) Heat Flux for Tests with Sparging (11) and Without (8 \& 6); Melt Composition and Quench Conditions are Identical for the Three Tests. (b) Calculated Heat Flux for all Nine Quench Tests. 


\subsection{CATEGORY 2 TEST RESULTS}

This test category focused on examining new design features that enhance coolability under ex-vessel accident conditions. As described in Section 1.0, two approaches for achieving this objective have been conceived, which are: i) a cold crucible technique, and ii) melt fragmentation by water injection. As shown in Table 1-2, a total of three tests were carried out to provide data for these two approaches. The results are summarized below under these same two general headings; refer to [5] for detailed descriptions of the test facilities and experiment results for the various tests.

\subsection{Water Cooled Basemat Test}

The high-level experiment objective of the Water Cooled Basmat (WCB-1) test was to provide reactor material test data on the transient evolution and stabilization of a core melt within a generic water-cooled core catcher design for advanced plant applications. The experiment approach was to incorporate a test section featuring a water-cooled basemat into the Core Concrete Interaction (CCI) test facility to study thermal performance under long-term conditions in which melt resistance heating was provided to simulate decay heat. Test specifications for WCB-1 are summarized in Table 3-1.

Table 3-1. Specifications for WCB-1.

\begin{tabular}{|c|c|}
\hline Parameter & Specification \\
\hline Corium & $100 \%$ oxidized PWR with 8 wt $\%$ siliceous concrete \\
\hline Test section cross-sectional area & $50 \mathrm{~cm} \times 50 \mathrm{~cm}$ \\
\hline Test section sidewall construction & Inert $\mathrm{MgO}$ protected by $\mathrm{UO}_{2}$ pellet layer. \\
\hline \multirow{2}{*}{ Basemat construction } & $0-15 \mathrm{~cm}$ depth: siliceous concrete \\
\hline & 15-19.4 cm: water-cooled basemat, 5 parallel channels \\
\hline System operating pressure & Atmospheric \\
\hline Melt formation technique (timescale) & Chemical reaction ( $\sim 30$ seconds) \\
\hline Initial melt mass (depth) & $400 \mathrm{~kg}(25 \mathrm{~cm})$ \\
\hline Initial melt temperature & $1950^{\circ} \mathrm{C}$ \\
\hline Melt heating technique & Direct Electrical (Joule) Heating \\
\hline Initial power input level & Constant power at $80 \mathrm{~kW}^{\mathrm{a}}$ \\
\hline Inlet water temperature & $15^{\circ} \mathrm{C}$ \\
\hline Inlet water flow rate & 2 liters/second \\
\hline Sustained water depth over melt & $50 \pm 5 \mathrm{~cm}$ \\
\hline
\end{tabular}

${ }^{\mathrm{a}}$ Based on $150 \mathrm{~kW} / \mathrm{m}^{2}$ design heat flux to bottom and top surfaces of melt $\left(0.5 \mathrm{~m}^{2}\right.$ area), plus an additional $5 \mathrm{~kW}$ to compensate for a long-term heat losses of $10 \mathrm{~kW} / \mathrm{m}^{2}$ to $\mathrm{MgO}$ sidewalls $\left(0.5 \mathrm{~m}^{2}\right.$ area).

\subsubsection{Apparatus}

The WCB-1 test facility consisted of a test apparatus, a power supply for Direct Electrical Heating (DEH) of the corium, a basemat water supply system, a corium top flooding water supply system, two steam condensation (quench) tanks, a ventilation system to complete filtration and exhaust the off-gases, and a data acquisition system. A schematic illustration of the facility is provided in Figure 3-1. The apparatus consisted of three rectilinear sidewall sections 
and a lid. The overall structure was $3.4 \mathrm{~m}$ tall. The sidewall sections had a square internal cross sectional area of nominally $50 \mathrm{~cm}$ x $50 \mathrm{~cm}$.

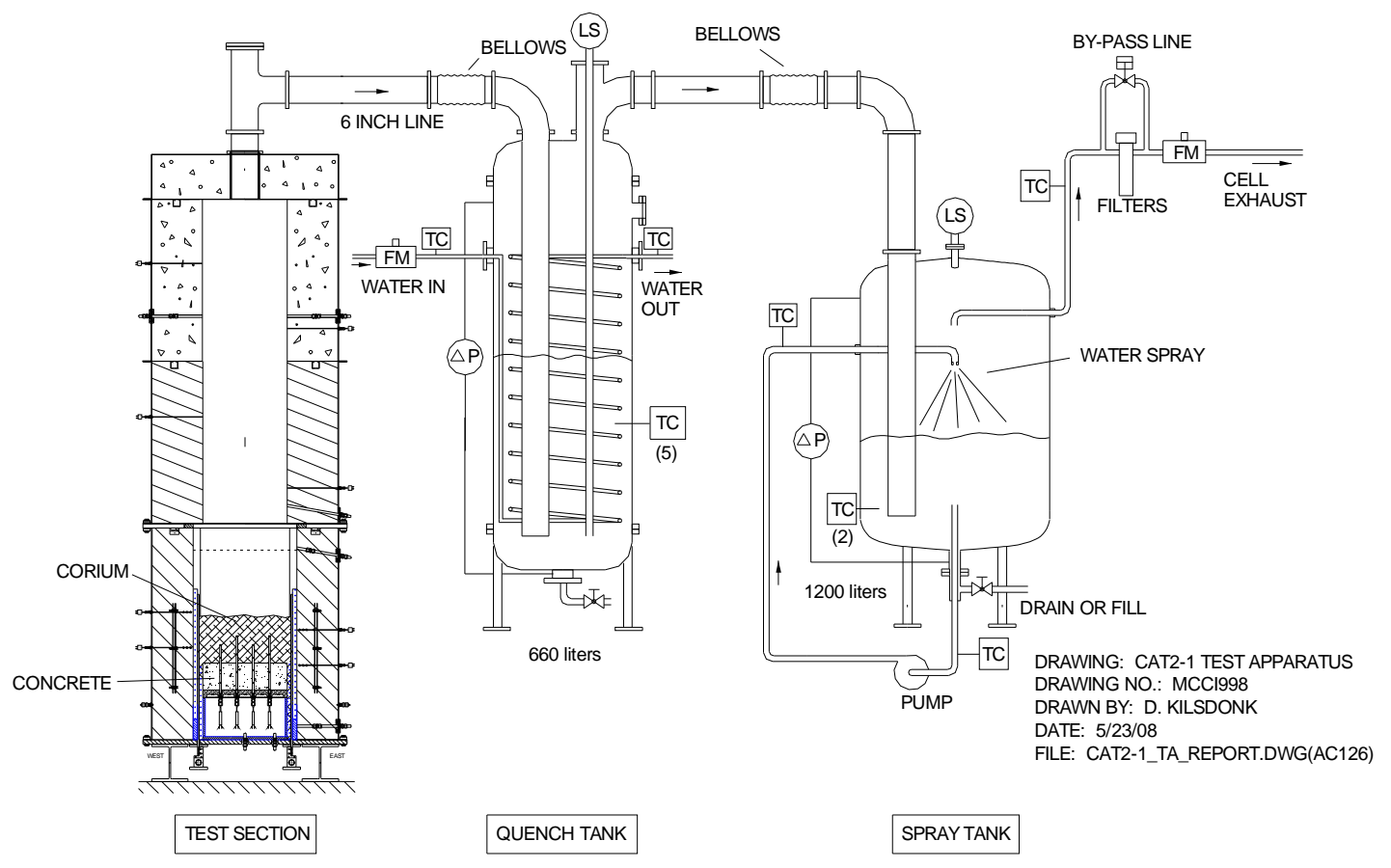

Figure 3-1. Schematic of WCB-1 Test Facility.

The test section for containment of the core melt was located at the bottom of the apparatus. Cross-sectional views showing the water-cooled basemat installation are provided in Figure 3-2. The design utilized four refractory $\mathrm{MgO}$ sidewalls that were each lined with a layer of crushed $\mathrm{UO}_{2}$ pellets. The pellets served as an inert (i.e., non-ablative) and highly insulating wall surface. As shown in the figure, the refractory walls were equipped with instrumented tungsten backup plates to preclude sidewall melt-through if the pellet layer were to fail and sidewall erosion occurred. This detection/mitigation system formed part of the safety planning for the experiments, and on this basis the feed throughs for the basemat water lines and instruments were brought in from the bottom of the test section. The refractory sidewalls were contained within a flanged steel form that was used to secure the lower section to the bottom test section support plate and the middle sidewall section. The flanges allowed the lower sidewalls to be disassembled to reveal the solidified corium and water-cooled basemat following the test. Aside from the instrumented basemat, multi-junction Type $\mathrm{C}$ thermocouple assemblies were cast in the sidewalls so that the heat losses from the melt could be calculated given the wall temperature profile and thermal conductivity of the $\mathrm{MgO}$.

Details of the water-cooled basemat design are shown in Figures 3-3. The overall layout consisted of a $15 \mathrm{~cm}$ deep layer of sacrificial concrete that sat on top of the water-cooled basemat plate. The plate consisted of five parallel cooling channels that were machined out of a monolithic piece of $4.4 \mathrm{~cm}$ thick Type 304 stainless steel. Although carbon steel would be a more attractive construction material due to the higher thermal conductivity, melting point, and 
lower material cost, a non-magnetic material was used to preclude induction heating of the plate by the power supply used to resistively heat the melt. Although the monolithic design required a great deal of machining, it was nonetheless adopted to minimize the chance of spurious water leaks that could develop if the plate were manufactured using a cheaper method in which parts were sealed with gaskets, since these interfaces could develop leaks if thermal stresses warped the plate during the test.

The plate instrumentation layout was also designed to minimize penetration of the water channels that could lead to the development of leaks during the test. The feed throughs for the multi-junction thermocouple assemblies devoted to measuring melt temperature and basemat erosion were mounted in the unmachined regions between the individual coolant channels. This somewhat limited potential locations for the assemblies, but nonetheless ensured that the feed throughs could not provide leakage paths for water. Another design requirement was to electrically isolate these thermocouple assemblies from the basemat to prevent ground loops that would present alternative current paths for the current providing DEH to the melt. This was accomplished by using ceramic-sleeve gland seals to mount the thermocouples to the basemat plate. In addition, the tungsten thermowells that protected the melt temperature thermocouple assemblies were electrically isolated with ceramic sleeves that were used to seat the base of the wells in the plate.

Aside from the thermocouple assemblies, the water channels were also instrumented with high temperature heat flux meters to provide local heat flux measurements. For these units to be effective, they had to be installed directly in the cooling channel so there was no choice but to provide feed throughs that passed through the channel cover plate. To ensure a leak-tight fit, specialty units were used that allowed the feed throughs to be sealed using high-grade compression fittings that provided reasonable assurance that leaks would not develop during the test. Once the heat flux meters were installed, the channels were sealed with stainless steel cover plates that were welded in place.

Each water coolant channel was equipped with an independent water measurement and control system that included both manual and remote isolation valves and an ultrasonic flowmeter. Temperature rise across each channel was measured using Type $\mathrm{K}$ thermocouples. The channel piping was constructed from $1.3 \mathrm{~cm}$ ID tubing. The individual channel flowrate and water temperature rise data allowed the average heat flux to each channel to be calculated. Each channel was also equipped with a secondary supply line with manual and remote isolation valves that could provide additional water flow to selected channels during the test if excessive heatup was observed. Both the primary and makeup supply lines were fed from $3.9 \mathrm{~cm}$ diameter header manifolds, and vented through a common manifold of the same diameter. The bulk temperature rise across the supply and return manifolds and total mass flowrate allowed the average heat flux to the plate to be calculated for comparison to the local channel measurements determined by the heat flux meters and the individual channel mass flux and temperature rise measurements. 
OECD/MCCI-2010-TR06, Rev. 1

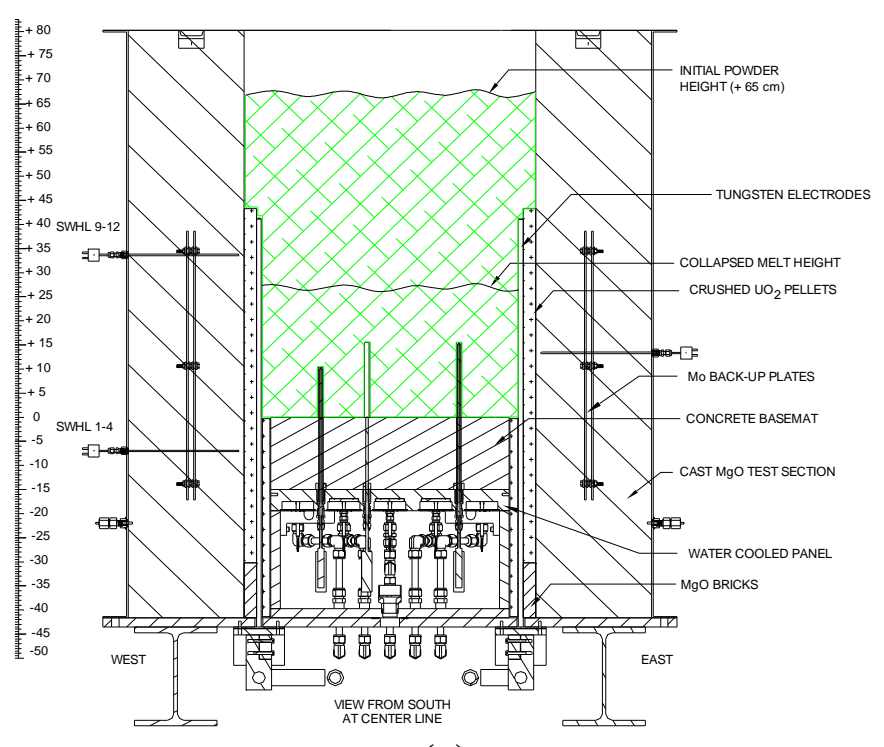

(a)

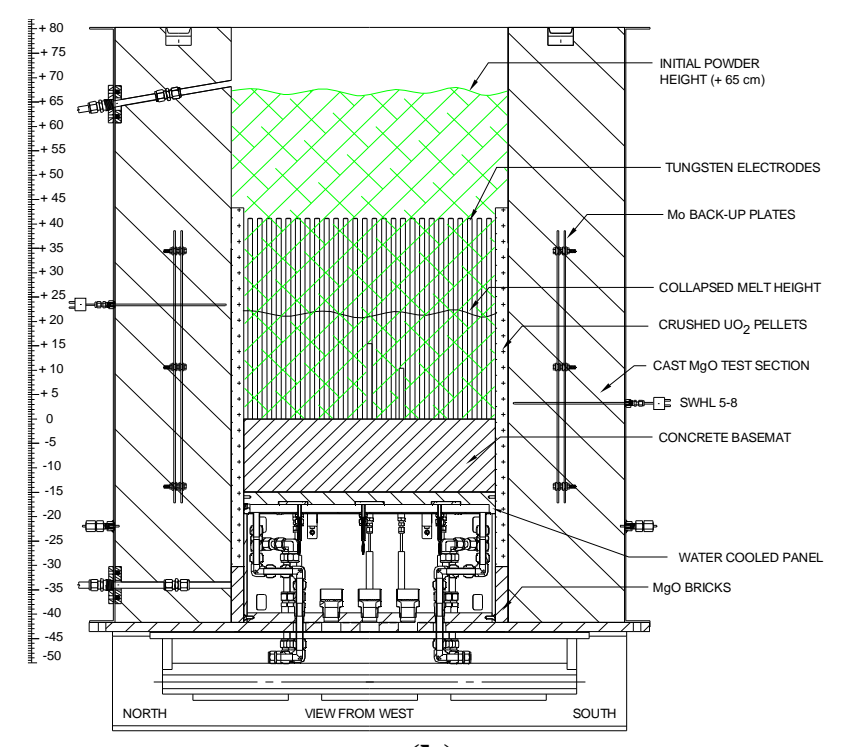

(b)

Figure 3-2. (a) Electrode and (b) Non-Electrode Sidewall Views of WCB-1 Lower Test Section.
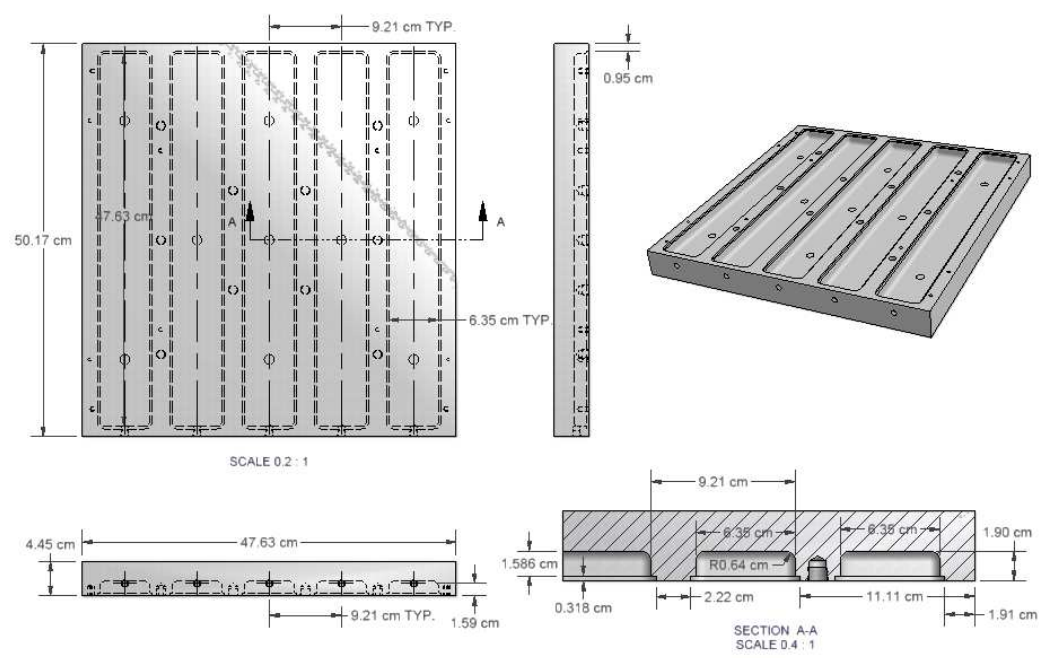

(a)

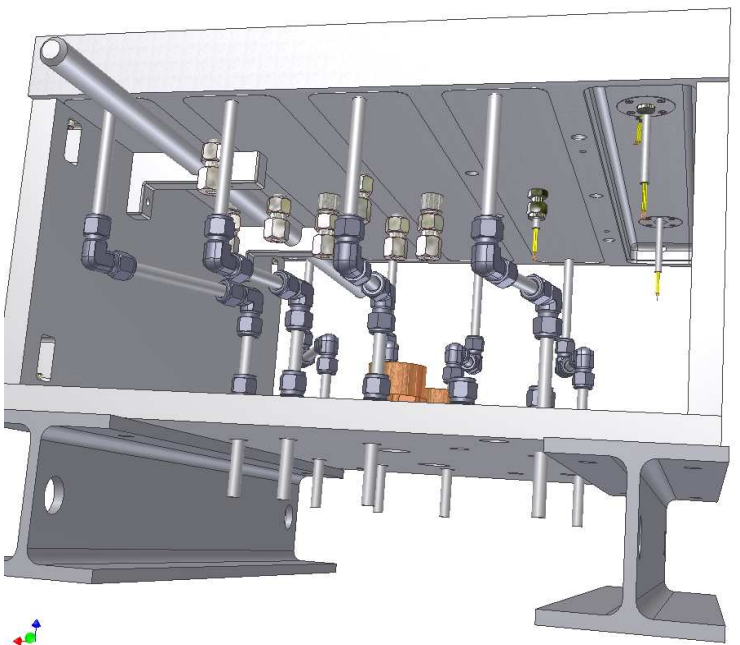

(b)

Figure 3-3. (a) Design Details and (b) Instrument Feed Through Locations for Water-Cooled Basemat Plate. 
Since the basemat water inlet and exits were from the bottom of the plate, the test could not investigate situations in which the bulk water outlet temperature approached saturation, otherwise the channels could vapor-lock and cause premature test termination. On this basis, the water flowrate through the channels was selected to achieve a highly subcooled boiling regime at a design basis surface heat flux of $150 \mathrm{~kW} / \mathrm{m}^{2}$ into the plate. Based on design calculations [58], after the system equilibrated at the design heat flux, the water temperature rise across the watercooled channels was expected to be $\sim 9^{\circ} \mathrm{C}$ with the boundary condition on the plate inner surface being highly subcooled nucleate boiling. The top surface of the plate was expected to equilibrate at $\sim 373{ }^{\circ} \mathrm{C}$, with the plate protected by a $\sim 1 \mathrm{~cm}$ deep corium (or concrete slag) crust.

The melt was produced through an exothermic chemical reaction yielding the target mass over a timescale of $\sim 30$ seconds. After the chemical reaction, DEH simulating decay heat was applied through two banks of tungsten electrodes. As shown in Figure 3-2, the electrodes lined the interior surfaces of the two opposing $\mathrm{MgO}$ sidewalls. The electrodes were $9.5 \mathrm{~mm}$ in diameter and pitched at $1.9 \mathrm{~cm}$; they were attached to a $560 \mathrm{~kW}$ AC power supply by copper clamps and water-cooled buss bars.

A few minutes after the melt was formed, ablation of the concrete basemat commenced. As shown in Figure 3-1, a $15 \mathrm{~cm}$ diameter gas line was used to vent the helium cover gas and the various gas species arising from the core-concrete interaction (i.e., $\mathrm{CO}, \mathrm{CO}_{2}, \mathrm{H}_{2} \mathrm{O}$, and $\mathrm{H}_{2}$ ) into adjacent tanks that were partially filled with water. In the initial phase of the experiment as the concrete eroded, the tanks served to cool the off-gases and filter aerosols generated from the core-concrete interaction. In the late phase after the cavity was flooded, the tanks served to condense the steam and, based on the measured condensation rate, provide data on the corium cooling rate. In either case, the helium covergas and non-condensables $\left(\mathrm{CO}, \mathrm{CO}_{2}\right.$, and $\left.\mathrm{H}_{2}\right)$ passed through the tanks and were vented through an off gas system that included a demister and filters. The gases were eventually exhausted through the containment ventilation system and a series of high efficiency filters before finally being released from the building stack.

After a specified period of interaction, the cavity was flooded from an instrumented water supply system. The water entered the test section through two weirs located in the opposing (non-electrode) sidewalls of the top test section. The water flowed down the test section interior walls and then atop the melt. Following initial water addition, makeup was periodically added to maintain the water level over the melt at $50 \pm 5 \mathrm{~cm}$.

The WCB-1 facility was instrumented to monitor and guide experiment operation and to $\log$ data for subsequent evaluation. Principal parameters that were monitored during the course of the test include the power supply voltage, current, and gross input power to the melt; melt temperature and temperatures within the concrete basemat, sidewalls, and water-cooled basemat; supply water flow rate to the basemat and to the test section; water volume and temperature within the test apparatus, and water volume and temperature within the quench system tanks. Other key data recorded during the test included temperatures within test section structural sidewalls, melt/crust upper surface temperature, off gas temperature, and pressures at various locations within the system. Measurement uncertainties for the various instruments utilized in the tests are provided in [5]. 
Plan and elevation views of the basemat thermocouple layout are provided in Figure 3-4. The basemat was instrumented to monitor melt temperature during both the concrete ablation and plate-cooling phases of the test using multijunction Type $\mathrm{C}$ thermocouples in tungsten thermowells, and also to track concrete ablation during the early sacrificial erosion phase using multi-junction Type $\mathrm{K}$ thermocouples cast directly into the concrete. Other significant test instrumentation included a lid-mounted video camera for observing physical characteristics of the interaction. In addition, a pyrometer was used to measure the debris upper surface temperature during periods in which aerosol production did not optically occlude the view of the surface

As shown in Table 3-1, the corium composition for WCB-1 was specified to contain 8 wt $\%$ calcined siliceous concrete as an initial constituent. As previously noted, the melt pool was produced through an exothermic 'thermite' type chemical reaction that yielded the target melt composition over a timescale of $\sim 30$ seconds. The post-reaction melt composition is provided in Table 3-2.

The composition of the WCB-1 concrete was siliceous. The mix was identical to that
Table 3-2. Initial Melt Composition for WCB-1.

\begin{tabular}{|c|c|c|}
\hline Constituent & Wt\% & Mass (kg) \\
\hline $\mathrm{UO}_{2}$ & 60.97 & 243.88 \\
\hline $\mathrm{ZrO}_{2}$ & 25.04 & 100.16 \\
\hline $\mathrm{SiO}_{2}$ & 6.38 & 25.52 \\
\hline $\mathrm{MgO}$ & 0.07 & 0.28 \\
\hline $\mathrm{Al}_{2} \mathrm{O}_{3}$ & 0.38 & 1.52 \\
\hline $\mathrm{CaO}$ & 1.25 & 5.00 \\
\hline $\mathrm{Cr}$ & 5.91 & 23.64 \\
\hline Total & 100.00 & 400.00 \\
\hline
\end{tabular}

Table 3-3. Composition of WCB-1 Siliceous Concrete.

\begin{tabular}{|c|c|}
\hline Constituent & Wt \% \\
\hline $\mathrm{SiO}_{2}$ & 60.99 \\
\hline $\mathrm{CaO}$ & 17.09 \\
\hline $\mathrm{Al}_{2} \mathrm{O}_{3}$ & 3.61 \\
\hline $\mathrm{Fe}_{2} \mathrm{O}_{3}$ & 1.52 \\
\hline $\mathrm{MgO}$ & 0.87 \\
\hline $\mathrm{MnO}$ & 0.04 \\
\hline $\mathrm{SrO}$ & 0.04 \\
\hline $\mathrm{TiO}_{2}$ & 0.16 \\
\hline $\mathrm{SO}_{3}$ & 0.44 \\
\hline $\mathrm{Na}_{2} \mathrm{O}$ & 0.67 \\
\hline $\mathrm{K}_{2} \mathrm{O}$ & 0.83 \\
\hline $\mathrm{CO}_{2}$ & 9.98 \\
\hline $\mathrm{H}_{2} \mathrm{O}$ & $3.76^{\mathrm{a}}$ \\
\hline
\end{tabular}

${ }^{\mathrm{a}}$ Free and bound water contents are 2.33 and 1.43 wt $\%$, respectively. used in the CCI-3 experiment [1]. The sand and aggregate were supplied by CEA as an in-kind contribution to the program. The chemical composition for this concrete is provided in Table 33. These data are based on analysis of a specimen taken from the CCI-3 concrete archive sample [1]. The concrete density was determined to be $2270 \mathrm{~kg} / \mathrm{m}^{3}$ from the archive sample using the standard mass-volume method.

In terms of test operations, the planned procedure was to raise input power to the initial target level of $80 \mathrm{~kW}$ for the core-concrete interaction phase of the experiment following completion of the thermite reaction that produced the core melt. Input power would be held constant at this level until the concrete was eroded to a depth of $12.5 \mathrm{~cm}$, leaving a concrete layer $2.5 \mathrm{~cm}$ thick over the water-cooled basemat, at which point the cavity would be flooded. The system would then be allowed to come to thermal equilibrium for at least 15 minutes (as evidenced by steaming rate from the test section, as well as the melt and water channel exit temperatures). After this initial constant power operating phase at $80 \mathrm{~kW}$, the power would be gradually reduced in $10 \mathrm{~kW}$ intervals and the system would be allowed to equilibrate at each new power level. After each adjustment, the power supply would be run in a constant voltage mode 
OECD/MCCI-2010-TR06, Rev. 1

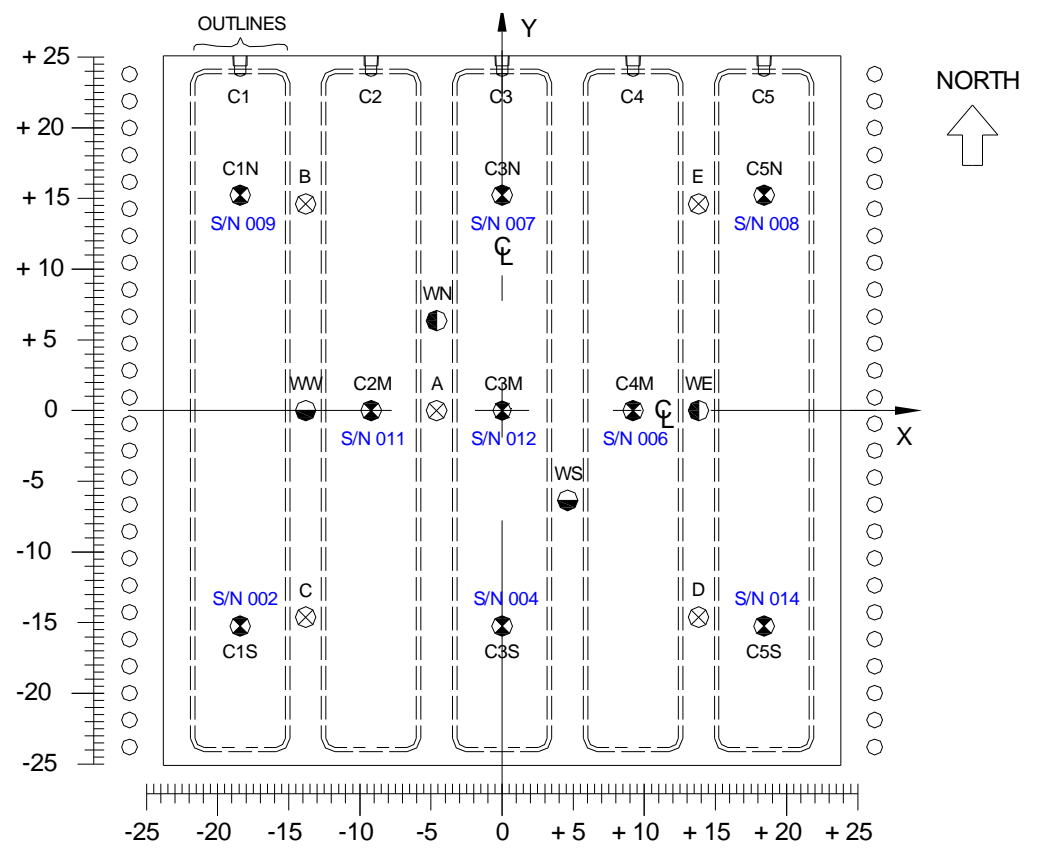

- HEAT FLUX METER FOR MEASUREMENT OF CHANNEL WALL TEMPERATURE AND WALL HEAT FLUX. (9 UNITS, 2 WIRE PAIRS/UNIT, 18 WIRE PAIRS TOTAL)

$\otimes$ EIGHT JUNCTION TYPE K ARRAYS FOR MEASURING BASEMAT TEMPERATURE AND EROSION. JUNCTIONS AT: 0.0, -2.5, -5.0, -7.5 $-10.0,-12.5,-15.0,-17.25 \mathrm{~cm}$ FROM CONCRETE SURFACE. (5 UNITS, 8 WIRE PAIRS/UNIT, 40 WIRE PAIRS TOTAL)

- FOUR JUNCTION TYPE C ARRAYS FOR MEASURING MELT TEMPERATURES. JUNCTIONS AT: + $15.0,+5.0,-5.0,-15.0 \mathrm{~cm}$. (2 UNITS, 4 WIRE PAIRS/UNIT, 8 WIRE PAIRS TOTAL)

- FOUR JUNCTION TYPE C ARRAYS FOR MEASURING MELT TEMPERATURES. JUNCTIONS AT: + 10.0, +3.0, $-4.0,-11.0 \mathrm{~cm}$. (2 UNITS, 4 WIRE PAIRS/UNIT, 8 WIRE PAIRS TOTAL)

(a)

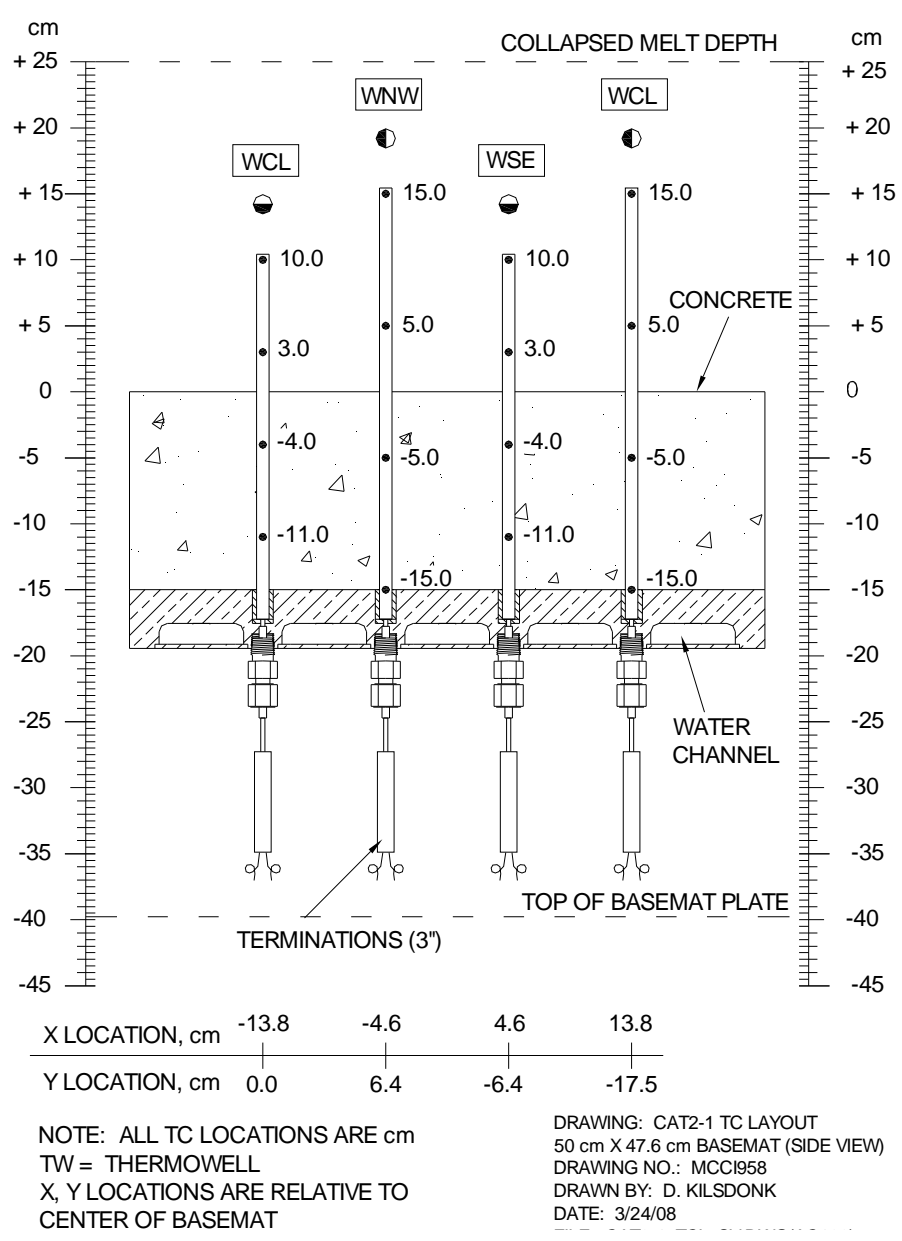

(b)

Figure 3-4. (a) Plan View of Basemat Instrumentation and (b) Elevation View of Type C Instrument Locations. 
for a period of $\sim 15$ minutes to look for the possibility of water ingression, as would be evidenced by reducing input power at constant voltage. ${ }^{2}$ Operation in this manner would continue until the input power was reduced to zero, either by gradual quench, or by periodic operator reductions in power level.

\subsubsection{Results and Discussion}

The overall objective of WCB-1 was to provide reactor material test data on the transient evolution and stabilization of a core melt within a generic water-cooled core catcher design for advanced plant applications. Important operational information consisted of the DEH input power as a function of time, which is shown in Figure 3-5. Time $t=0$ in this and all other graphs corresponds to initial melt contact with the concrete basemat surface (i.e., completion of the thermite burn). From the viewpoint of the coreconcrete interaction, key data included local melt temperatures, concrete ablation rates, and debris/water heat flux after cavity flooding; this information is provided in Figures 3-6 through 3-8. The criterion used to define the onset of concrete ablation at a given location in Figure 3-7 was that the local temperature reached the siliceous concrete liquidus temperature of $1250{ }^{\circ} \mathrm{C}$ [7]. With respect to the plate thermal response, key measurements included local plate heat fluxes and surface temperatures; these

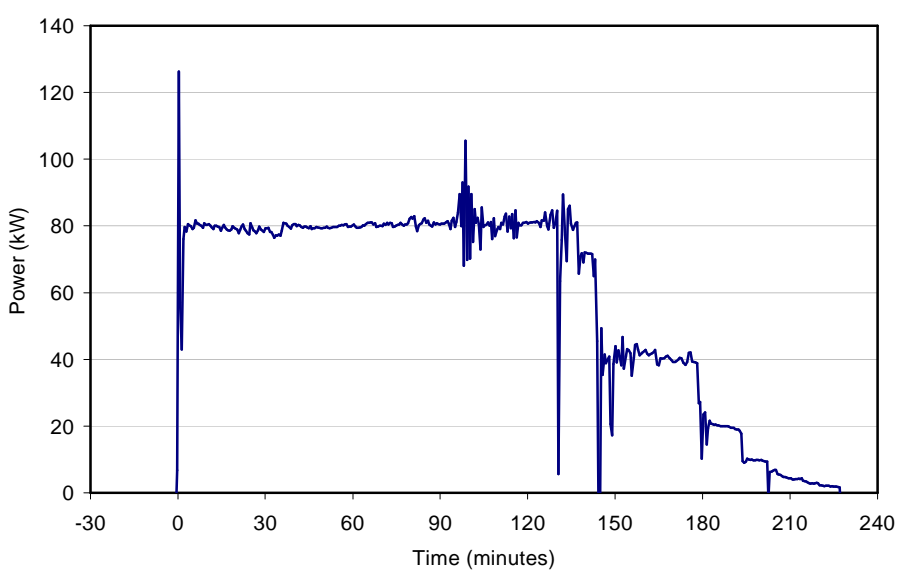

Figure 3-5. DEH Input Power for WCB-1.

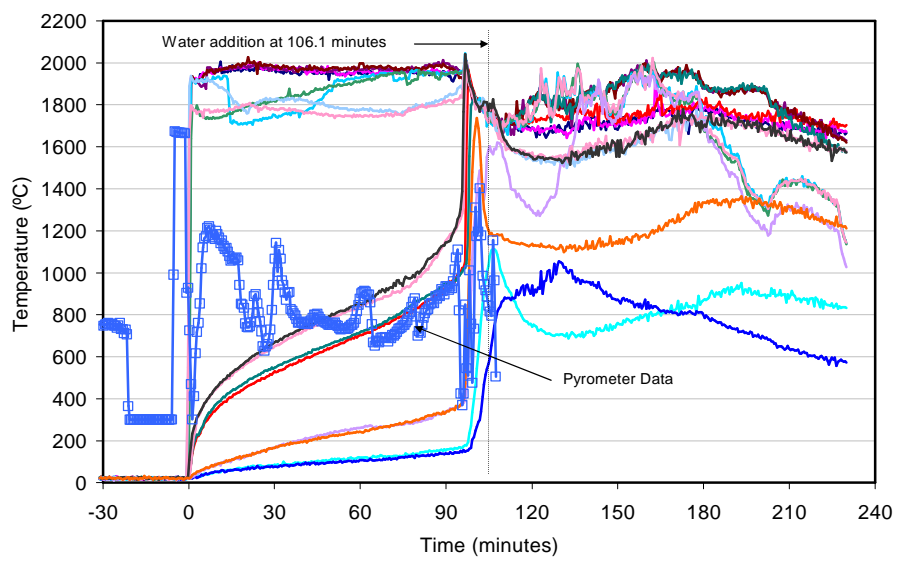

Figure 3-6. WCB-1 Melt Temperature Data.

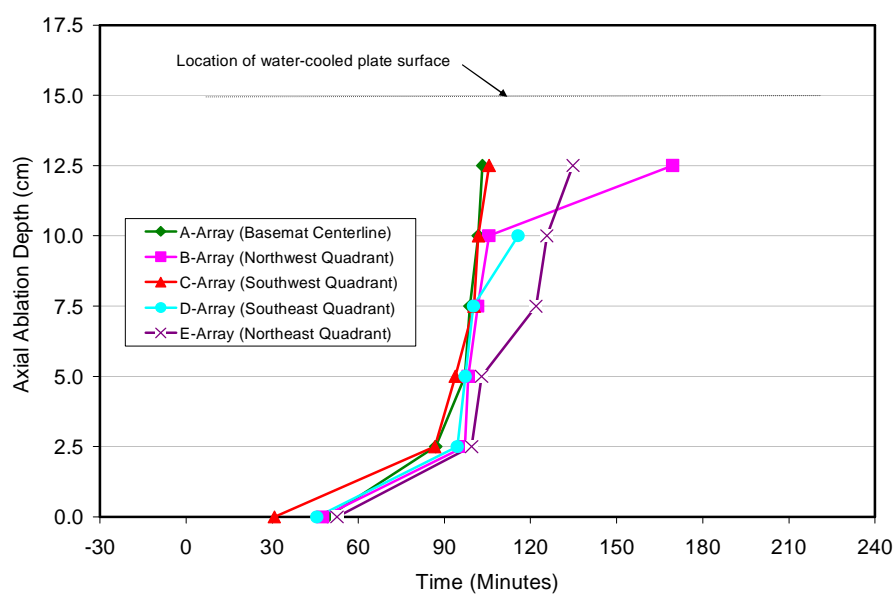

Figure 3-7. WCB-1 Basemat Ablation Data.

\footnotetext{
${ }^{2}$ Following concrete erosion, melt sparging would cease. As a result, the test conditions would resemble a water ingression test [3] but with sustained heating. Thus, when operating with constant voltage, the power should decrease as the material quenched if water ingression occurred. However, if the power did not fall appreciably, then the power level would be above the dryout limit. In this event, the power would be reduced in $10 \mathrm{~kW}$ intervals spaced at $\sim 15$ minute intervals until the power began to decrease at constant voltage. This would define the dryout limit for the melt, which would be additional data to add to the SSWICS water ingression database
} 
data are provided in Figures 3-9 and 3-10. Operationally, the test was deemed to be successful: a core melt at $\sim 1950{ }^{\circ} \mathrm{C}$ was produced over a water-cooled basemat that was originally protected by a $15 \mathrm{~cm}$ thick layer of siliceous concrete, the concrete was eroded, and the melt came to equilibrium at the plate surface.

As in previous tests conducted as part of this (see Section 4 and [1]) and other programs [37], there was a quiescent period following melt generation in which the concrete surface was protected by an insulating corium crust that formed on initial melt contact with the cold concrete. However, continued heating of the corium eventually led to heatup of the concrete beneath and the crust eventually remelted or failed, leading to onset of rapid basemat ablation. The data (Figure 3-7) indicated that this transition point occurred at $\sim 90$ minutes following initial melt contact with the concrete surface. During the quiescent period, melt temperatures were scattered in the range of 1750 to $2000{ }^{\circ} \mathrm{C}$. Melt sparging would have been minimal during this phase due to limited ablation $(\leq 2.5$ $\mathrm{cm})$ and so there was no convection within the melt to smooth out temperature variations that developed as a result of the input power to this refractory (i.e., low thermal conductivity) material.

After onset of ablation at

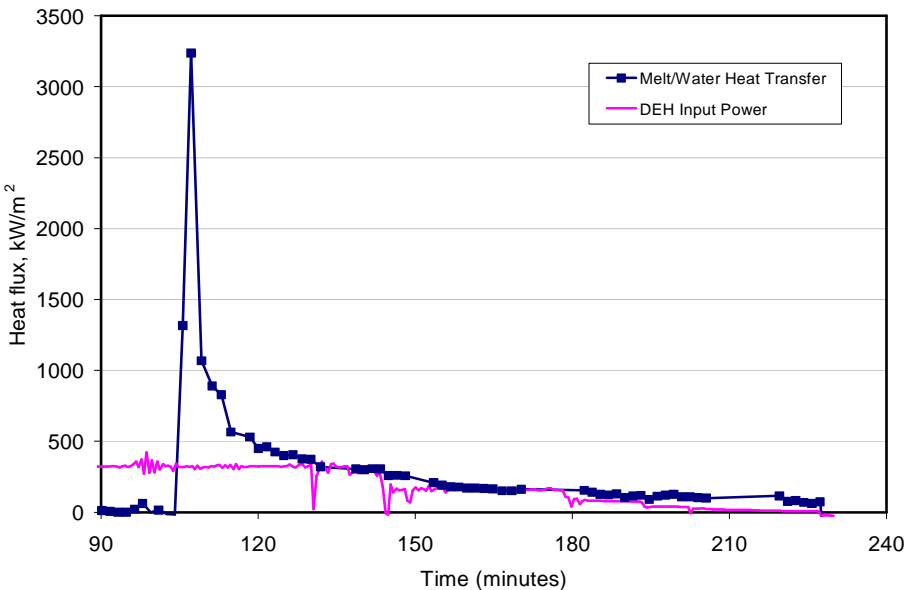

Figure 3-8. WCB-1 Heat Flux to Overlying Water.

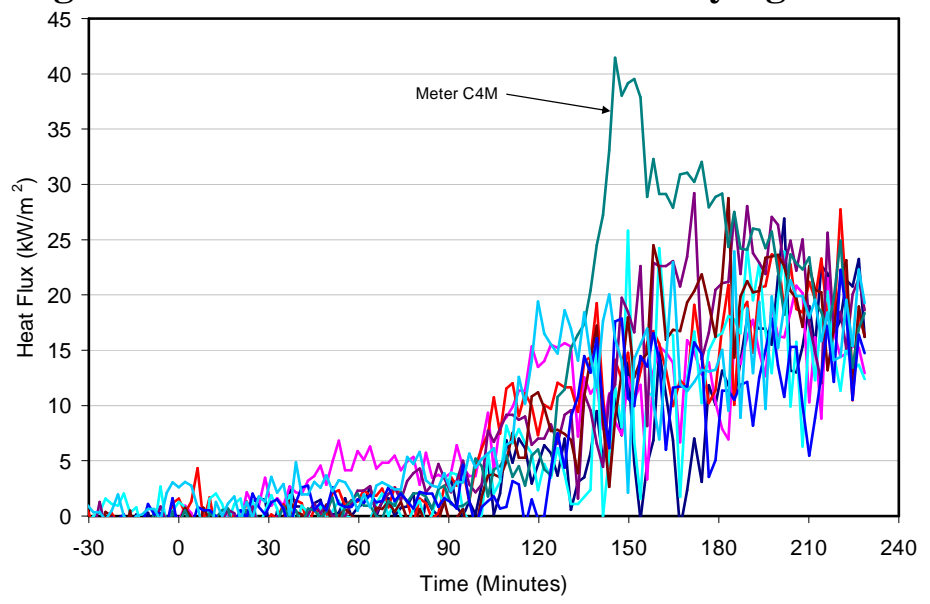

Figure 3-9. Data from All Water-Cooled Basemat Heat Flux Meters.

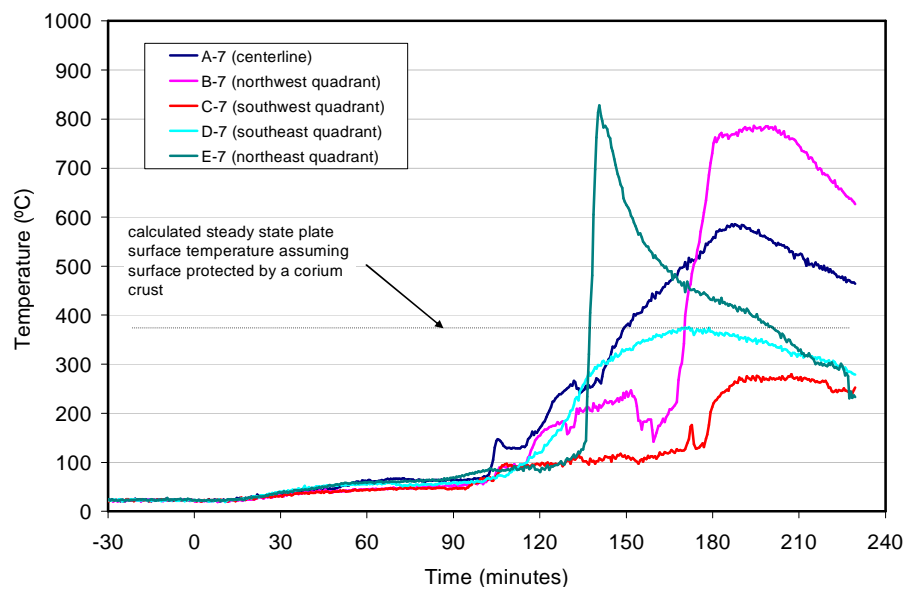

Figure 3-10. Water-Cooled Basemat Upper Surface Temperatures.

90 minutes, a rapid transient occurred in which the remaining $\sim 10 \mathrm{~cm}$ of the concrete was consumed by erosion over a time interval of $\sim 15$ minutes, resulting in an average ablation rate of 
$\sim 6.7 \mathrm{~mm} /$ minute. This rapid concrete erosion rate can partially be rationalized by considering the preceding 90 minutes of the interaction, wherein the concrete beneath the corium crust would have undergone significant heatup and dryout. Thus, when erosion finally commenced, the effective concrete decomposition enthalpy was significantly reduced, thereby allowing for an accelerated rate of ablation for a given heat flux to the concrete surface. However, it is noteworthy that at all basemat thermocouple locations, the progression of the ablation front was terminated as the water-cooled plate was approached. This observation was confirmed during posttest examinations, which verified that the plate survived the experiment intact (see Figure 311(a)). During this phase, the melt temperature measurements banded more closely together due to convection from gas sparging in the melt pool. The bulk temperature declined from $\sim 2000{ }^{\circ} \mathrm{C}$ at 90 minutes to $\sim 1800{ }^{\circ} \mathrm{C}$ at the time of cavity flooding. Up until this time, the water-cooled basemat plate remained relatively cool due to the insulating properties of the overlying concrete.

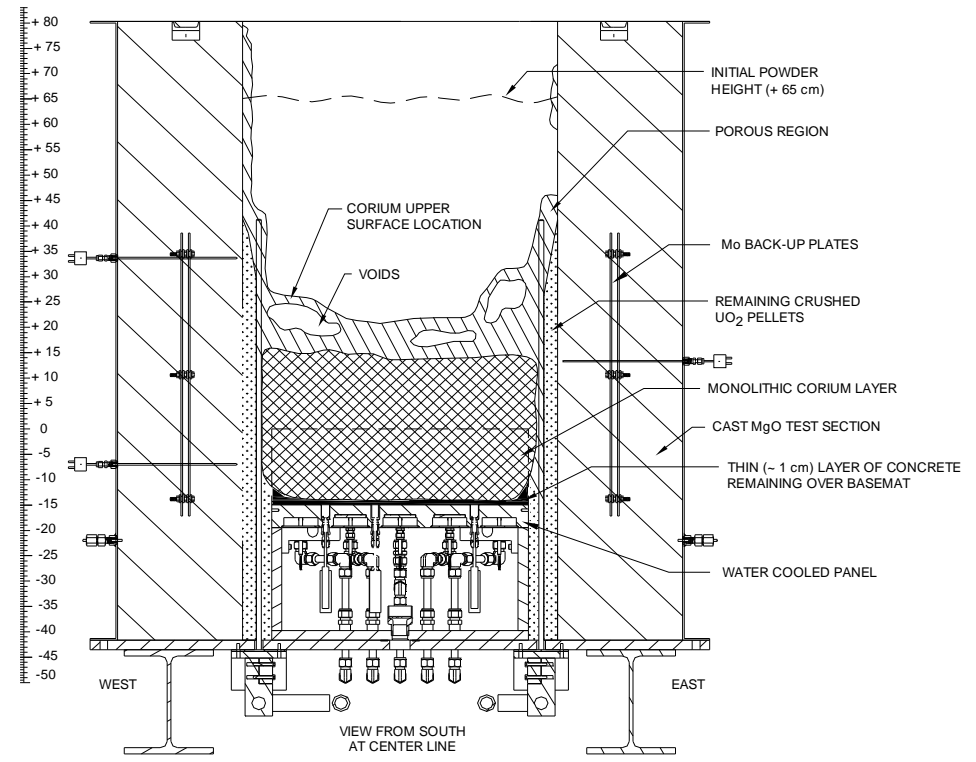

(a)

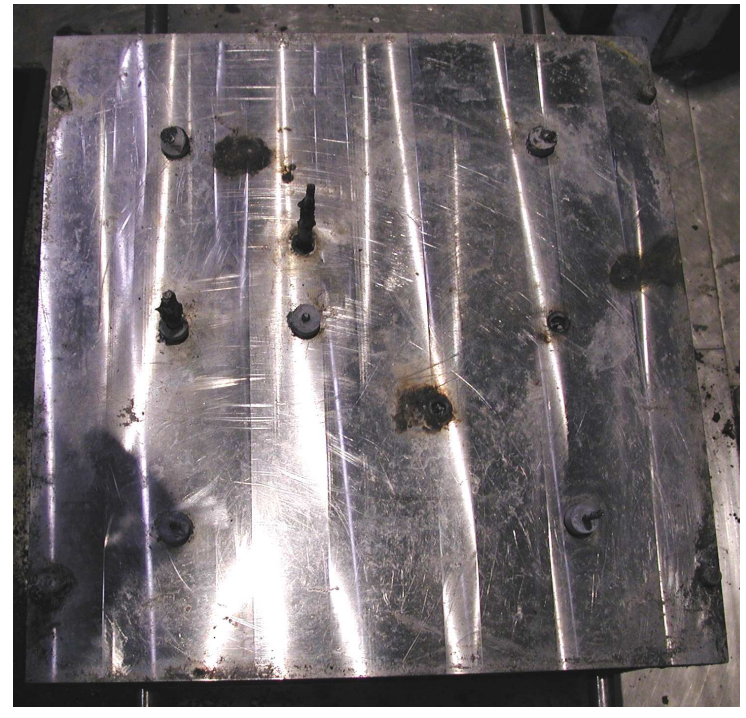

(b)

Figure 3-11. (a) Rendering of WCB-1 Posttest Debris; (b) Photo of Top Surface of Water-Cooled Plate after Debris Removal. (both views are from the south)

At 105 minutes, the ablation depth had reached the $12.5 \mathrm{~cm}$ depth at several locations within the basemat, and on this basis, the cavity was flooded according to the normal test procedure. In the five minute interval following flooding, the melt temperature declined an additional $100{ }^{\circ} \mathrm{C}$ before stabilizing at $\sim 1700{ }^{\circ} \mathrm{C}$. At this point, a stable crust probably formed at the melt upper surface, terminating the bulk cooling transient. Following the initial transient, effectively all of the concrete had been consumed over the water-cooled basemat plate. Thus, pool gas sparging would have ceased at this time, and melt temperature measurements again diverged due to the lack of melt convection. The temperatures banded in the range of 1600 to $2000{ }^{\circ} \mathrm{C}$ until the power was reduced to $20 \mathrm{~kW}$ at 178.4 minutes. After this time, all remaining functional junctions indicated a steady melt temperature decline until the test was terminated at 230 minutes. In terms of the melt-water heat transfer rate, the heat flux varied from $3.3 \mathrm{MW} / \mathrm{m}^{2}$ immediately after cavity flooding, down to $\sim 100 \mathrm{~kW} / \mathrm{m}^{2}$ at the time the test was terminated. The 
data indicates that the heat flux to overlying water met or exceeded the DEH input power over the entire test, indicating that the up-down power split was biased heavily upwards.

Aside from the above information, additional data was gathered regarding the plate thermal response during the experiment. The design-basis heat flux to the plate was $150 \mathrm{~kW} / \mathrm{m}^{2}$, which corresponds to a 50-50 up-down power split at the initial DEH input power level of $80 \mathrm{~kW}$ in the $50 \mathrm{~cm} \times 50 \mathrm{~cm}$ test section. Based on this value, the plate cooling system was expected to evolve such that the temperature rise across the water-cooled channels would approach $9{ }^{\circ} \mathrm{C}$, with the boundary condition on the plate inner surface being highly subcooled nucleate boiling. The top surface of the plate was expected to come to equilibrium at $\sim 373{ }^{\circ} \mathrm{C}$, with the plate protected by a $\sim 1 \mathrm{~cm}$ deep corium (or concrete slag) crust. In reality, the plate thermal response data also indicated that the up-down power split after concrete erosion was biased heavily towards the overlying water. In particular, the measured heat fluxes to the plate were exceedingly low, predominately in the range of $10-25 \mathrm{~kW} / \mathrm{m}^{2}$ (Figure 3-9), which is almost an order of magnitude below the design basis value of $150 \mathrm{~kW} / \mathrm{m}^{2}$. Measurements on the water side of the channels were also consistent with this finding; i.e., the coolant temperature rise was only $1-2{ }^{\circ} \mathrm{C}$, which is far lower than the $9^{\circ} \mathrm{C}$ based on the design basis heat flux.

The collection of data from this experiment thus indicates that for a configuration in which a corium melt pool is covered by overlying water with an underlying water-cooled plate, the power split will be biased heavily towards the overlying water. From a different point of view, these findings are also consistent with the previous SSWICS test results [3] that indicate that cracks and fissures that form in the debris during quench result in cooling rates that exceed the conduction limitation. Results from the Category 1 tests (see Section 2) indicate that when this quench process occurs in the presence of sparging gas, the cooling rate is increased even further. Heat transfer to the underlying impervious water-cooled plate would have been limited by conduction across a crust to a heat sink temperature that at most would have approached the water saturation temperature. The heat sink temperature established by the overlying water pool would have also corresponded to the water saturation temperature. Thus, given that the heat sink temperatures on the top and bottom of the melt were effectively identical, the data from this test supports the concept that corium quenched by overlying water forms a morphology in which the heat flux to the coolant does indeed exceed the conduction limitation.

Aside from these positive overall findings, several hot spots were noted to form on the coolant plate steel surface during the course of the experiment that significantly exceeded the peak temperature expected on the basis of the engineering design calculations (i.e, $373{ }^{\circ} \mathrm{C}$ ). Moreover, posttest examinations revealed that several spots on the plate surface had been corroded (but not ablated); see Figure 3-11(b). The hot spots seemed to form rapidly, and this resulted in the operators reducing the input power from the initial target value at 145 minutes, and a second reduction was executed at 178 minutes. However, it should be noted that these high temperature measurements were taken in the region of the plate that included the steel ribbing that divided each coolant channel. The temperature at these locations should have been higher in comparison to those in the channel itself. However, the extent of this increase was not estimated as part of this study since this would require a fairly detailed three-dimensional heat transfer analysis in a complicated geometrical configuration. 


\subsection{Bottom Water Injection Tests}

The high-level experiment objective of these tests was to examine the influence of water injection characteristics on the debris cooling rate when the coolant is introduced into the bottom of the melt from isolated nozzles that are cast in the basemat. The first test, denoted SSWICS12 , examined the influence of nozzle water pressure on the debris quenching rate. The second test, denoted SSWICS-13, investigated the effect of concurrent noncondensable (i.e., $\mathrm{N}_{2}$ ) gas injection on the local debris cooling rate. Specifications for the tests are provided in Table 3-4.

Table 3-4. Specifications for SSWICS-12 and -13.

\begin{tabular}{|c|c|c|}
\hline Parameter & SSWICS-12 & SSWICS-13 \\
\hline Corium & $\begin{array}{l}100 \% \text { oxidized PWR with } \\
15 \mathrm{wt} \% \text { siliceous concrete }\end{array}$ & $\begin{array}{l}100 \% \text { oxidized PWR with } \\
15 \mathrm{wt} \% \text { siliceous concrete }\end{array}$ \\
\hline Test section cross-sectional area & $30 \mathrm{~cm} \mathrm{ID}$ & $30 \mathrm{~cm} \mathrm{ID}$ \\
\hline Test Section sidewall construction & Inert $\mathrm{MgO}$ & Inert $\mathrm{MgO}$ \\
\hline Basemat construction & Inert $\mathrm{MgO}$ & $\begin{array}{l}25 \mathrm{~mm} \text { thick LCS concrete over } 38 \\
\mathrm{~mm} \text { thick inert } \mathrm{MgO}\end{array}$ \\
\hline System operating pressure & Atmospheric & Atmospheric \\
\hline Melt formation technique (timescale) & $\begin{array}{l}\text { Chemical reaction }(\sim 30 \\
\text { seconds) }\end{array}$ & Chemical reaction ( $\sim 30$ seconds) \\
\hline Initial melt mass (depth) & $136 \mathrm{~kg}(30 \mathrm{~cm})$ & $136 \mathrm{~kg}(30 \mathrm{~cm})$ \\
\hline Initial melt temperature & $2000^{\circ} \mathrm{C}$ & $2000^{\circ} \mathrm{C}$ \\
\hline Melt heating technique & None & None \\
\hline Basemat nozzles & 4 each $($ same radius $=108 \mathrm{~mm}$ ) & $\begin{array}{l}4 \text { each: } 2 \text { ea water; } 2 \text { ea water/gas } \\
\text { (same radius }=106 \mathrm{~mm} \text { ) }\end{array}$ \\
\hline Nozzle diameter & $32 \mathrm{~mm}$ & $13.2 \mathrm{~mm}$ \\
\hline Nozzle characteristics & Porous concrete & $\begin{array}{l}\text { Single tube for water } \\
\text { Double tube for water/gas }\end{array}$ \\
\hline Concrete thickness above nozzles & $0 \mathrm{~mm}$ & $10 \mathrm{~mm}$ \\
\hline Partition & 4 regions & 2 regions \\
\hline Water supply pressure & $0.2,0.15,0.1,0.05$ bar & 0.2 bar \\
\hline Maximum water flow rate & $\sim 2.4 \mathrm{lpm}$ & $\sim 1.2 \mathrm{lpm}$ \\
\hline Maximum gas flow rate & N.A. & $0.24 \mathrm{lpm}$ ( $20 \%$ of water flow rate) \\
\hline
\end{tabular}

\subsubsection{Apparatus}

The apparatuses for both tests were quite similar. Thus, the facility for SSWICS-12 is summarized first, followed by a description of hardware modifications required to carry out SSWICS-13 that is provided at the end of this section.

\subsubsection{SSWICS-12 Apparatus}

The SSWICS reaction vessel (RV) was designed to hold at least $100 \mathrm{~kg}$ of melt at an initial temperature of $2500^{\circ} \mathrm{C}$. The RV lower plenum consists of a $67.3 \mathrm{~cm}$ long, $45.7 \mathrm{~cm}$ outer diameter carbon steel pipe (Figure 3-12). The pipe was insulated from the melt by a $6.4 \mathrm{~cm}$ thick annulus of cast $\mathrm{MgO}$ that was denoted the "liner". The selected pipe and insulation dimensions 
resulted in a melt diameter of $30 \mathrm{~cm}$ and a surface area of $707 \mathrm{~cm}^{2}$. The melt depth for a typical corium charge of $75 \mathrm{~kg}$ was about $15 \mathrm{~cm}$. The RV lower flange was insulated with a $6.4 \mathrm{~cm}$ thick slab of cast $\mathrm{MgO}$ (the "basemat") that spanned the entire inner diameter of the pipe. The basemat and liner formed the crucible that held the corium.

The RV upper plenum consisted of a second section of pipe with a stainless steel protective liner. Three $10 \mathrm{~cm}$ pipes welded near the top of the vessel provided 1) a vent line for the initial surge of hot noncondensable gases generated by the thermite reaction, 2) a pressure relief line with a rupture disk $(7.7 \mathrm{bar}$ at $100^{\circ} \mathrm{C}$ ), and 3) an instrument flange for the absolute pressure transmitter that measured the reaction vessel pressure. A baffle was mounted below the upper flange to prevent water droplets from being carried up towards the condenser, which would have adversely affected the heat flux measurement. A fourth $10 \mathrm{~cm}$ pipe welded to the top flange provided an outlet for steam from the quenching melt to four cooling coils. The watercooled coils condensed the steam, which was collected within a $200 \mathrm{~cm}$ high, $20 \mathrm{~cm}$ diameter condensate tank (CT). Figure 3-13 provides an overview of the SSWICS test facility.

For SSWICS-12, the corium was divided into quadrants by $10 \mathrm{~mm}$ thick tungsten plates. The partitions

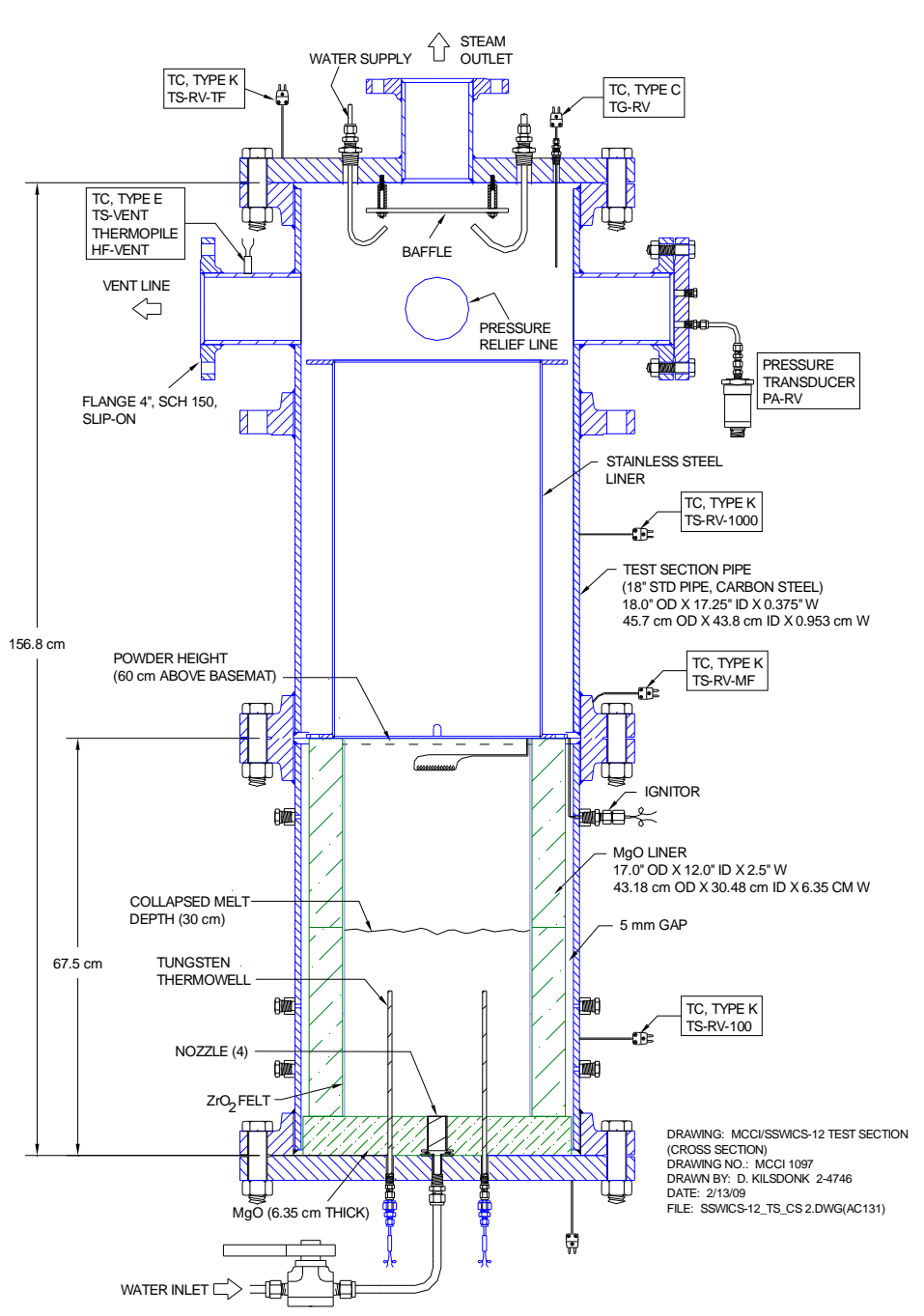

Figure 3-12. Side View of Reaction Vessel. had machined slots so that one fit over the other in an interlocking cruciform. They were supported by $20 \mathrm{~mm}$ deep grooves in the liner to limit shifting under lateral loads. The partition consisted of two stacked sections, each with a height of $20 \mathrm{~cm}$, creating a $40 \mathrm{~cm}$ high wall within the melt. Figure 3-14 provides a detailed views and a photograph of the lower plenum and basemat including the tungsten partitions.

Four 36-liter tanks provided independent reservoirs to supply the nozzles with water. The nozzles were gravity fed and so the driving pressure for injection was set by the elevation difference between the nozzle and the tank water level. A check valve in each line prevented 
OECD/MCCI-2010-TR06, Rev. 1

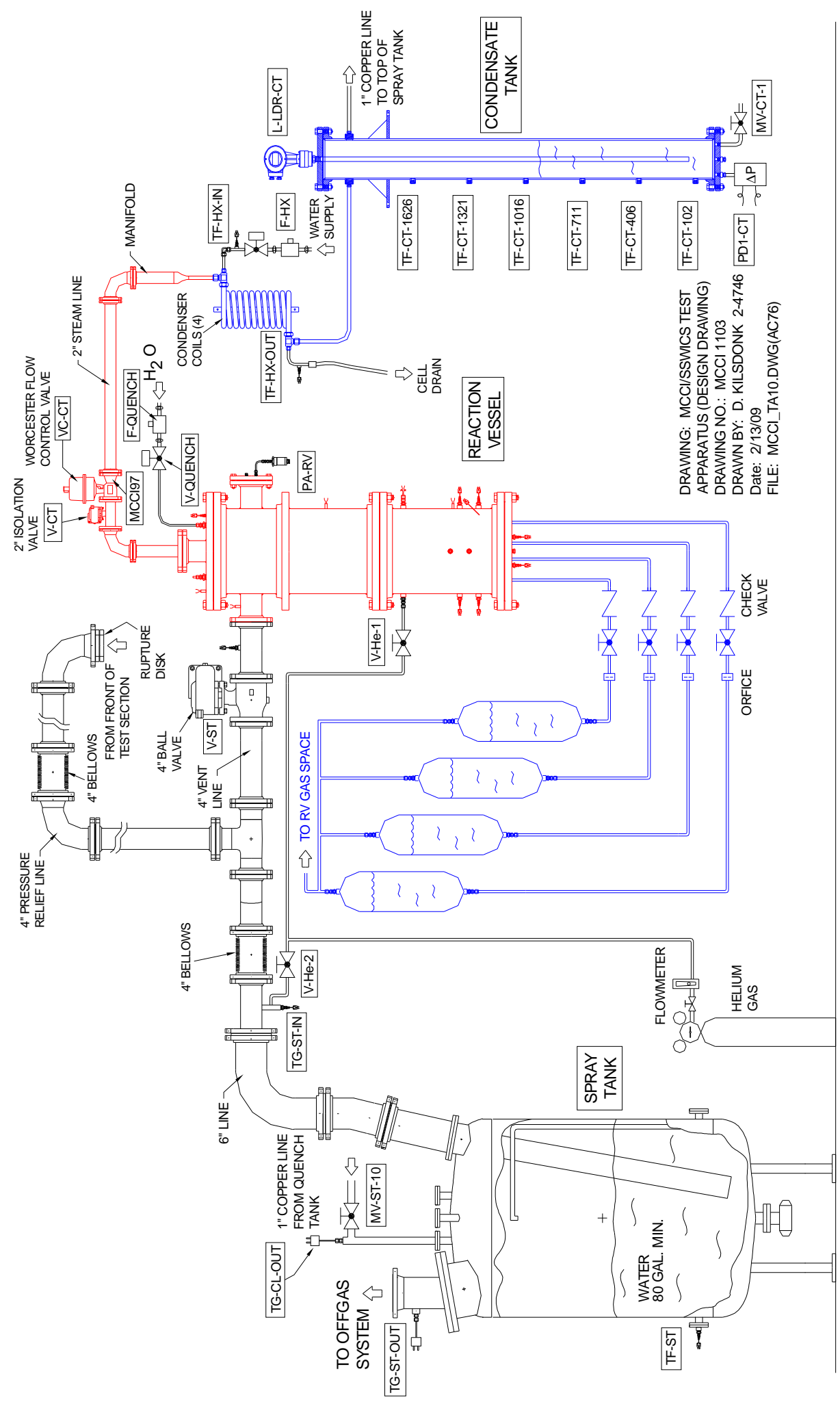

: 

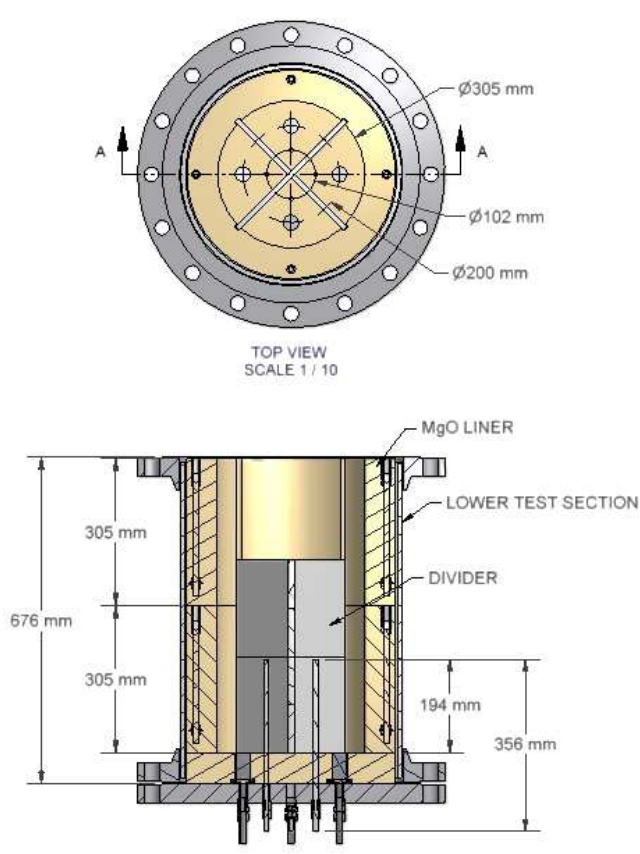

(a)

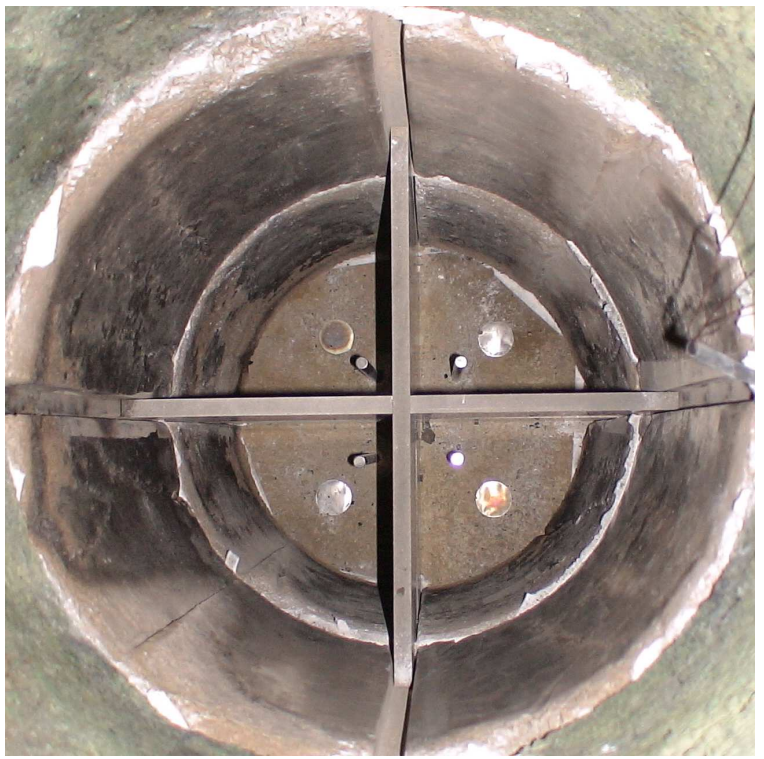

(b)

Figure 3-14. (a) Design Details and (b) Photograph of SSWICS-12 Lower Plenum.

back flow up into the tank and isolation valves were opened when the RV preheat phase of the test began. For SSWICS-12, the tanks were positioned at different levels to generate the desired range of driving pressures. A pressure equalization line linked the RV gas space to the gas spaces of all four tanks, ensuring that the head was set only by the nozzle - tank elevation difference. This was necessary because the RV pressure fluctuated following initial water injection. The tanks were positioned to provide initial net driving heads of $0.05,0.1,0.15$, and 0.2 bar. The driving head accounted for the effect of the melt hydrostatic pressure on the elevation evaluation [5]. The tanks contained sufficient water inventory to completely quench the melt to saturation so that makeup water would not be needed during the test.

The design for the concrete nozzles
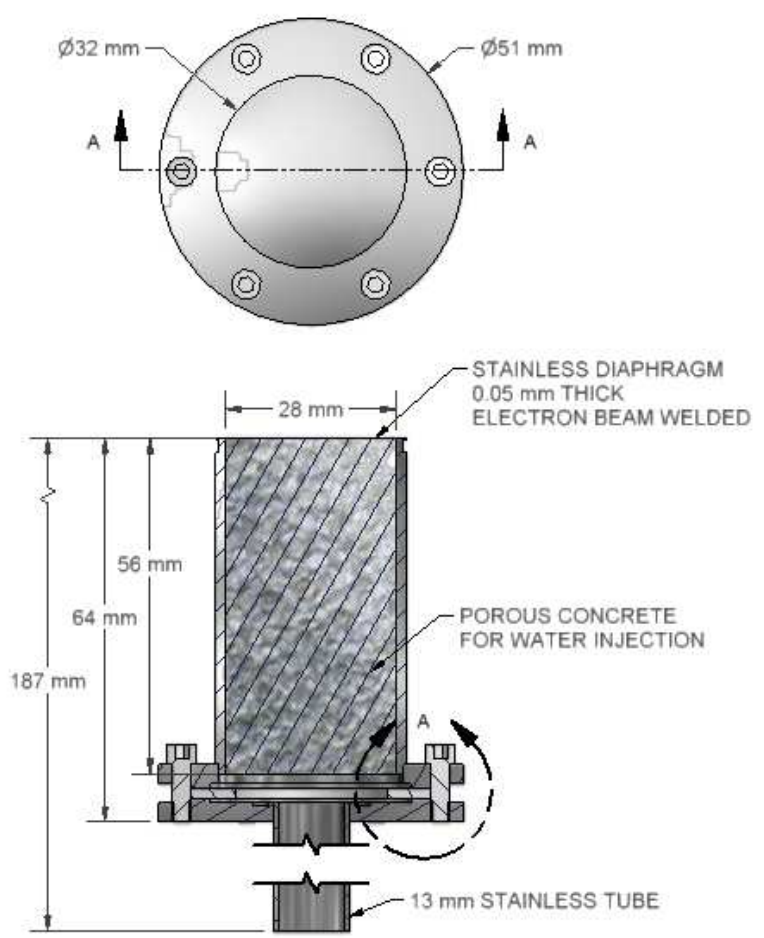

Figure 3-15. SSWICS-12 Nozzle Design.

that were used in SSWICS-12 is shown in Figure 3-15. Four nozzles were cast within the basemat and positioned so that they were roughly equidistant from the liner and neighboring partitions. The top of each nozzle was flush with the basemat surface and each was filled with a 
specialty design porous concrete [5] to provide a path for water flow up into the melt while preventing melt flow downward into the nozzle. A leak-tight $0.05 \mathrm{~mm}$-thick stainless steel diaphragm was welded over the top of each nozzle to serve as a temporary seal to prevent water flow from the feed line up into the thermite during the vessel preheat phase of the experiment. Melt contact following the thermite burn rapidly ablated through these thin diaphragms, thereby initiating the water injection phase of the experiment.

As part of pretest operations, orifices (i.e., needle valves) on each of the supply lines from the header tanks to the nozzles were adjusted so that the peak flowrate to each nozzle was limited to $0.01 \mathrm{~kg} / \mathrm{sec}$. This action effectively capped the peak corium quenching rate at a level of $\sim 1.2$ $\mathrm{MW} / \mathrm{m}^{2}$ at saturated coolant conditions if all four nozzles opened completely. This step was taken since the results of previous COMET tests [22] on the same test stand indicated that melt dispersal within the test section could be significant if the steaming rate was not limited.

Sufficient instrumentation was provided to determine the boundary conditions and cooling behavior for each of the four melt quadrants used in the test. The flow rate and driving pressure of each nozzle was measured along with melt temperatures. The condensate collection and measurement system could not provide the cooling rate of any particular partition. Rather, the gross melt cooling rate was measured. Only indirect indications of individual partition cooling rates, obtained through measurements of melt temperature and water flow rate into each quadrant, were available for these tests. In terms of melt temperature measurements, each partition was allotted a 5-junction C-type thermocouple in a tungsten thermowell. The thermocouples were spaced every $51 \mathrm{~mm}$ so that the uppermost thermocouple was $190 \mathrm{~mm}$ above the basemat surface. The tungsten thermowells were $9.5 \mathrm{~mm}$ diameter, which is the same size used in the WCB-1 (see Section 3.1), but larger than that used in previous SSWICS tests (6 $\mathrm{mm}$ ). Though thermowell size should be minimized to limit fin cooling effects, the thermowells for this test were too long to fabricate in a diameter less than $9.5 \mathrm{~mm}$.

Aside from the test section, the balance of the facility was instrumented to provide the necessary information to assess the nozzle injection flowrates as well as the overall steaming rate from the test section. The instrument locations are shown in Figure 3-13. Water levels in the header tanks were monitored with differential pressure transducers; the time-derivative of this data was used to provide the estimate of water flow rate to the nozzles. Temperature rise across the condenser was measured with Type $\mathrm{K}$ thermocouples, while water flow rate through the condenser was measured with a paddlewheel flowmeter. The water level in the CT was monitored with a time domain reflectometer with a redundant measurement provided by a differential pressure transducer. Measurement uncertainties for the various instruments utilized in the tests are provided in [5].

The composition of the corium oxide phase for SSWICS-12 and -13 was the same as that used in SSWICS-6 (i.e., 60.3/24.7/15.0 wt \% $\mathrm{UO}_{2} / \mathrm{ZrO}_{2} /$ siliceous concrete [3]). However, the thermite was reformulated to react at a higher temperature to minimize crust formation on the basemat that might impair initial water flow through the nozzles. The initial melt temperature for SSWICS-6 was $\sim 1950^{\circ} \mathrm{C}$ while the target initial temperature for these tests was $\sim 2100^{\circ} \mathrm{C}$. Reformulation of the thermite to produce the higher reaction temperature resulted in a slightly 
higher $\mathrm{Cr}$ metal byproduct content of $7.6 \mathrm{wt} \%$ in the melt, which can be compared to the level of $6.4 \mathrm{wt} \%$ for SSWICS-6. The initial thermite powder loading for both SSWICS tests is shown in Table 3-5, while the pre-and post-reaction compositions are provided in Table 3-6.

\subsubsection{SSWICS-13 Apparatus}

The overall facility design for SSWICS-13 was the same as that used for SSWICS-12, but with the following exceptions: i) the apparatus was modified such that the melt was partitioned into two sectors instead of four, ii) the injector design was changed from porous concrete to a tubular steel construction, and iii) the supply system to the injectors was modified to provide a two-phase gas-water mixture to selected injectors. These changes required some instrumentation modifications, principally to characterize the two-phase flow to the nozzles.

The results of SSWICS-12 indicated that the 10 mm thick tungsten plates that were used to partition the melt survived the test intact, and so the same design (but new material) was used for SSWICS-13. The test section was divided into two by a $60 \mathrm{~cm}$-high wall made up of three $20 \mathrm{~cm}$ high, $10 \mathrm{~mm}$ thick plates. Figure 3-16 provides a detailed view and a photograph of the lower plenum and basemat including the tungsten partition. The partition was supported by grooves that were cast in the $\mathrm{MgO}$ liner to prevent shifting under lateral loads.

Another modification for SSWICS-13 was the fact that the upper $25 \mathrm{~mm}$ of the basemat was fabricated from limestone/common sand concrete. As
Table 3-5. Thermite Charge for SSWICS Tests.

\begin{tabular}{|c|c|}
\hline Constituent & Mass (kg) \\
\hline $\mathrm{U}_{3} \mathrm{O}_{8}$ & 78.61 \\
$\mathrm{CrO}_{3}$ & 19.90 \\
$\mathrm{CaO}$ & 2.96 \\
$\mathrm{Zr}$ & 22.98 \\
$\mathrm{Mg}$ & 0.10 \\
$\mathrm{Si}$ & 3.51 \\
$\mathrm{SiO}_{2}$ & 7.49 \\
$\mathrm{Al}$ & 0.45 \\
\hline Total & 136.0 \\
\hline
\end{tabular}

Table 3-6. SSWICS Thermite Reaction Compositions.

\begin{tabular}{|c|c|c|}
\hline \multirow{2}{*}{ Constituent } & \multicolumn{2}{|c|}{$\mathrm{Wt} \%$} \\
\cline { 2 - 3 } & Reactant & Product \\
\hline $\mathrm{U}_{3} \mathrm{O}_{8}$ & 57.80 & - \\
\hline $\mathrm{UO}_{2}$ & - & 55.61 \\
\hline $\mathrm{Zr}$ & 16.90 & - \\
\hline $\mathrm{ZrO}_{2}$ & - & 22.84 \\
\hline $\mathrm{Si}$ & 2.58 & - \\
\hline $\mathrm{SiO}$ & 5.51 & 11.03 \\
\hline $\mathrm{Mg}$ & 0.07 & - \\
\hline $\mathrm{MgO}$ & - & 0.11 \\
\hline $\mathrm{Al}$ & 0.33 & - \\
\hline $\mathrm{Al} \mathrm{O}_{3}$ & - & 0.63 \\
\hline $\mathrm{CaO}$ & 2.18 & 2.18 \\
\hline $\mathrm{CrO}$ & 14.63 & - \\
\hline $\mathrm{Cr}$ & - & 7.60 \\
\hline
\end{tabular}
shown in Figure 3-17, the injection nozzles were positioned $10 \mathrm{~mm}$ beneath the concrete surface. The purpose of the concrete was to protect the nozzles from coming into immediate contact with melt following the thermite burn. As for SSWICS-12, each nozzle was fed by a single supply tank so that a differential pressure transmitter could be used to measure the flow rate to individual nozzles. One change for SSWICS-13 was that an isolation valve was added on each nozzle supply line that could be opened remotely from the control room once the melt had contacted the basemat. This feature was added since the SSWICS-13 injection tubes were not sealed at the top as they were (using a thin steel diaphragm) in SSWICS-12. Thus premature opening of these lines would have led to water seepage into the thermite, and this would have severely degraded the thermite reaction. 
Details of the nozzle design for SSWICS-13 are provided in Figure 3-18. Water left the nozzle and entered the melt through four $1 \mathrm{~mm}$-diameter holes. The holes were positioned 4.5 $\mathrm{mm}$ from the nozzle center. The nozzle itself had a diameter of $12 \mathrm{~mm}$ and all components were made of stainless steel. The two nozzles injecting nitrogen had an additional 1-mm hole at the center. The nitrogen and water were expected to mix together as they entered the melt. The driving pressure for all four units was set to 0.2 bar on both the water and gas sides for this test.

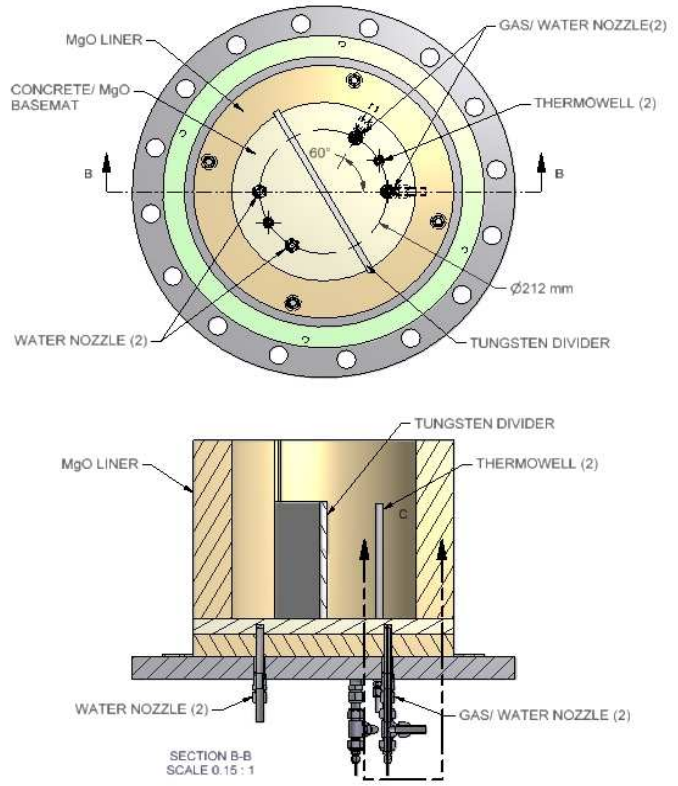

(a)

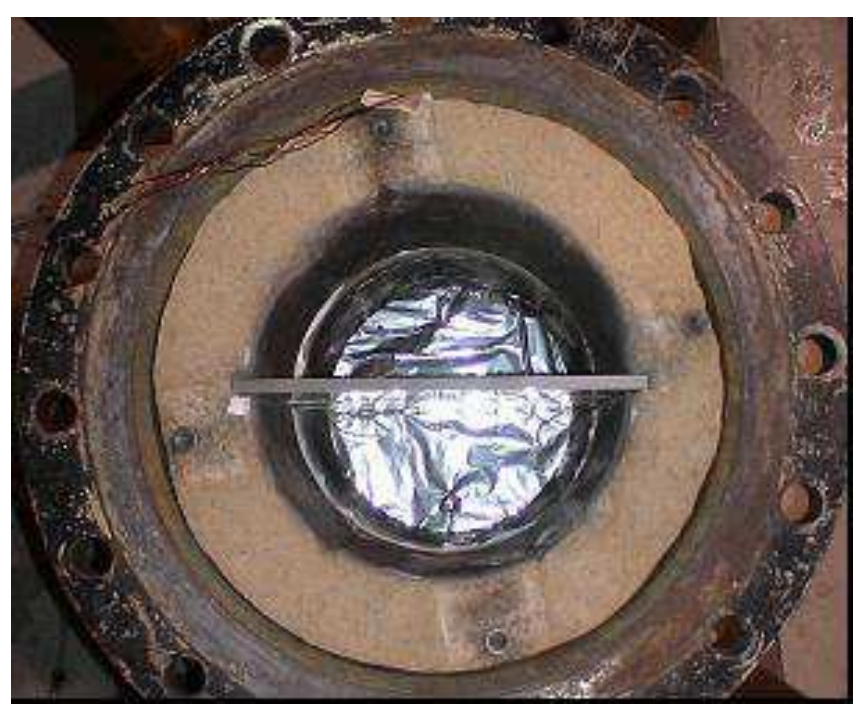

(b)

Figure 3-16. (a) Design Details and (b) Photograph of SSWICS-13 Lower Plenum.

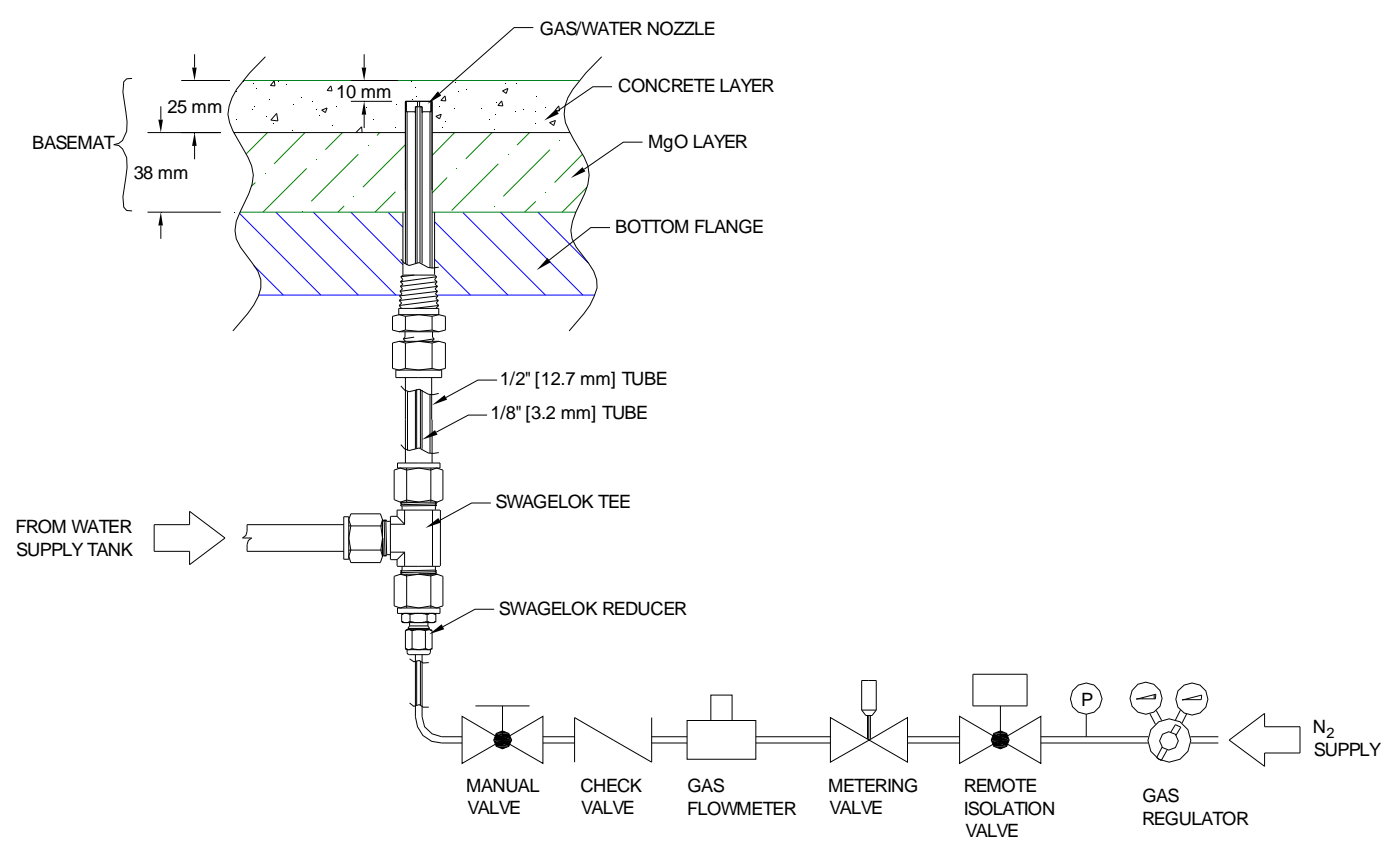

Figure 3-17. Details of Nozzle Design with Gas Injection. 
As discussed earlier, the water flowrate to each nozzle for SSWICS-12 was limited to $0.01 \mathrm{~kg} / \mathrm{s}$ in an attempt to minimize melt dispersal from the expanding steam in the early portion of the test. However, the results indicated that even with this restriction, melt was ejected from the lower plenum leaving a coating over most of the inside of the RV that caused a peak plenum temperature of $1700^{\circ} \mathrm{C}$. To further limit melt dispersal, metering valves on each supply line were adjusted to allow a peak water flowrate of $0.005 \mathrm{~kg} / \mathrm{s}$ at the initial fill level, which was half of that for SSWICS-12. This step limited the maximum achievable debris cooling rate by bottom water injection to a level $\sim 600 \mathrm{~kW} / \mathrm{m}^{2}$ at saturated coolant conditions.

The gas flowrate to the two nozzles that injected a two-phase mixture was specified to be $20 \%$ of the initial volumetric flow rate of the water. The gas system (Figure 3-17) was configured with an approach similar to that used for the water. The initial flow rate to each nozzle was defined $(0.06 \mathrm{lpm})$, as was the maximum driving pressure at the nozzle exit $(0.2$ bar to match the initial net driving head set for the water). The head associated with the corium was 0.15 bar and so the gas source pressure was set at 0.35 bar to provide the net 0.2 bar driving pressure. A metering valve was used to adjust the line losses to achieve the target flow rate at the line pressure of 0.35 bar [5].

As for SSWICS-12, sufficient instrumentation was provided to determine the boundary conditions and cooling behavior of the two partitions. The water flow rate and driving pressure to each nozzle was measured. The nitrogen gas flow to each of the two nozzles was also measured. Each melt partition was allotted a 5-junction C-type thermocouple assembly in a tungsten thermowell with the junction elevations the same as that used in SSWICS-12.

\subsubsection{Results and Discussion}

Operationally, both SSWICS-12 and SSWICS-13 functioned as designed. SSWICS-12 featured an inert $\mathrm{MgO}$ basemat with four porous concrete injection nozzles mounted flush with the $\mathrm{MgO}$ surface. Water driving pressure was the key parameter investigated in this test, with heads of $0.05,0.1,0.15$ and 0.2 bar applied to the four nozzles. Each nozzle was separated from the other by a tungsten cruciform that effectively divided the test section into four quadrants. In SSWICS-13, a specialty tube design was employed. The design was further refined by injecting water through two tubes in one sector of the melt, while a nitrogen gas-water mixture $(20 \%$ void fraction) was injected through two tubes in the other. Both water and gas were injected under a constant net driving pressure of 0.2 bar. The additional step was taken to cover the upper surface 
of the injection tubes with a $10 \mathrm{~mm}$ thick layer of concrete to prevent direct contact with the melt following the thermite burn.

Principal results from the two tests were the melt pool temperature response in each melt sector, average debris-water heat fluxes, and the nozzle coolant and gas (for SSWICS-13) injection flow rates. Representative melt temperature data for SSWICS-12 and -13 are provided in Figures 3-19 and 3-20, respectively; junction elevations are shown in these figures as $\mathrm{mm}$ above the initial substrate surface. In addition, corium-coolant heat fluxes are shown collectively in Figure 3-21. Finally, top views of the test apparatuses that illustrate the posttest debris morphology are provided in Figure 3-22.

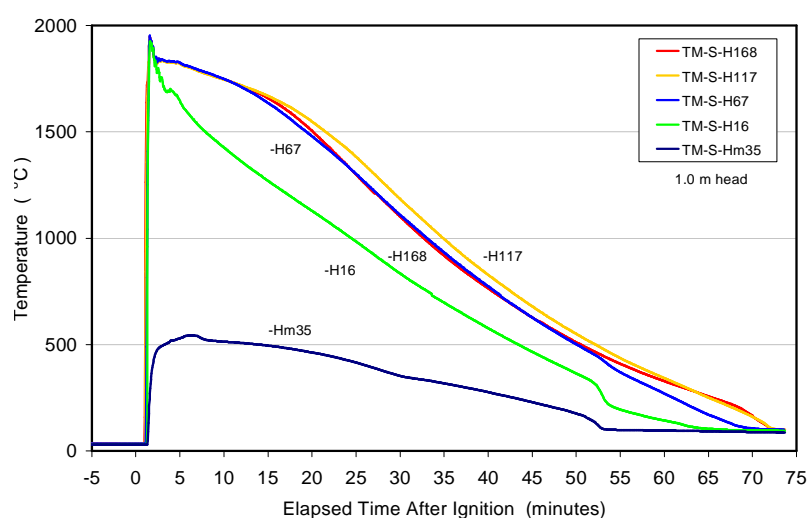

(a)

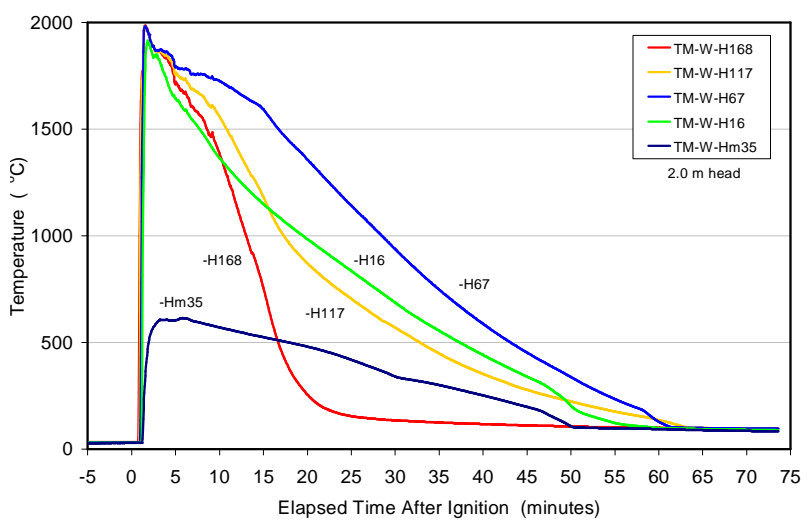

(b)

Figure 3-19. SSWICS-12 Melt Temperatures in Quadrants with (a) 0.1 and (b) 0.2 Bar Static Water Head.

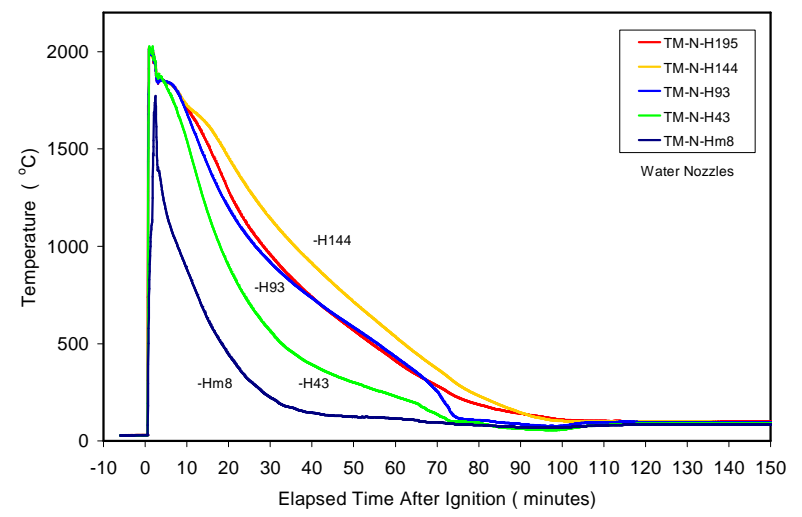

(a)

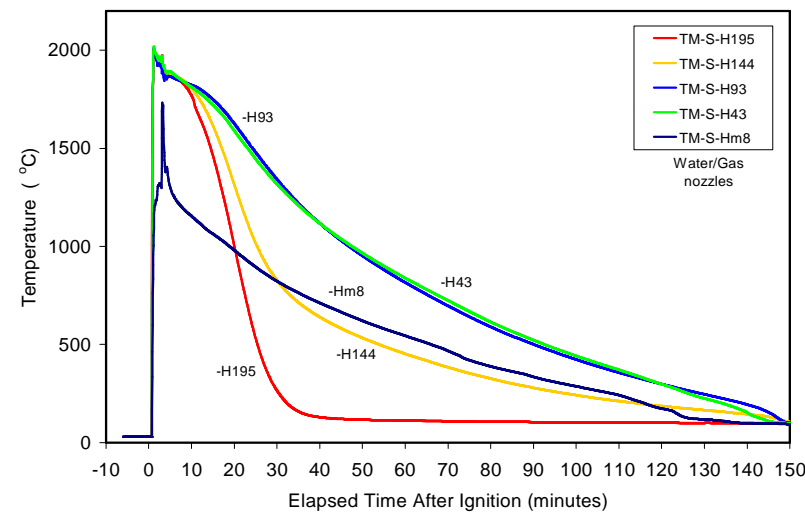

(b)

Figure 3-20. SSWICS-13 Melt Temperatures in Partitions with (a) Water Only and (b) Gas-Water Nozzles.

In SSWICS-12, the nozzles were throttled to provide a peak debris cooling rate of 1.2 $\mathrm{MW} / \mathrm{m}^{2}$ referenced to saturated coolant conditions. All four nozzles successfully opened upon contact with the melt, and debris quenching was achieved over a timescale of nominally 65 minutes (Figure 3-19). The average debris cooling rate over this time interval was $640 \mathrm{~kW} / \mathrm{m}^{2}$, 
which is $\sim 50 \%$ of the peak limit set by the nozzle orificing (Figure 3-21). There was no discernable effect of water head on the rate of cooling. At the throttled flowrate for this test, melt dispersal was quite large, leading to a highly porous posttest debris configuration as well as melt coating of the interior of the test section (Figure 3-22). As a result, water was added from the top in an effort to cool the upper internals of the RV. This somewhat complicated the data analysis, but it did not change the fact that the melt was quenched rapidly and effectively at a rate that exceeded by considerable margin the cooling rates achieved in the other SSWICS tests in which the melts were cooled by top flooding [3].

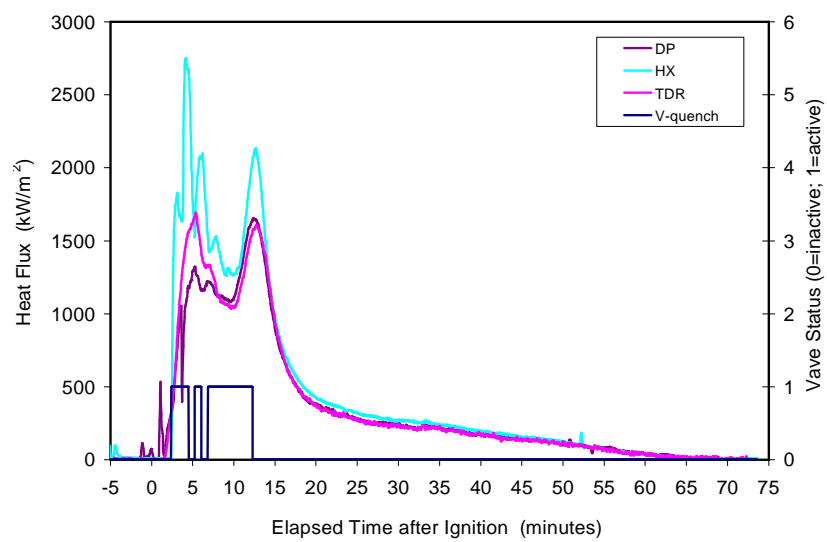

(a)

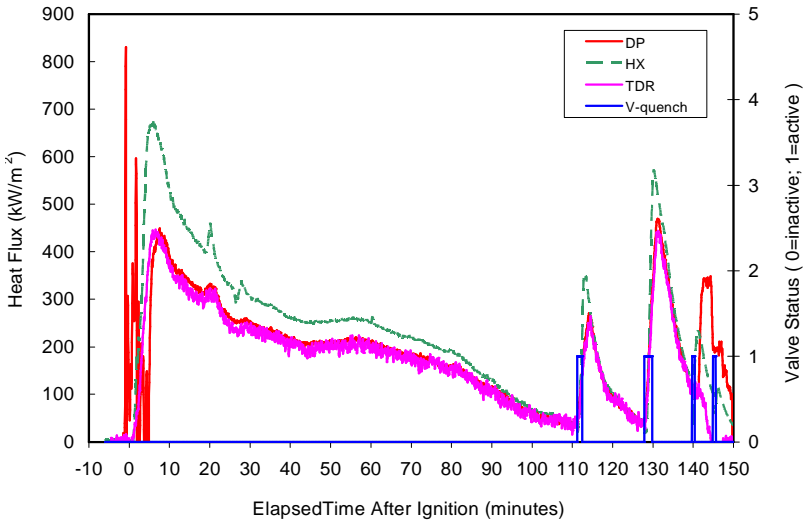

(b)

Figure 3-21. Debris-Water Heat Fluxes for (a) SSWICS-12 and (b) SSWICS-13.

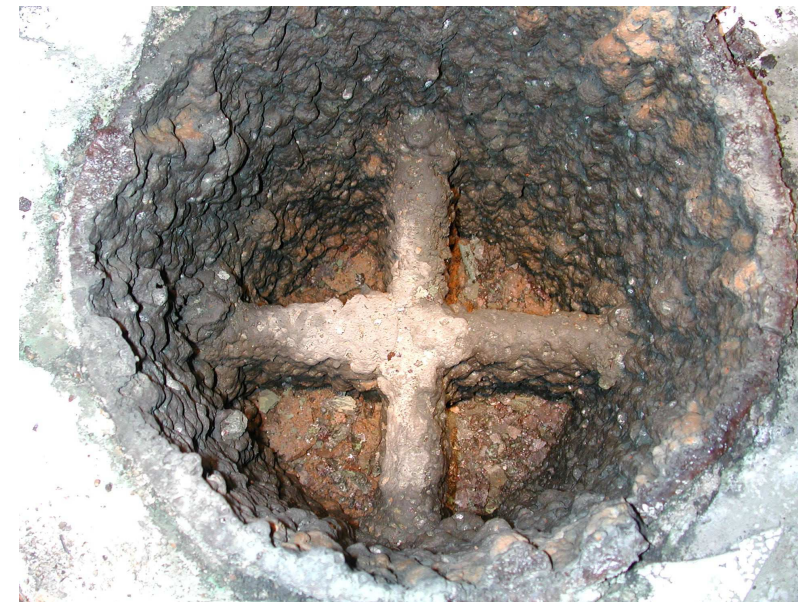

(a)

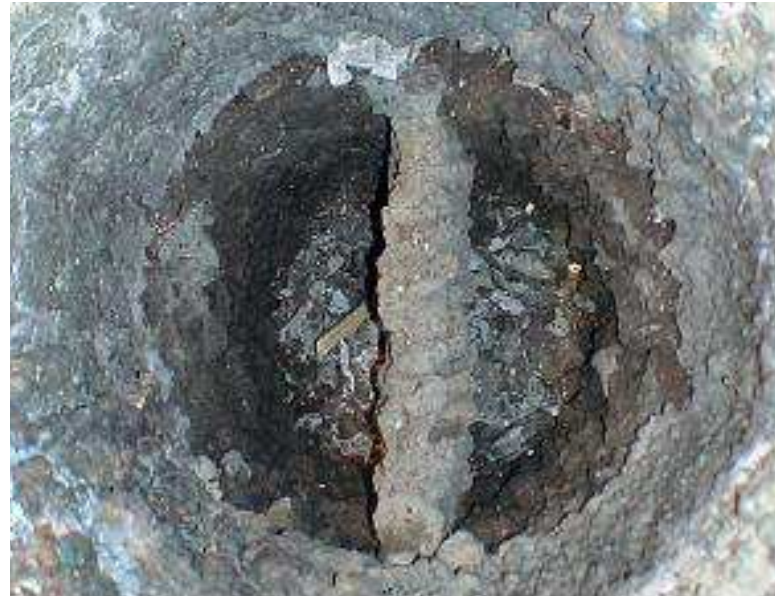

(b)

Figure 3-22. Posttest Debris Distributions for (a) SSWICS-12 and (b) SSWICS-13.

For SSWICS-13, the nozzles were further throttled to provide a peak debris cooling rate of $\sim 600 \mathrm{~kW} / \mathrm{m}^{2}$ referenced to saturation conditions. Following the thermite burn, the melt was able to ablate through the $10 \mathrm{~mm}$ thick concrete layer overlying the nozzles and flow was initially established in all four nozzles. However, shortly afterwards one of the nozzles fed by the gas/water mixture plugged so that additional water injection through this nozzle did not occur. 
For the three nozzles that did open, the co-injection of gas through the third nozzle was found to have no discernable influence on the overall average water injection flowrate when compared to the water-only nozzles. Once water flow was established, the injection flowrate appeared to be relatively constant at a flowrate that was $\sim 90 \%$ of the throttled value. Based on the time to quench (Figure 3-20), it is estimated that the debris cooling rate in the sector where both water nozzles opened was on average $450 \mathrm{~kW} / \mathrm{m}^{2}$ (Figure $3-21$ ), which is $\sim 75 \%$ of that estimated based on the assumption of saturated coolant conditions in the melt pool. In this test, melt dispersal still occurred due to steam sparging through the melt, but not nearly to the extent as that seen in SSWICS-12 (Figure 3-22). Melt quenching in SSWICS-13 also occurred at a rate that significantly exceeded that observed in the previous SSWICS top flooding experiments [3].

In summary, the results of both tests confirmed that melt cooling by bottom water injection is an effective method for quenching the core melt. The results of SSWICS-12 showed that water head on the nozzles had no discernable effect on the debris quenching rate in the range investigated (viz. 0.05-0.2 bar). All four porous concrete nozzles that were used in this test opened upon melt contact and provided a pathway for water to enter the melt. For SSWICS-13, the concurrent gas injection was found to have a negligible impact on the average debris quenching rate relative to that measured for pure water. In this test, three of the four nozzles opened upon melt contact, while the fourth opened briefly and then plugged for the balance of the test. The nozzle that plugged was intended to inject the water-gas mixture. 


\subsection{CATEGORY 3 TEST RESULTS}

Two additional large scale CCI experiments were completed [6] in this test category that focused on broadening the database that was developed as part of the MCCI-1 program [1]. The overall objective of the test series was to provide information in the following areas: i) lateral vs. axial power split during dry core-concrete interaction, ii) integral debris coolability data following late phase flooding, and iii) data regarding the nature and extent of the cooling transient following breach of the crust formed at the melt-water interface. Specifications for all tests are provided in Table 4-1. Tests CCI-1 through CCI-3 in MCCI-1 [1] principally addressed the effect of concrete type on 2-D cavity erosion behavior and late phase debris coolability. Test CCI-4 expanded the parameter base addressed in the series by examining the influence of core melt composition on cavity erosion behavior and coolability. The specific objectives were to: i) increase the metal content of the melt to the highest practical level to more accurately mock up a BWR core melt composition, and ii) modify the apparatus design to increase the duration of the dry core-concrete interaction phase. Conversely, Test CCI-5 focused on examining the influence of melt pool aspect ratio on the radial/axial power split under dry cavity conditions. The detailed objective was to increase the test section aspect ratio (i.e., test section width/melt depth) to the greatest extent possible to more accurately mock up prototypic conditions.

\subsection{Apparatus}

Principal elements of the facility consisted of a test apparatus, a power supply for Direct Electrical Heating (DEH) of the corium, a water supply system, two steam condensation (quench) tanks, an off gas system to filter and vent the off-gases, and a data acquisition system. A schematic illustration of the facility is provided in Figure 4-1.

The overall facility design was effectively the same for both tests. However, the apparatus for each experiment was modified in order to achieve the specific test objectives. Thus, a single description is provided for common facility elements, while design variations are explicitly addressed for each test.

\subsubsection{CCI-4 Test Apparatus}

The principal components of the apparatus, shown in Figure 4-1, consisted of a bottom support plate, three sidewall sections, and an upper enclosure lid. The overall structure was $3.4 \mathrm{~m}$ tall. The two upper sidewall sections had a square internal cross sectional area of $50 \mathrm{~cm} \mathrm{x} 50 \mathrm{~cm}$. The concrete test section for containment of the core melt was located at the bottom of the apparatus. Side and top views of this component are shown in Figures 4-2 and 4-3, respectively. The cross-sectional area of the cavity was $50 \mathrm{~cm} \mathrm{x} 40 \mathrm{~cm}$. The distance between the tungsten electrodes was the same as that of previous tests [1] $(50 \mathrm{~cm})$, while the distance between the concrete walls was reduced by $10 \mathrm{~cm}$ to a width of $40 \mathrm{~cm}$. This increase in sidewall thickness, combined with a $5 \mathrm{~cm}$ extension in allowable ablation, provided a total of ten extra centimeters of concrete for lateral ablation per sidewall. The basemat thickness was increased to accommodate up to $42.5 \mathrm{~cm}$ of axial ablation. The design maintained a concrete thickness of $15 \mathrm{~cm}$ in both the walls and basemat for final melt containment. 
OECD/MCCI-2010-TR06, Rev. 1

Table 4-1. Specifications for CCI Tests.

\begin{tabular}{|c|c|c|c|c|c|}
\hline \multirow[t]{2}{*}{ Parameter } & \multicolumn{5}{|c|}{ Specifications for Test: } \\
\hline & CCI-1 & CCI-2 & CCI-3 & CCI-4 & CCI-5 \\
\hline Corium & $\begin{array}{c}100 \% \text { oxidized PWR + } \\
8 \mathrm{wt} \% \text { SIL }\end{array}$ & $\begin{array}{c}100 \% \text { oxidized PWR + } \\
8 \mathrm{wt} \% \text { LCS }\end{array}$ & $\begin{array}{c}100 \% \text { oxidized PWR + } \\
15 \mathrm{wt} \% \text { SIL }\end{array}$ & $\begin{array}{c}78 \% \text { oxidized BWR } \\
\text { with } 7.7 \text { wt } \% \text { SS and } 10 \\
\text { wt } \% \mathrm{LCS}^{\mathrm{b}}\end{array}$ & $\begin{array}{c}100 \% \text { oxidized PWR + } \\
15 \mathrm{wt} \% \text { SIL }\end{array}$ \\
\hline Concrete type $^{\mathrm{a}}$ & SIL (U.S.-type) & LCS & SIL (EU-type) & LCS & SIL (EU-type) \\
\hline Basemat cross-section & $50 \mathrm{~cm} \times 50 \mathrm{~cm}$ & $50 \mathrm{~cm} \times 50 \mathrm{~cm}$ & $50 \mathrm{~cm} \times 50 \mathrm{~cm}$ & $50 \mathrm{~cm} \mathrm{x} 40 \mathrm{~cm}$ & $50 \mathrm{~cm} \times 79 \mathrm{~cm}$ \\
\hline Initial melt mass (depth) & $400 \mathrm{~kg}(25 \mathrm{~cm})$ & $400 \mathrm{~kg}(25 \mathrm{~cm})$ & $375 \mathrm{~kg}(25 \mathrm{~cm})$ & $300 \mathrm{~kg}(25 \mathrm{~cm})$ & $590 \mathrm{~kg}(25 \mathrm{~cm})$ \\
\hline $\begin{array}{l}\text { Test section sidewall } \\
\text { construction }\end{array}$ & $\begin{array}{l}\text { Electrode walls: Inert } \\
\text { Nonelectrode walls: } \\
\text { concrete }\end{array}$ & $\begin{array}{l}\text { Electrode walls: Inert } \\
\text { Nonelectrode walls: } \\
\text { concrete }\end{array}$ & $\begin{array}{l}\text { Electrode walls: Inert } \\
\text { Nonelectrode walls: } \\
\text { concrete }\end{array}$ & $\begin{array}{l}\text { Electrode walls: Inert } \\
\text { Nonelectrode walls: } \\
\text { concrete }\end{array}$ & $\begin{array}{l}\text { Electrode walls: Inert } \\
\text { Nonelectrode wall No. 1: } \\
\text { concrete } \\
\text { Nonelectrode wall No. 2: } \\
\text { Inert }\end{array}$ \\
\hline Lateral/Axial ablation limit & $35 / 35 \mathrm{~cm}$ & $35 / 35 \mathrm{~cm}$ & $35 / 35 \mathrm{~cm}$ & $45 / 42.5 \mathrm{~cm}$ & $40 / 42.5 \mathrm{~cm}$ \\
\hline Initial melt temperature & $1950^{\circ} \mathrm{C}$ & $1880^{\circ} \mathrm{C}$ & $1950^{\circ} \mathrm{C}$ & $1850^{\circ} \mathrm{C}$ & $1950^{\circ} \mathrm{C}$ \\
\hline System pressure & \multicolumn{5}{|c|}{ Atmospheric } \\
\hline Melt formation tech. & \multicolumn{5}{|c|}{ Chem. reaction $(\sim 30 \mathrm{~s})$} \\
\hline Melt heating technique & \multicolumn{5}{|c|}{ DEH } \\
\hline $\begin{array}{l}\text { Power supply operation } \\
\text { prior to water addition }\end{array}$ & Constant @150kW & Constant@120kW & Constant@120kW & Constant@95 kW & Constant@145kW \\
\hline Criteria for water addition & $\begin{array}{l}\text { 1) } 5.5 \text { hours of operation } \\
\text { 2) ablation } \rightarrow 5 \mathrm{~cm} \text { of } \\
\text { limit }\end{array}$ & $\begin{array}{l}\text { 1) } 5.5 \text { hours of operation } \\
\text { 2) ablation } \rightarrow 5 \mathrm{~cm} \text { of } \\
\text { limit }\end{array}$ & $\begin{array}{l}\text { 1) } 5.5 \text { hours of operation } \\
\text { 2) ablation } \rightarrow 5 \mathrm{~cm} \text { of } \\
\text { limit }\end{array}$ & $\begin{array}{l}\text { 1) } 7.0 \text { hours of } \\
\text { operation } 2 \text { ) ablation } \rightarrow \\
5 \mathrm{~cm} \text { of limit }\end{array}$ & $\begin{array}{l}\text { 1) } 6.0 \text { hours of operation } \\
\text { 2) ablation } \rightarrow 5 \mathrm{~cm} \text { of } \\
\text { limit }\end{array}$ \\
\hline Inlet water flowrate/temp. & \multicolumn{5}{|c|}{$2 \mathrm{lps} / 20^{\circ} \mathrm{C}$} \\
\hline Water depth over melt & \multicolumn{5}{|c|}{$50 \pm 5 \mathrm{~cm}$} \\
\hline $\begin{array}{l}\text { Power supply operation } \\
\text { after water addition }\end{array}$ & \multicolumn{5}{|c|}{ Constant voltage } \\
\hline Test termination criteria & \multicolumn{5}{|c|}{ 1) $\mathrm{T}_{\text {melt }}<\mathrm{T}_{\mathrm{con}, \mathrm{sol}}, 2$ ) ablation arrested, or 3) ablation $\rightarrow$ limit } \\
\hline Operational Summary & $\begin{array}{l}\text { Successful: pronounced } \\
\text { lateral erosion in one } \\
\text { sidewall }\end{array}$ & $\begin{array}{l}\text { Successful: symmetrical } \\
\text { cavity erosion }\end{array}$ & $\begin{array}{l}\text { Successful: pronounced } \\
\text { lateral erosion }\end{array}$ & $\begin{array}{c}\text { Successful: symmetrical } \\
\text { cavity erosion }\end{array}$ & $\begin{array}{l}\text { Successful: pronounced } \\
\text { lateral erosion; cavity } \\
\text { not flooded due to offgas } \\
\text { system plugging }\end{array}$ \\
\hline
\end{tabular}

${ }^{\mathrm{a} S I L}$ denotes siliceous concrete, LCS denotes Limestone/Common Sand concrete.

${ }^{\mathrm{b}}$ After erosion of concrete/metal inserts and at start of basemat ablation 
OECD/MCCI-2010-TR06, Rev. 1

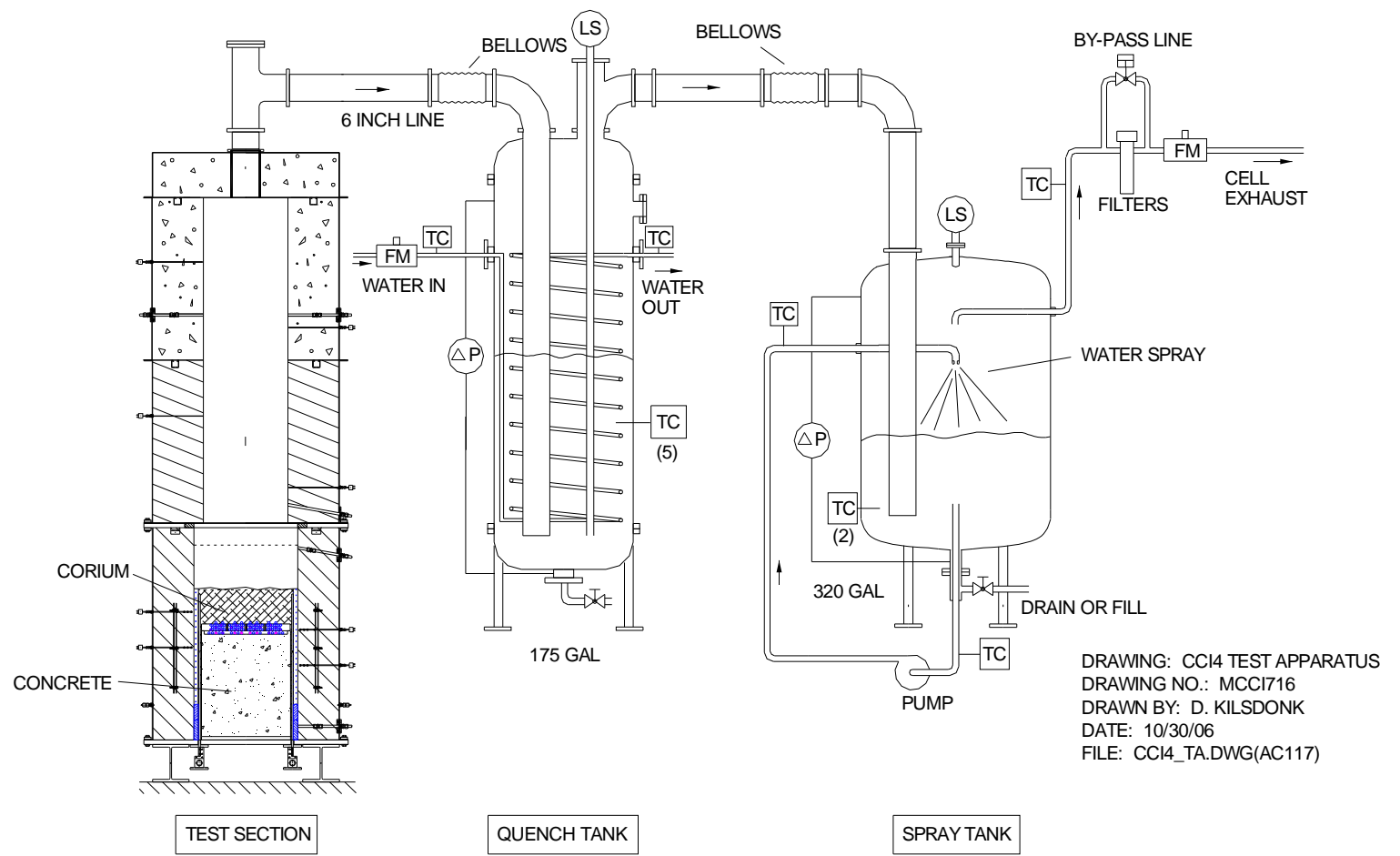

Figure 4-1. Key Elements of the CCI Test Apparatus.

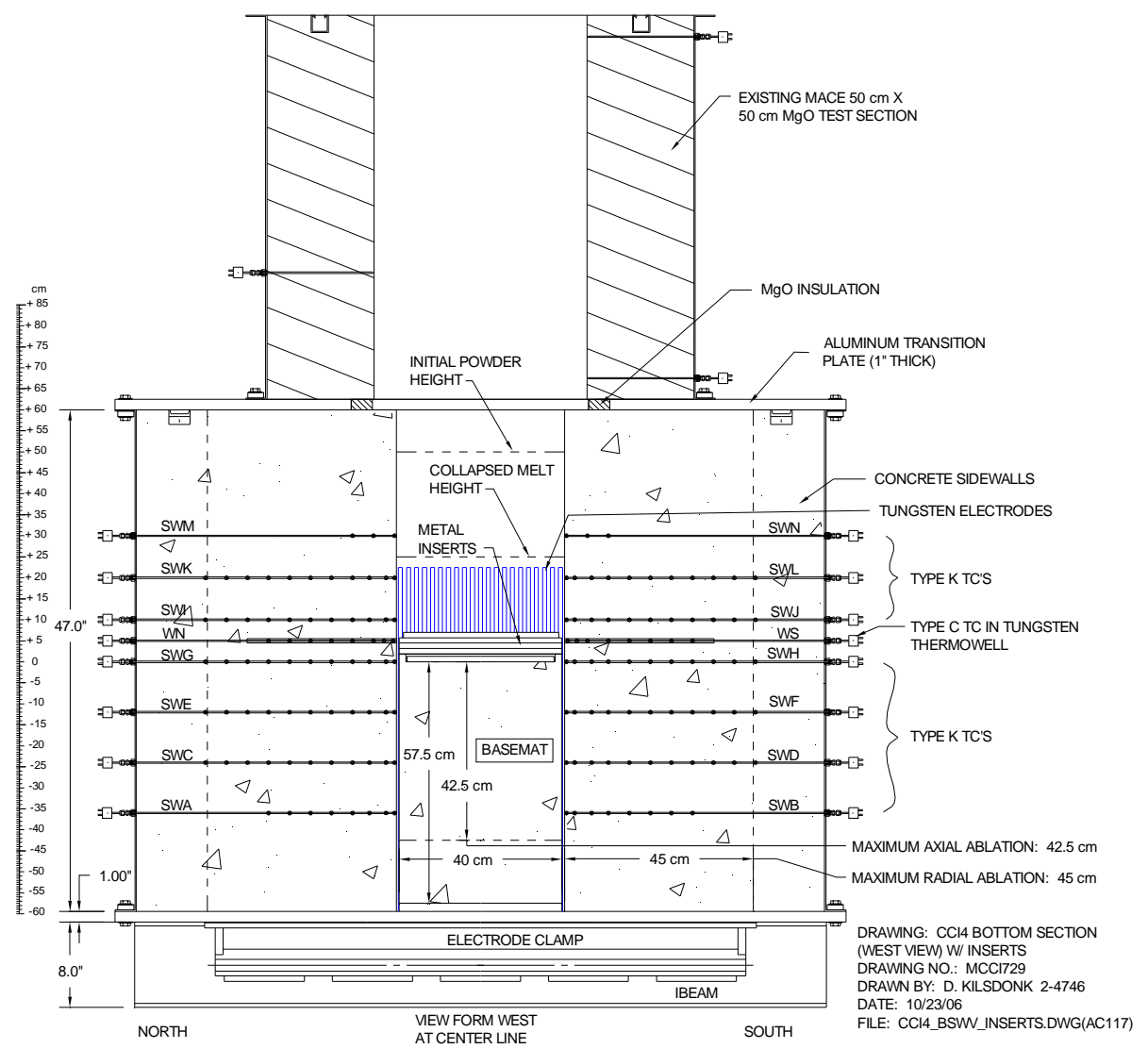

Figure 4-2. Side View of CCI-4 Lower Test Section Showing Concrete Sidewall Sections. 
The electrode sidewalls of the lower section were fabricated from castable $\mathrm{MgO}$ refractory, while the nonelectrode sidewalls were fabricated from Limestone/Common Sand (LCS) concrete. The middle sidewall section was fabricated from a high temperature refractory concrete $^{3}$, while the upper section was made from LCS concrete. The concrete and $\mathrm{MgO}$ were contained within flanged 11 gauge steel forms that secured the lower section to the balance of the existing test section components with an aluminum transition plate. The lower section was fabricated with vertical, flanged casting seams between the $\mathrm{MgO}$ and concrete so that the walls could be disassembled to reveal the solidified debris following the test. The $\mathrm{MgO}$ walls were reused, while the concrete walls were disposed of as radioactive waste.

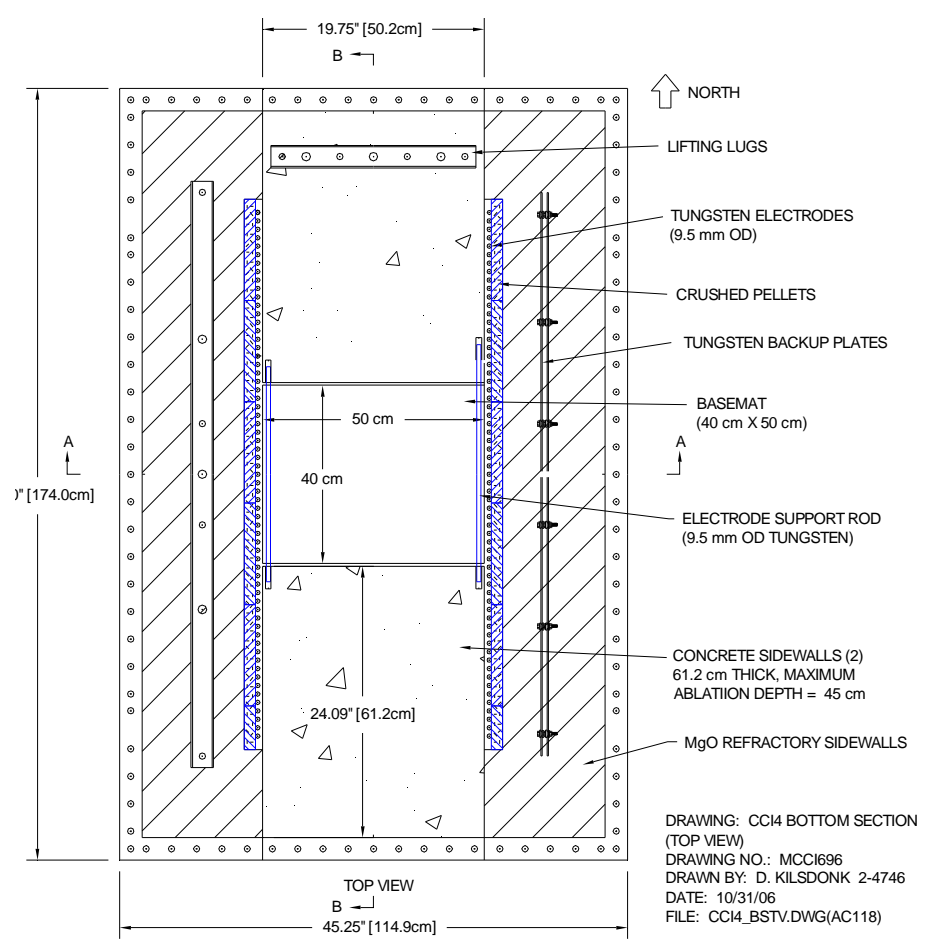

Figure 4-3. Top View of CCI-4 Lower Test Section.

A layer of crushed $\mathrm{UO}_{2}$ pellets was used to protect the interior surface of the two $\mathrm{MgO}$ sidewalls against thermo-chemical attack by the corium. In the event that this layer failed, 3.2 $\mathrm{mm}$ thick tungsten and molybdenum back-up plates were embedded in these walls as a final barrier to terminate sidewall attack. The plates were instrumented to provide an indication of corium contact with these surfaces during the test. Multi-junction Type $\mathrm{C}$ thermocouple assemblies were also cast within the $\mathrm{MgO}$ to provide the information required to evaluate conduction heat losses into these walls.

Melt pool generation was achieved through an exothermic "thermite" chemical reaction that produced the target initial melt mass over a timescale of $\sim 30$ seconds. After the chemical reaction, DEH was supplied to the melt to simulate decay heat through two banks of tungsten electrodes that lined the interior surfaces of the opposing $\mathrm{MgO}$ sidewalls. The copper electrode clamps were attached to the $2.5 \mathrm{~cm}$ thick aluminum bottom support plate that formed the foundation for the apparatus. A total of sixty three $91 \mathrm{~cm}$ long, $0.95 \mathrm{~cm}$ diameter tungsten electrodes were attached to each electrode clamp at a pitch of $1.9 \mathrm{~cm}$. The clamps were attached with water-cooled buss bars to a $560 \mathrm{~kW}$ AC power supply. As illustrated in Figure 4-3, the electrodes spanned a total width of $120 \mathrm{~cm}$ on each sidewall of the lower section. At the start of the experiment, the electrical current was drawn through the center $40 \mathrm{~cm}$ lateral span of electrodes that were in direct contact with the melt. As the test progressed and the concrete sidewalls eroded, additional electrodes were exposed to the corium. Electrical current was drawn through these newly exposed heating elements, thereby maintaining a uniform heating pattern in

\footnotetext{
${ }^{3}$ Tufffloor 2500, Matrix Refractories, Columbus, $\mathrm{OH}$.
} 
the melt over the course of the experiment. Given the overall electrode span of $120 \mathrm{~cm}$, up to 45 $\mathrm{cm}$ of sidewall ablation could be accommodated while maintaining uniform heat input.

As shown in Figure 4-1, a $15 \mathrm{~cm}$ diameter gas line was used to vent the helium cover gas and the various gas species arising from the core-concrete interaction into two adjacent tanks that were partially filled with water. In the initial phase of the experiment, while the cavity remained dry, the tanks served to cool the reaction product gases and filter aerosols generated from the core-concrete interaction. In the late phase, after the cavity was flooded, the tanks served to condense the steam and, based on the measured condensation rate, provide data on the corium cooling rate. In either case, the helium cover gas and noncondensables $\left(\mathrm{CO}, \mathrm{CO}_{2}\right.$, and $\left.\mathrm{H}_{2}\right)$ passed through the tanks and were vented through an off-gas system that included a demister, filters, and a gas flow meter. The gases were exhausted through the containment ventilation system and a series of high efficiency filters before finally being released from the building stack.

After a specified period of core-concrete interaction, the cavity was flooded using an instrumented water supply system. The water entered the test section through two weirs located in the opposing (non-electrode) sidewalls of the top test section. After initial water addition, the water level over the corium was kept roughly in the range of $50 \pm 5 \mathrm{~cm}$ by periodically adding makeup. Once a stable crust formed at the melt-water interface, an insertable lance was used in an attempt to break the crust to obtain data on the nature and extent of debris cooling that occurs following transient crust breach. As described in Section 1, this is a cooling mechanism that is expected to be active at plant scale owing to the mechanical instability of crusts that would form in the typical 5-6 m cavity span of most plants. The lance was simply a $2.54 \mathrm{~cm}$ diameter, 304 stainless steel rod with a pointed tip. The lance was inserted through a seal in the lid of the test section. The driving force for the lance was a $450 \mathrm{~kg}$ dead weight that was remotely lowered with the cell crane during the test.

\subsubsection{CCI-5 Test Apparatus}

Test CCI-5 focused on examining the influence of melt pool aspect ratio on the radial/axial power split under dry cavity conditions. Specifically, the test section aspect ratio (i.e., test section width/melt depth) was increased to the greatest extent possible by modifying the test section design to include a single concrete sidewall that would undergo ablation, while the opposing sidewall was made from refractory $\mathrm{MgO}$ that essentially created an adiabatic boundary condition. Top and side views of the modified lower test section design are provided in Figures 4-4 and 4-5, respectively. The thickness of the new non-electrode sidewall was the same as the existing $\mathrm{MgO}$ electrode walls (i.e., $25 \mathrm{~cm}$ ), and it was also protected with a crushed $\mathrm{UO}_{2}$ pellet liner. As shown in Figure 4-5, the underside of the test section transition plate was exposed due to the addition of the thin $\mathrm{MgO}$ sidewall. To provide thermal protection, the plate was lined with $\mathrm{Al}_{2} \mathrm{O}_{3}$ insulation and a tungsten heat shield. A similar heat shield design was found to be highly successful in protecting the inner surface of the ACE/MCCI test apparatus lid [7].

The selected sidewall dimensions increased the basemat width from the nominal value of $50 \mathrm{~cm}$ in Tests CCI-1 through CCI-3 to $79 \mathrm{~cm}$ for CCI-5. Taking credit for the symmetry boundary condition, then the aspect (width/melt depth) ratio was increased from 1.0 in tests CCI1 through CCI-3 to 3.2 for CCI-5, given the initial melt depth of $25 \mathrm{~cm}$ for CCI-5 (see Table 4-1). 
As for Test CCI-4, the safety plan for the tests assumed that a minimum thickness of $15 \mathrm{~cm}$ was maintained for all concrete components to ensure final containment of the melt. On this basis, up to $40 \mathrm{~cm}$ of lateral ablation could be accommodated in the concrete sidewall. Conversely, up to $42.5 \mathrm{~cm}$ of axial ablation could be accommodated given the initial basemat thickness of $57.5 \mathrm{~cm}$. The balance of the test section design above the lower section was identical to that used in CCI-4.

\subsubsection{Concrete Compositions}

As shown in Table 4-1, concrete type was one of the key parametric variations in the experimental series. Test CCI-4 was conducted with Limestone-Common Sand (LCS) concrete, while CCI-5

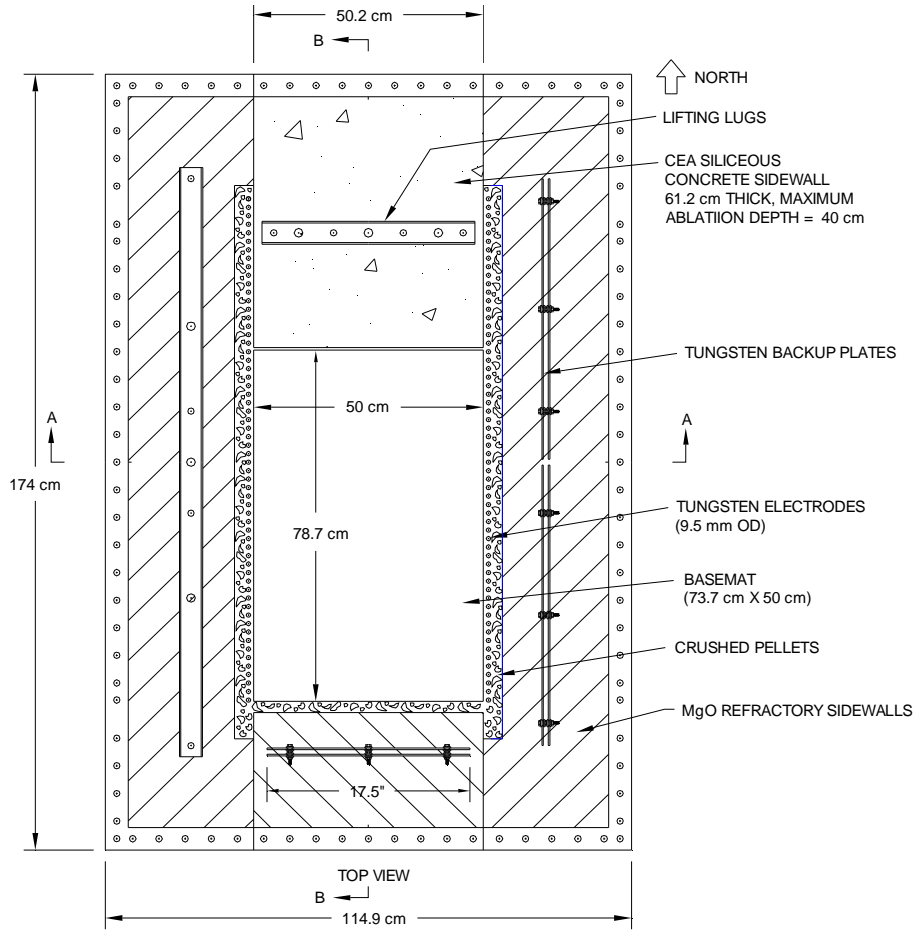

Figure 4-4. Top View of CCI-5 Lower Test Section.

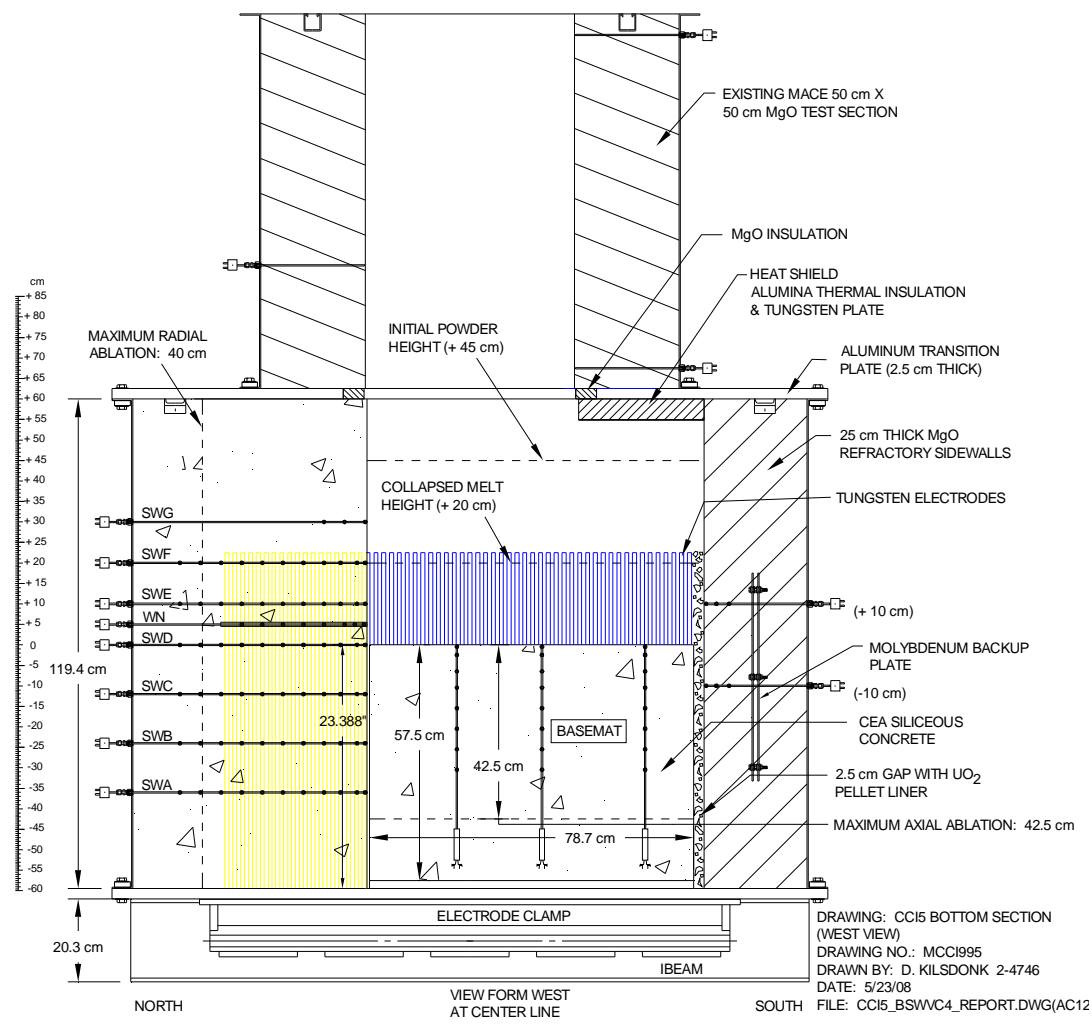

Figure 4-5. Side View of CCI-5 Lower Test Section Showing Concrete Sidewall. 
was conducted with siliceous concrete. The chemical compositions of the two concrete types are shown in Table 4-2. The compositions were determined through chemical analysis of samples taken from concrete archives that were produced while fabricating the basemat and sidewall components for each test. Refer to the individual data reports $[59,60]$ for additional information regarding the engineering compositions (i.e., mix ratios) for each concrete type.

The densities of the concretes used in the tests are shown in Table 4-3. These densities were calculated on the basis of the measured mass and volumes of the concrete archive samples for each test. Instrumentation locations within the sidewalls and basemat are described later in this section.

\subsubsection{Corium Compositions}

As shown in Table 4-1, the initial corium compositions for the tests were quite different, with CCI-4 conducted with a partially oxidized BWR core melt, while CCI-5 was conducted with a fully oxidized PWR core melt. The compositions for the two tests contained various proportions of calcined concrete as initial constituents. The compositions of the concrete additives were consistent with the type of concrete used for the sidewalls and basemat for each test. Aside from lowering the melting point of the mixtures [61], the additives were incorporated to account for concrete erosion that is expected to occur during the corium spreading

Table 4-2. Chemical Composition of Concretes.

\begin{tabular}{|c|c|c|}
\hline Oxide & $\begin{array}{c}\text { CCI-4 } \\
\text { Wt\% }\end{array}$ & $\begin{array}{c}\text { CCI-5 } \\
\text { Wt \% }\end{array}$ \\
\hline $\mathrm{SiO}_{2}$ & 25.99 & 58.27 \\
\hline $\mathrm{Al}_{2} \mathrm{O}_{3}$ & 2.78 & 3.51 \\
\hline $\mathrm{Fe}_{2} \mathrm{O}_{3}$ & 1.40 & 1.33 \\
\hline $\mathrm{CaO}$ & 27.81 & 20.20 \\
\hline $\mathrm{MgO}$ & 9.21 & 0.92 \\
\hline $\mathrm{SO}_{3}$ & 0.91 & 0.45 \\
\hline $\mathrm{Na}_{2} \mathrm{O}$ & 0.39 & 0.49 \\
\hline $\mathrm{K}_{2} 0$ & 0.54 & 0.80 \\
\hline $\mathrm{TiO}_{2}$ & 0.17 & 0.15 \\
\hline $\mathrm{P}_{2} \mathrm{O}_{5}$ & 0.09 & 0.07 \\
\hline $\mathrm{Mn}_{2} \mathrm{O}_{3}$ & 0.04 & 0.05 \\
\hline $\mathrm{SrO}_{\mathrm{CO}}$ & 0.02 & 0.03 \\
\hline $\mathrm{H}_{2} \mathrm{O}$, Free & 23.80 & 9.50 \\
\hline $\mathrm{H}_{2} \mathrm{O}$, Bound & 3.58 & 1.90 \\
\hline Total & 100.15 & 100.54 \\
\hline
\end{tabular}

Table 4-3. Concrete Densities.

\begin{tabular}{|c|c|}
\hline Test & $\begin{array}{c}\text { Concrete Density } \\
\left(\mathbf{k g} / \mathbf{m}^{\mathbf{3}}\right)\end{array}$ \\
\hline CCI-4 & 2404 \\
\hline CCI-5 & 2382 \\
\hline
\end{tabular}
phase following breach of the Reactor Pressure Vessel (RPV) [62].

For test CCI-4, one objective was to increase the metal content of the melt to the highest practical level to more accurately mock up a prototypic BWR core melt, with the target value being $15 \mathrm{wt} \%$. The approach for achieving this objective was to place a metal-bearing concrete insert that overlaid the basemat for dissolution into the melt prior to onset of basemat ablation. ${ }^{4}$ The initial melt compositions at the start of the interaction with the concrete basemats for the two tests are shown in Table 4-4. For CCI-4, the composition includes both the initial melt volume produced by the thermite, as well as the materials in the inserts that were ablated into the melt prior to contacting the basemat. ${ }^{5}$ For CCI-5, the melt content simply corresponds to the posttest thermite reaction composition as no inserts were used in that experiment.

\footnotetext{
${ }^{4}$ This technique was originally developed as part of the ACE/MCCI test series [7].

${ }^{5}$ The estimate includes the expected oxidation of $\mathrm{Zr}$ with $\mathrm{H}_{2} \mathrm{O}$ and $\mathrm{CO}_{2}$ gases liberated upon decomposition of the concrete in the inserts.
} 
Table 4-4. Detailed Melt Compositions at the Start of Basemat Ablation.

\begin{tabular}{|c|c|c|c|c|}
\hline \multirow{2}{*}{ Constituent } & \multicolumn{2}{|c|}{ CCI-4 } & \multicolumn{2}{c|}{ CCI-5 } \\
\cline { 2 - 5 } & Wt \% & Mass (kg) & Wt \% & Mass (kg) \\
\hline $\mathrm{UO}_{2}$ & 56.52 & 169.36 & 56.32 & 332.29 \\
\hline $\mathrm{ZrO}_{2}$ & 21.53 & 64.51 & 23.13 & 136.47 \\
\hline $\mathrm{SiO}_{2}$ & 4.05 & 12.15 & 11.17 & 65.90 \\
\hline $\mathrm{Al}_{2} \mathrm{O}_{3}$ & 0.49 & 1.47 & 0.64 & 3.78 \\
\hline $\mathrm{MgO}$ & 1.36 & 4.08 & 0.12 & 0.70 \\
\hline $\mathrm{CaO}$ & 3.75 & 11.23 & 2.21 & 13.04 \\
\hline $\mathrm{Zr}$ & 4.61 & 13.82 & 0.00 & 0.00 \\
\hline $\mathrm{Cr}$ & 4.70 & 14.08 & 6.41 & 37.82 \\
\hline $\mathrm{Fe}$ & 2.99 & 8.97 & 0.00 & 0.00 \\
\hline Total & 100.00 & 299.67 & 100.00 & 590.00 \\
\hline
\end{tabular}

\subsubsection{Instrumentation}

The CCI facility was instrumented to monitor and guide experimental operation and to $\log$ data for subsequent evaluation. Principal parameters monitored during the course of the test included the power supply voltage, current, and gross input power to the melt; melt temperature and temperatures within the concrete basemat and sidewalls; crust lance position and applied load; supply water flow rate; water volume and temperature within the test apparatus, and water volume and temperature within the quench system tanks. Other key data recorded by the DAS included temperatures within test section structural sidewalls, off gas temperature and flow rate, and pressures at various locations within the system. Measurement uncertainties for the various instruments utilized in the tests are provided in [6].

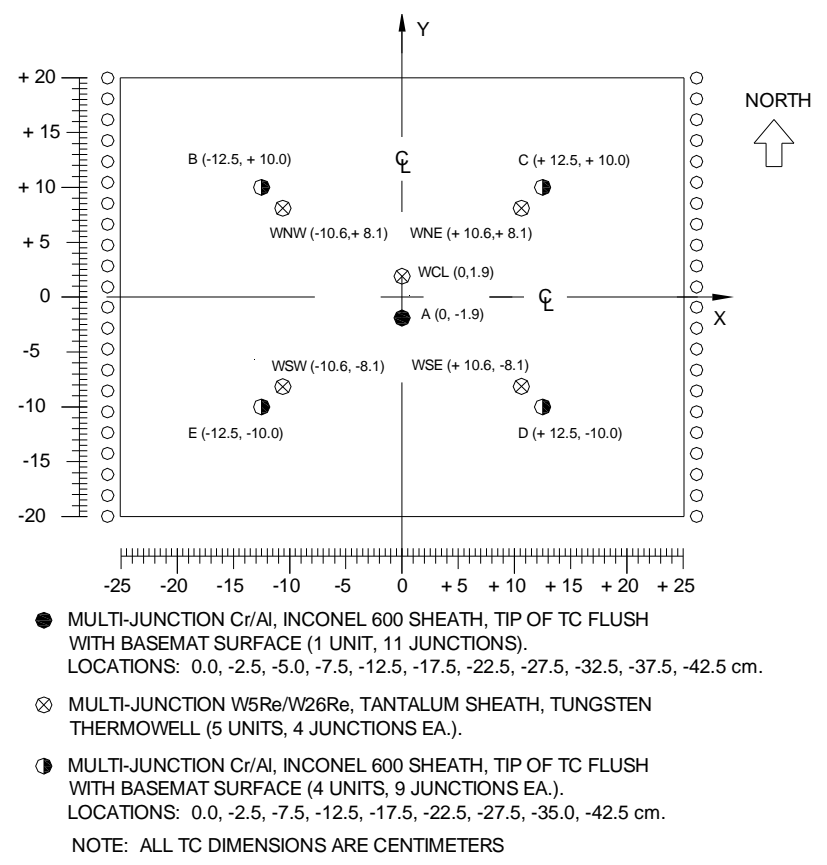

Figure 4-6. Plan View of CCI-4 Basemat Instrument Locations.

The concrete sidewall instrumentation locations for CCI-4 and CCI-5 are shown in Figures 4-2 and 4-5, respectively, while plan views of the basemat thermocouple layouts for these two tests are provided in Figures 4-6 and 4-7. Both the basemat and sidewalls were instrumented with multi-junction Type $\mathrm{K}$ thermocouple assemblies to determine the 2-D ablation profile as a function of time. In addition, multiple Type $\mathrm{C}$ thermocouple assemblies that were protected by tungsten thermowells were mounted vertically within the basemats and horizontally through the concrete sidewalls. The purpose of these instruments was to provide data on the axial and lateral 
melt temperature distributions versus time. Other significant test instrumentation included a stationary (lid mounted) video camera for observing physical characteristics of the core-concrete interaction. In addition, for CCI5, a two-color optical pyrometer was used to provide melt surface temperature data during the test.

\subsection{Results and Discussion}

As a whole, The CCI test series investigated the effects of concrete type and input power on two-dimensional core-concrete interaction under both wet and dry cavity conditions. The purpose of this section is to compare the results from the two experiments conducted as part of the current test series with the data from the test series as a whole [1] to identify key parametric effects. Principal variables measured during the experiments included

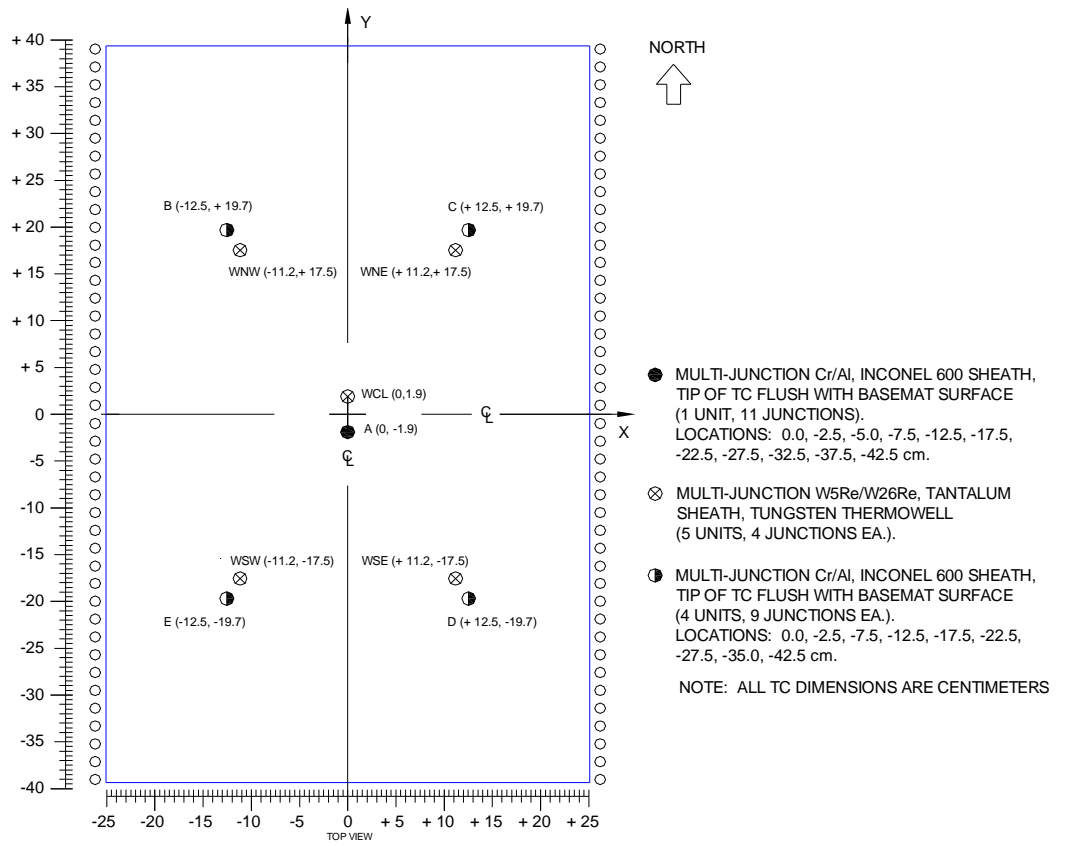

Figure 4-7. Plan View of CCI-5 Basemat Instrument Locations. melt temperature, local concrete ablation rates, and debris/water heat flux after cavity flooding. However, tests CCI-4 and CCI-5 did not provide any prototypic debris coolability data for direct comparison to the data obtained under late cavity flooding conditions as part of the MCCI-1 program [1]. In CCI-4, direct meltwater contact was precluded by the presence of a large mantle crust that formed in the upper regions of the test section due to extensive melt foaming that occurred over the course of the experiment [6]. For CCI-5, the cavity was not flooded due to plugging of the main gas line for the apparatus [6]. Thus, the following discussion focuses on core-concrete interaction behavior as opposed to debris coolability, with discussions regarding coolability aspects deferred to Section 5. The reader is referred elsewhere [1] for a discussion of the results regarding debris coolability under late flooding conditions obtained as part of MCCI-1. Conversely, additional data and discussions regarding coolability under early flooding conditions are provided in Section 5 of this report.

A comparison of key results from the CCI test series is provided in Figures 4-8 through 410 , which provide the estimated average melt temperature and characteristic lateral and axial concrete ablation rates for each of the tests. As shown in Figure 4-8, the initial melt temperature for all tests was in the range of $1880-1950{ }^{\circ} \mathrm{C}$. The differences were due to uncertainty/variability in the thermite reaction temperatures for the different chemical mixtures used to generate the initial melt compositions. During dry cavity operations, all tests showed the overall trend of decreasing melt temperature as ablation progressed, which was due to a heat sink effect as relatively cool concrete slag was introduced into the melt, as well as the increasing heat 
transfer surface area as the melts expanded into the concrete crucibles. The decline in melt temperature may further reflect the evolution of the pool boundary freezing temperature that decreased as additional concrete was eroded into the melt over the course of the tests.

One of the key objectives of the current test series was to investigate the effect of unoxidized $\mathrm{Zr}$ cladding on the thermalhydraulics of the core-concrete interaction. To examine this effect, CCI-4 was conducted with a $78 \%$ oxidized BWR melt composition. As is evident from Figure 4-8, the effect of the oxidation reaction between $\mathrm{Zr}$ and sparging concrete decomposition gases $\left(\mathrm{CO}_{2}, \mathrm{H}_{2} \mathrm{O}\right)$ was to cause an exothermic transient in which the melt temperature increased by $\sim 100{ }^{\circ} \mathrm{C}$ during the first 20 minutes of the test. This same type of transient was observed in metal tests conducted at Sandia [30-31] and KIT [33]. In addition, the effect of $\mathrm{Zr}$ oxidation was also investigated as part of the ACE/MCCI test series with core oxide material [7]. Unfortunately, tests conducted in this series with partially oxidized melt and LCS concrete were of very short duration (i.e., several minutes), and so the long term effects of the oxidation reactions on thermalhydraulic behavior were not clear. However, CCI-4 ran for several hours past the point at which all the cladding had oxidized. Moreover, CCI2 can be considered a counterpart experiment insofar as cladding oxidation state is concerned. Comparison of the results indicates that cladding oxidation reactions cause an early exothermic temperature transient in the melt, and after the reaction is complete, the temperature drops to that consistent with fully oxidized melt conditions.

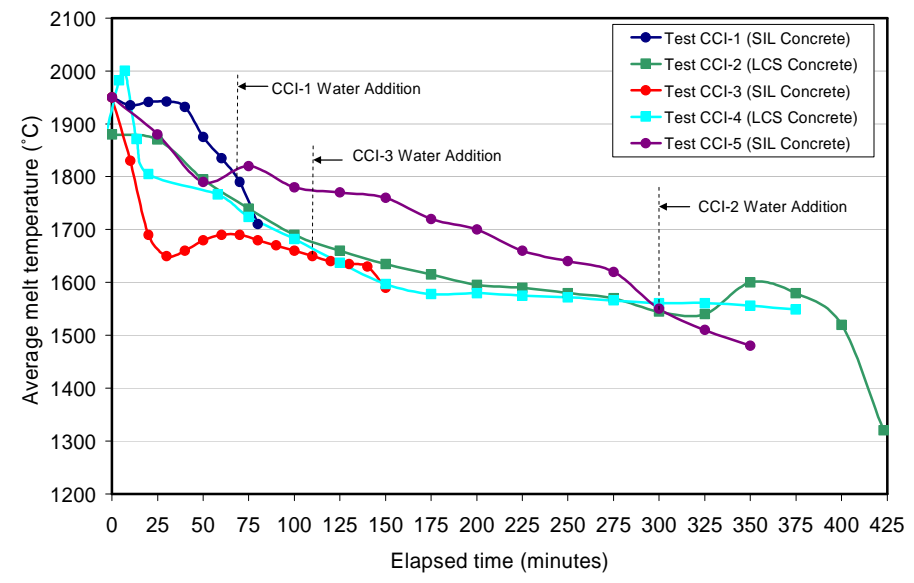

Figure 4-8. Melt Temperatures for CCI Tests.

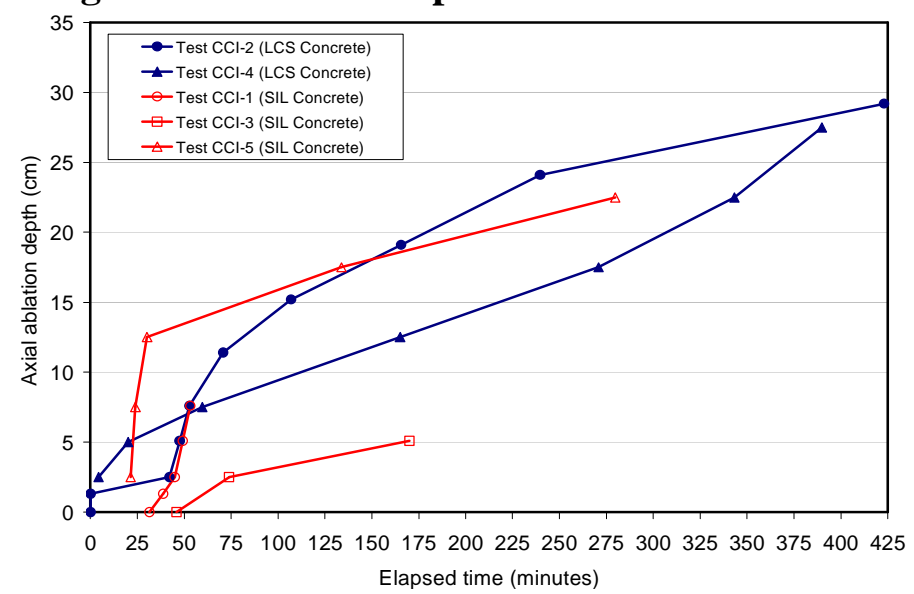

Figure 4-9. Axial Ablation for CCI Tests.

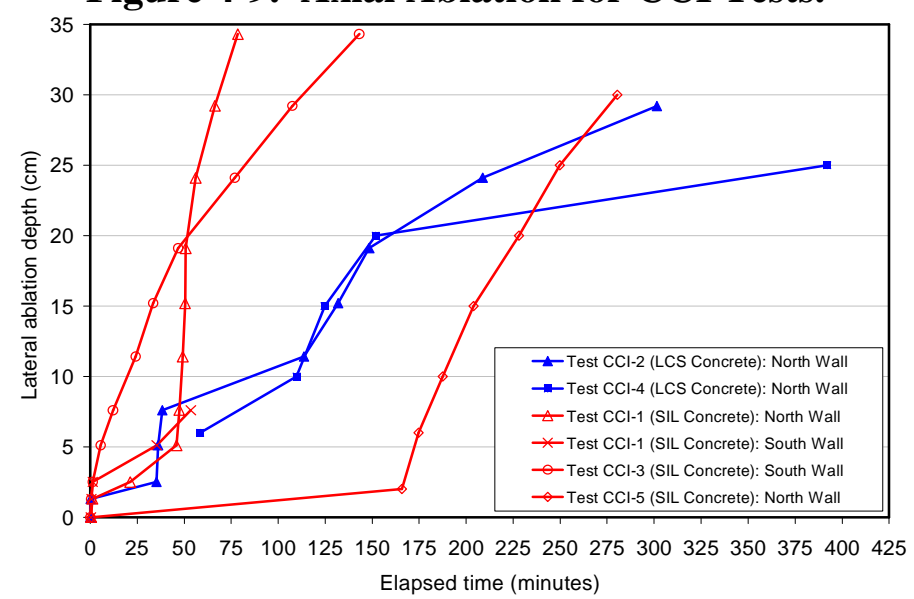

Figure 4-10. Lateral Ablation for CCI Tests. 
Additional examination of Figure 4-8 indicates that CCI-1 exhibited slightly different melt temperature behavior compared to the other fully oxidized tests. In this test, the melt temperature was relatively constant over the first $\sim 40$ minutes of the interaction. One possible contributor to this trend was the fact that this test was run at a $25 \%$ higher power level in comparison to the other CCI tests. In particular, CCI-1 was run at a power level that was consistent with a heat flux of $200 \mathrm{~kW} / \mathrm{m}^{2}$ spread over all surfaces initially in contact with the melt (i.e., axial and lateral concrete surfaces, as well as the overlying atmosphere), whereas the other tests were initiated at a power level consistent with a flux of $150 \mathrm{~kW} / \mathrm{m}^{2}$ (see Table $4-1$ for initial gross power levels). However, the lack of a temperature decline may have also been caused by crust formation at the core-concrete interfaces that acted to insulate the melt. Relatively low heat transfer rates to the concrete boundaries were evidenced by the low ablation rates exhibited over the first 40 minutes. Note that this type of behavior is consistent with other transient core oxide tests carried out at Sandia [37], wherein fairly large-mass (200 $\mathrm{kg}$ ) substoichiometric melts consisting of $(\mathrm{U}, \mathrm{Zr}) \mathrm{O}_{2-\mathrm{x}}$ were dropped into concrete test sections and allowed to cool with no further heating. In these tests, no concrete ablation occurred and the conclusion was drawn that crusts acted to thermally protect the concrete. However, in the current tests the melts were continuously heated. Thus, once the surface crusts failed in CCI-1, ablation proceeded vigorously and the melt temperature fell rapidly in comparison to the other tests. This initial stable crust behavior may have been linked to the exceptionally low gas content for this concrete type in comparison to others used in the test series (see Table 3-18 in [1]). In particular, gas sparging at the core-concrete interface may provide the mechanical force required to dislodge the crust material from the interface, thereby allowing ablation to proceed. If this interpretation is correct, then the reduced gas sparging allowed the insulating crusts to remain stable over an extended period of time in Test CCI-1, which in turn caused the melt temperature to increase.

Aside from Test CCI-1, examination of Figures 4-9 and 4-10 indicates that the other CCI tests also showed evidence of early crust formation phases that influenced the overall ablation behavior. For CCI-2, both axial and lateral ablation rates were quite low and the melt temperature relatively constant until $\sim 30$ minutes, after which time a period of rapid erosion occurred. However, unlike CCI-1, these erosion bursts were not sustained. Rather, after $\sim 5 \mathrm{~cm}$ of ablation, both the axial and lateral ablation rates slowed significantly and approached quasisteady states. The reduced period of crust stability for CCI-2 is consistent with the idea that gas sparging can disrupt surface crusts, since the gas content of the CCI- 2 concrete was significantly greater compared to CCI-1.

Unlike tests CCI-1 and CCI-2, sidewall erosion in test CCI-3 commenced immediately upon contact with melt, and progressed steadily throughout the balance of the test. Conversely, the data suggests that the concrete basemat was protected by an insulating crust until $\sim 50$ minutes, at which point the crust failed and erosion commenced, albeit at a reduced rate relative to lateral ablation. In contrast, the results of CCI-5 suggest that the sidewall was protected by crust material for nearly 2.5 hours before ablation was initiated. However, once erosion began, the lateral ablation rate approached that observed in CCI-3.

Aside from initial crusting effects, examination of Figures 4-9 and 4-10 indicates that the long-term ablation process is influenced by concrete type. Estimates of average lateral and axial ablation rates for the five tests are provided in Table 4-5. This table also includes estimates of 
the concrete heat fluxes that were formulated based on the average erosion rates using a quasisteady concrete erosion assumption [6]. As shown in the table, long-term lateral and axial ablation rates for Tests CCI- 2 and CC-4, both of which were conducted with LCS concrete, were about the same. For CCI-2, the concrete erosion rate averaged $4 \mathrm{~cm} / \mathrm{hr}$ over several hours of interaction before gradually decreasing; the corresponding surface heat flux was $\sim 60 \mathrm{~kW} / \mathrm{m}^{2}$. For CCI-4, the fluxes were slightly lower (i.e, $\sim 40 \mathrm{~kW} / \mathrm{m}^{2}$ ), but this is due to a surface scaling effect as the initial cavity size and therefore input power level were reduced to expand the test duration. Thus, the lateral/axial heat flux ratios for these LCS tests are approximately unity.

Table 4-5. Lateral/Axial Ablation Rate and Power Split Estimates for CCI Tests.

\begin{tabular}{|c|c|c|c|c|c|c|}
\hline \multirow[b]{2}{*}{ Test } & \multirow[b]{2}{*}{$\begin{array}{c}\text { Concrete } \\
\text { Type }\end{array}$} & \multicolumn{2}{|c|}{ Lateral Ablation } & \multicolumn{2}{|c|}{ Axial Ablation } & \multirow{2}{*}{$\begin{array}{c}\text { Lateral-Axial } \\
\text { Heat Flux } \\
\text { Ratio }\end{array}$} \\
\hline & & $\begin{array}{l}\text { Ablation } \\
\text { Rate } \\
(\mathrm{cm} / \mathrm{hr})\end{array}$ & $\begin{array}{c}\text { Heat Flux } \\
\left(\mathrm{kW} / \mathbf{m}^{2}\right)\end{array}$ & $\begin{array}{c}\text { Ablation } \\
\text { Rate } \\
(\mathbf{c m} / \mathbf{h r})\end{array}$ & $\begin{array}{c}\text { Heat Flux } \\
\left(\mathrm{kW} / \mathbf{m}^{2}\right)\end{array}$ & \\
\hline \multirow[t]{2}{*}{ CCI-1 } & \multirow[t]{2}{*}{ SIL (US) } & $\mathrm{N}: 39.1$ & 395 & \multirow[t]{2}{*}{$26.1^{\mathrm{b}}$} & \multirow[t]{2}{*}{265} & \multirow[t]{2}{*}{$-{ }^{\mathrm{a}}$} \\
\hline & & S: 8.4 & 86 & & & \\
\hline CCI-3 & SIL (EU) & 10.0 & 97 & 2.5 & 25 & 4.0 \\
\hline CCI-5 & SIL (EU) & 9.8 & 95 & 2.1 & 21 & 4.7 \\
\hline CCI-2 & LCS & 4.0 & 58 & 4.0 & 59 & 1.0 \\
\hline CCI-4 & LCS & 2.7 & 39 & 2.8 & 41 & 1.0 \\
\hline
\end{tabular}

${ }^{a}$ Heat flux ratio not evaluated for this test due to large asymmetry in lateral cavity erosion.

${ }^{\mathrm{b}}$ Ablation burst; rate appeared to slow significantly after this time interval; see Figure 4-9.

The relatively uniform power splits for CCI-2 and CCI-4 can be contrasted with the results of the three tests conducted with siliceous concrete. For test CCI-1, the ablation was highly non-uniform, with most of the ablation concentrated in the North sidewall of the test apparatus. As described above, this test was conducted at a higher power density in comparison to CCI-2 and CCI-3. Moreover, the concrete for this test had exceptionally low gas content (see Table 3-18 in [1]). Based on the discussion provided above, it thus appears that crust stability played a major role in determining the ablation progression for this experiment. In particular, the data suggests that after the insulating crust failed on the North concrete sidewall, the input power was dissipated predominately through ablation of this sidewall, while crusts continued to protect the basemat and south sidewall surfaces. As shown in Table 4-5, the ablation rate averaged 39 $\mathrm{cm} / \mathrm{hr}$ in the North wall over the last 30 minutes of dry cavity operations; the average concrete surface heat flux was $\sim 395 \mathrm{~kW} / \mathrm{m}^{2}$. Conversely, brief ablation bursts that reached $8.4 \mathrm{~cm} / \mathrm{hr}$ in the South wall and $26 \mathrm{~cm} / \mathrm{hr}$ axially occurred early in the experimental sequence, but the data suggests that crusts subsequently reformed on these surfaces, resulting in very little ablation over the balance of test operations. Based on these transient effects, a power split estimate was not formulated for this test, since the estimate would be highly speculative. 
In contrast to Test CCI-1, the other two tests conduced with siliceous concrete (CCI-3 and CCI-5) seemed to exhibit repeatable, albeit non-isotropic, ablation behavior. For CCI-3, fairly symmetrical ablation occurred insofar as the progression of the ablation fronts into the two opposing sidewalls of the apparatus is concerned. However, unlike Test CCI-2, the lateral ablation was highly pronounced in comparison to axial for this particular test. A similar trend was noted for CCI-5 that was conducted with a single siliceous concrete sidewall. As shown in Table 4-5, lateral ablation averaged $10 \mathrm{~cm} / \mathrm{hr}$ during the late phases of the CCI-3 and CCI-5 experiments, while the axial ablation rate was limited to 2.1 to $2.5 \mathrm{~cm} / \mathrm{hr}$ over the same timeframe for the two tests. The corresponding heat fluxes in the lateral and axial directions were roughly 100 and $25 \mathrm{~kW} / \mathrm{m}^{2}$, respectively. On this basis, the lateral/axial surface heat flux ratios for tests CCI-3 and CCI-5 were estimated as $\sim 4$ and $\sim 4.7$, respectively. These values are significantly higher than the near-unity ratios deduced for tests CCI-2 and CCI-4 with LCS concrete. Thus, the data suggests that there is an effect of concrete type on the spatial heat flux distribution at the core-concrete interface during dry core-concrete interaction. Between these two concrete types, possible explanations for differences in the erosion behavior are chemical composition (LCS concrete has a high $\mathrm{CaO} / \mathrm{SiO}_{2}$ ratio in comparison to siliceous), and concrete gas content (LCS has $~ 2.5$ times as much gas as siliceous). A third possible explanation was revealed during posttest examinations. In particular, the nature of the core-concrete interface was noticeably different for Test CCI-2 in comparison to Tests CCI-1, CCI-3, and CCI-5, as shown in Figure 4-11. (Note that a cross-sectional view of the CCI-4 debris is not included in this figure since there was so little core debris remaining on the concrete basemat). The ablation front for the three tests conducted with siliceous concrete is noted to consist of a region where the core oxide had locally displaced the cement that bonded the aggregate. Conversely, the ablation front for Test CCI-2 consisted of a powdery interface in which the core and concrete oxides were clearly separated. The interface characteristics may have influenced the heat transfer rate across the boundaries, thereby resulting in different ablation behavior for the two concrete types.

Finally, one of the key test objectives for CCI-5 was to examine the influence of melt pool aspect ratio on the radial/axial power split under dry cavity conditions. The specific objective was to increase the test section aspect ratio (i.e., test section width/melt depth) to the greatest extent possible to more accurately mock up prototypic conditions. The approach was to modify the test section design to include a single concrete sidewall that would undergo ablation, whereas the opposing sidewall was made from refractory $\mathrm{MgO}$ that essentially created an adiabatic boundary condition. As discussed in Section 2, with this approach the aspect ratio was increased from a value of $\sim 1$ for CCI-3 to $\sim 3.2$ for CCI-5. The relatively close agreement in long-term ablation behavior for tests CCI-3 and CCI-5 indicate that aspect ratio has little influence on ablation characteristics. This observation lends credibility to the measured power split for siliceous concrete insofar as extrapolating the results to plant conditions.

Aside from the overall cavity erosion behavior, video footage from the tests indicated that a crust was present over the melt upper surface during a large fraction of dry cavity ablation phase for all five tests. The crusts contained vent openings which allowed melt eruptions to occur as the tests progressed. The frequency and intensity of the eruptions were directly correlated to the gas content of the concrete for any given test. 


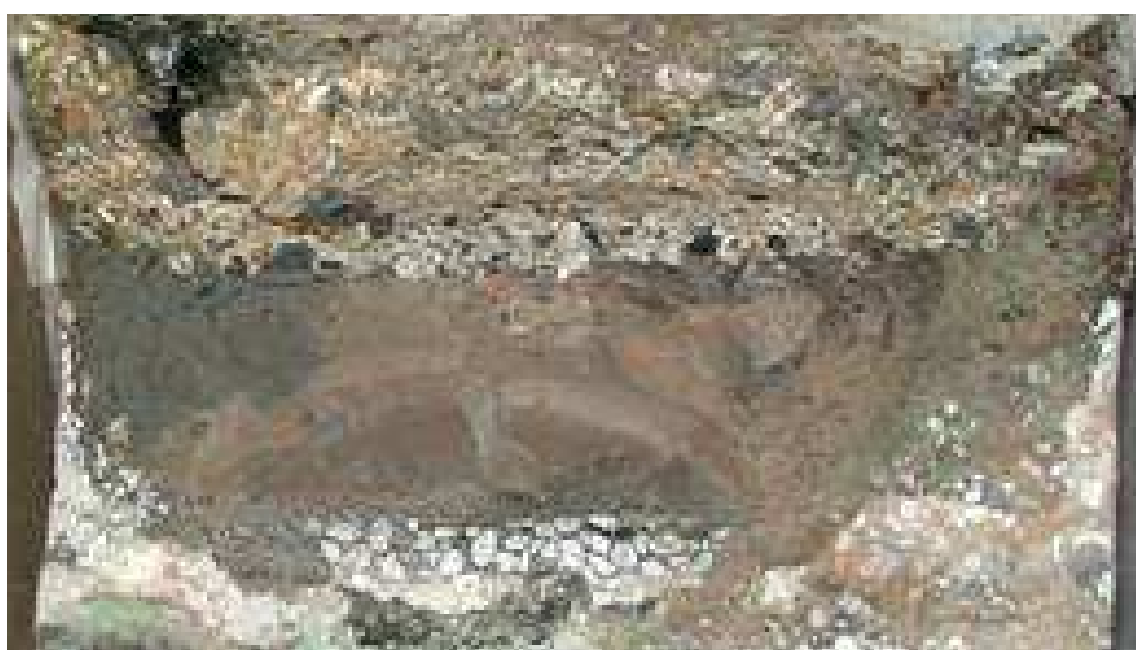

(a)

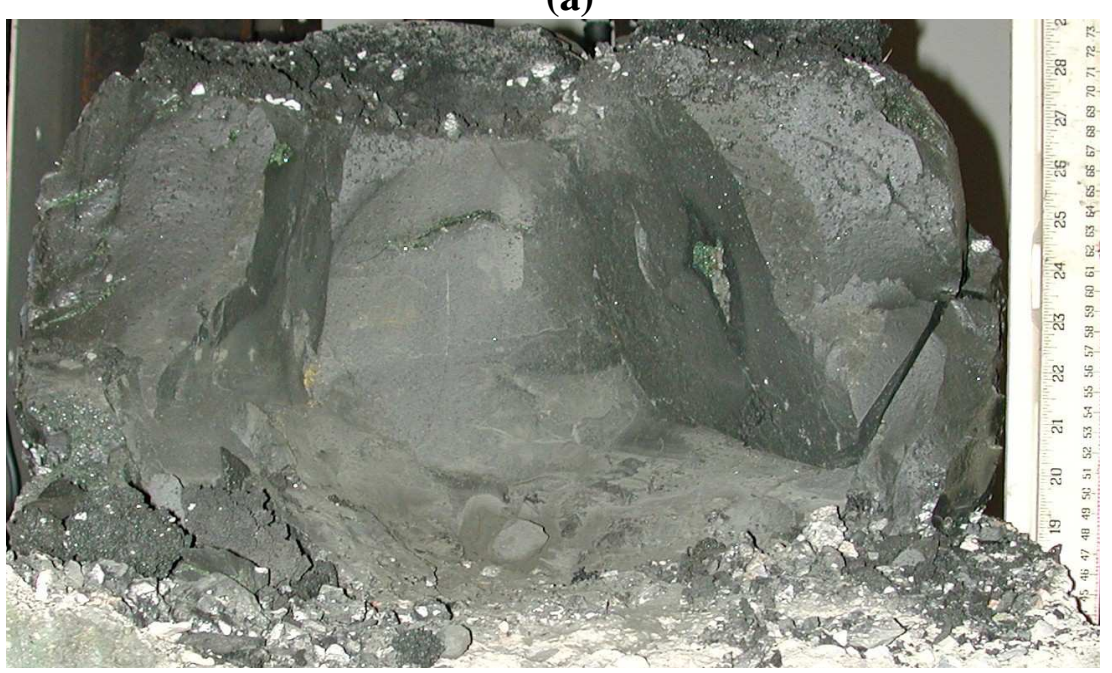

(c)

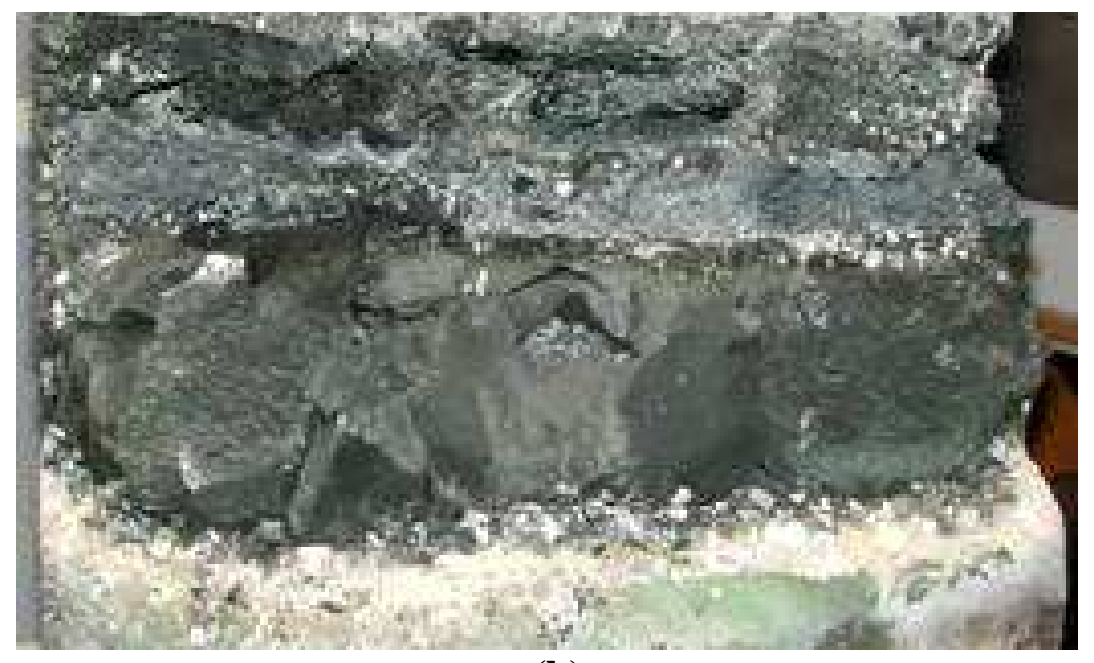

(b)

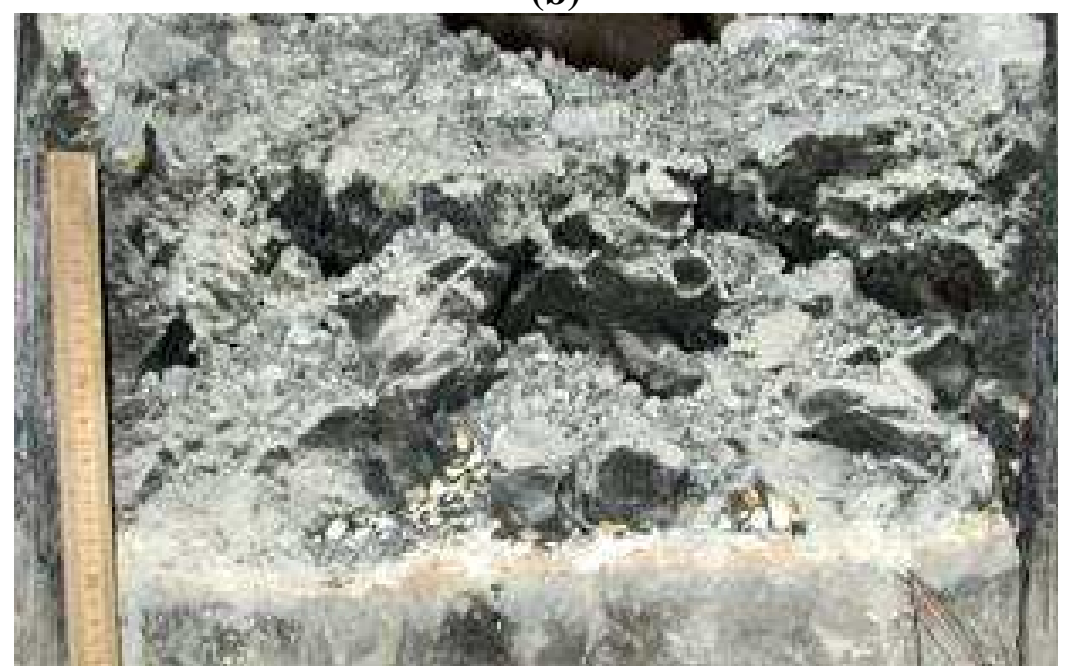

(d)

Figure 4-11. Axial Debris Morphology for Siliceous Concrete Tests (a) CCI-1, (b) CCI-3, and (c) CCI-5, and LCS Test (d) CCI-2. (All tests were flooded except CCI-5 (c)). 
In terms of the chemical analyses conducted as part of the test series, samples were collected to: i) characterize the lateral and axial composition variations of the solidified debris, and ii) characterize the composition of corium regions that played key roles in the coolability aspects of the tests (e.g., porous crust zones formed at the melt/water interface, and the material erupted after cavity flooding in CCI-2). See [1] for a discussion of the implications of these results for debris coolability in Tests CCI-1, -2, and -3. Analysis of samples taken to characterize the lateral composition variation indicate that for most tests, the corium in the central region of the test section had a higher concentration of core oxides in comparison to samples collected near the two ablating concrete sidewalls. Conversely, samples taken to characterize the axial composition variation over the vertical extent of the solidified corium remaining over the basemat indicate that general trend of slightly increasing core oxide concentration as the concrete surface is approached. For all three tests conducted with siliceous concrete, two zones appeared to be present: a heavy monolithic oxide phase immediately over the basemat that was enriched in core oxides, with a second overlying porous, light oxide phase that was enriched in concrete oxides. This axial phase distribution is clearly evident in Figure 4-11. 


\subsection{CATEGORY 4 TEST RESULTS}

A single large scale integral test was conducted in this test category with the objective of providing data for validation of severe accident codes under the conditions of early cavity flooding. In the event that the core melt was not quenched and stabilized in the early phase, an array of water injection nozzles was cast into the basemat so additional data on Category 2 bottom water injection cooling could be obtained during the late phase of the test. Specifications for the experiment are provided in Table 5-1. To minimize wall effects, the test section was enlarged to include a $70 \mathrm{~cm} \times 70 \mathrm{~cm}$ basemat, and the initial melt depth was increased to $28 \mathrm{~cm}$. To better reflect early flooding conditions, the thermite was redesigned to include a reduced amount of concrete decomposition products (i.e., $6 \mathrm{wt} \%$ ) relative to the previously performed CCI tests (see Section 4). In contrast to these previous tests, the core melt was flooded soon after the melt was produced and before significant cavity erosion had occurred.

Table 5-1. Specifications for CCI-6.

\begin{tabular}{|c|c|}
\hline Parameter & Specification \\
\hline Corium & $100 \%$ oxidized PWR with 6 wt \% siliceous concrete (CEA type) \\
\hline Test section cross-sectional area & $70 \mathrm{~cm} \mathrm{x} 70 \mathrm{~cm}$ \\
\hline Initial melt mass (depth) & $900 \mathrm{~kg}(28 \mathrm{~cm})$ \\
\hline Test section sidewall construction & $\begin{array}{l}24 \mathrm{~cm} \text { thick concrete followed by } \mathrm{MgO} \text { protected with a } 2.5 \mathrm{~cm} \\
\text { thick layer of crushed } \mathrm{UO}_{2} \text { pellets and powder. }\end{array}$ \\
\hline Test section basemat construction & $\begin{array}{l}48.1 \mathrm{~cm} \text { thick concrete with an array of water injection nozzles } \\
\text { embedded at a depth of } 27.5 \mathrm{~cm} \text { from the concrete top surface. } \\
\text { Nozzles are uniformly pitched at a lateral spacing of } 14.0 \mathrm{~cm} .\end{array}$ \\
\hline Sidewall maximum ablation depth & $24.0 \mathrm{~cm}$ \\
\hline Basemat maximum ablation depth & $32.5 \mathrm{~cm}$ \\
\hline System operating pressure & Atmospheric \\
\hline Melt formation technique & Chemical reaction ( $\sim 30$ second reaction time $)$ \\
\hline Initial melt temperature & $\sim 2300^{\circ} \mathrm{C}$ \\
\hline Melt heating technique & Direct Electrical (Joule) Heating \\
\hline Melt heating method (dry cavity) & Constant power at $210 \mathrm{~kW}^{\mathrm{a}}$ \\
\hline Melt heating method (wet cavity ) & Constant voltage (preserves melt specific power density) \\
\hline Criteria for top cavity flooding & $\begin{array}{l}\text { Any combination of two different thermocouples located } 2.5 \mathrm{~cm} \\
\text { within the concrete indicate arrival of the ablation front }\end{array}$ \\
\hline Top flooding water inlet conditions & $\begin{array}{l}\text { Inlet water temperature: } 15^{\circ} \mathrm{C} \\
\text { Inlet water flowrate: } \sim 2 \text { liters/sec } \\
\text { Sustained water depth over melt: } 25 \pm 5 \mathrm{~cm}\end{array}$ \\
\hline Criterion for bottom water injection & $\begin{array}{l}\text { Passive opening of nozzles once the axial ablation depth reaches } \\
27.5 \mathrm{~cm}\end{array}$ \\
\hline Bottom injection water inlet conditions & $\begin{array}{l}\text { Inlet water temperature: } \sim 15^{\circ} \mathrm{C} \\
\text { Inlet water flowrate: } 3.8 \mathrm{~g} / \mathrm{sec}^{\mathrm{b}} \text { per nozzle, or } 170 \mathrm{~g} / \mathrm{sec} \text { maximum } \\
\text { if all } 45 \text { basemat nozzles are opened } \\
\text { Inlet water pressure at nozzle opening: } 10 \pm 5 \mathrm{kPad}\end{array}$ \\
\hline Test termination criteria & $\begin{array}{l}\text { 1) melt is quenched, or 2) maximum axial ablation depth of } 32.5 \\
\mathrm{~cm} \text { is reached. }\end{array}$ \\
\hline
\end{tabular}

${ }^{\mathrm{a}}$ Based on $150 \mathrm{~kW} / \mathrm{m}^{2}$ design heat flux to top, bottom, and two sidewall concrete surfaces $\left(1.37 \mathrm{~m}^{2}\right.$ area), plus an additional $5 \mathrm{~kW}$ to compensate for a long-term heat losses of $10 \mathrm{~kW} / \mathrm{m}^{2}$ to $\mathrm{MgO}$ sidewalls $\left(0.5 \mathrm{~m}^{2}\right.$ area).

${ }^{\mathrm{b}}$ Corresponds to an average debris cooling rate of $500 \mathrm{~kW} / \mathrm{m}^{2} \mathrm{~g} / \mathrm{sec}$ if all 45 nozzles opened. 


\section{$5.1 \quad$ Test Apparatus}

The overall facility design and test operating procedures for CCI-6 contained many elements that were similar to those used in the CCI tests described in Section 4. However, several changes were made so that the test could serve as an increased scale integral experiment for validation of severe accident codes, and these changes are outlined below. Overall, the facility consisted of a test apparatus, a power supply for Direct Electrical Heating (DEH) of the corium, a top flooding water supply system, a basemat nozzle water supply system, two steam condensation (quench) tanks, a ventilation system to complete filtration and exhaust the offgases, and a data acquisition system. A schematic illustration of the overall setup is provided in Figure 5-1. The apparatus consisted of three rectilinear sidewall sections and a lid. The overall structure was $3.4 \mathrm{~m}$ tall. The two upper sidewall sections had a square internal cross sectional area of $50 \mathrm{~cm} \times 50 \mathrm{~cm}$.

The test section for containment of the core melt was located at the bottom of the apparatus. A top view of this component is shown in Figure 5-2, while a cross-sectional view of the non-electrode sidewalls is provided in Figures 5-3. The test section was enlarged to incorporate a $70 \mathrm{~cm} \times 70 \mathrm{~cm}$ basemat. The concrete sidewalls allowed for $24 \mathrm{~cm}$ of lateral erosion, and the sidewall design was modified to include refractory $\mathrm{MgO}$ with a $\mathrm{UO}_{2}$ pellet/ $\mathrm{U}_{3} \mathrm{O}_{8}$ powder liner. This is the same inert sidewall design that was successfully used behind the tungsten electrodes in all previous CCI tests. Thus, the sidewall design was intended to allow for continued test operation after the maximum lateral ablation depth of $24 \mathrm{~cm}$ was reached. In this manner, the core melt could be stabilized and allowed to proceed downwards to expose the water injection nozzles in the event that the melt was not successfully cooled by top flooding in the early part of the experiment, and/or rapid sidewall erosion occurred.

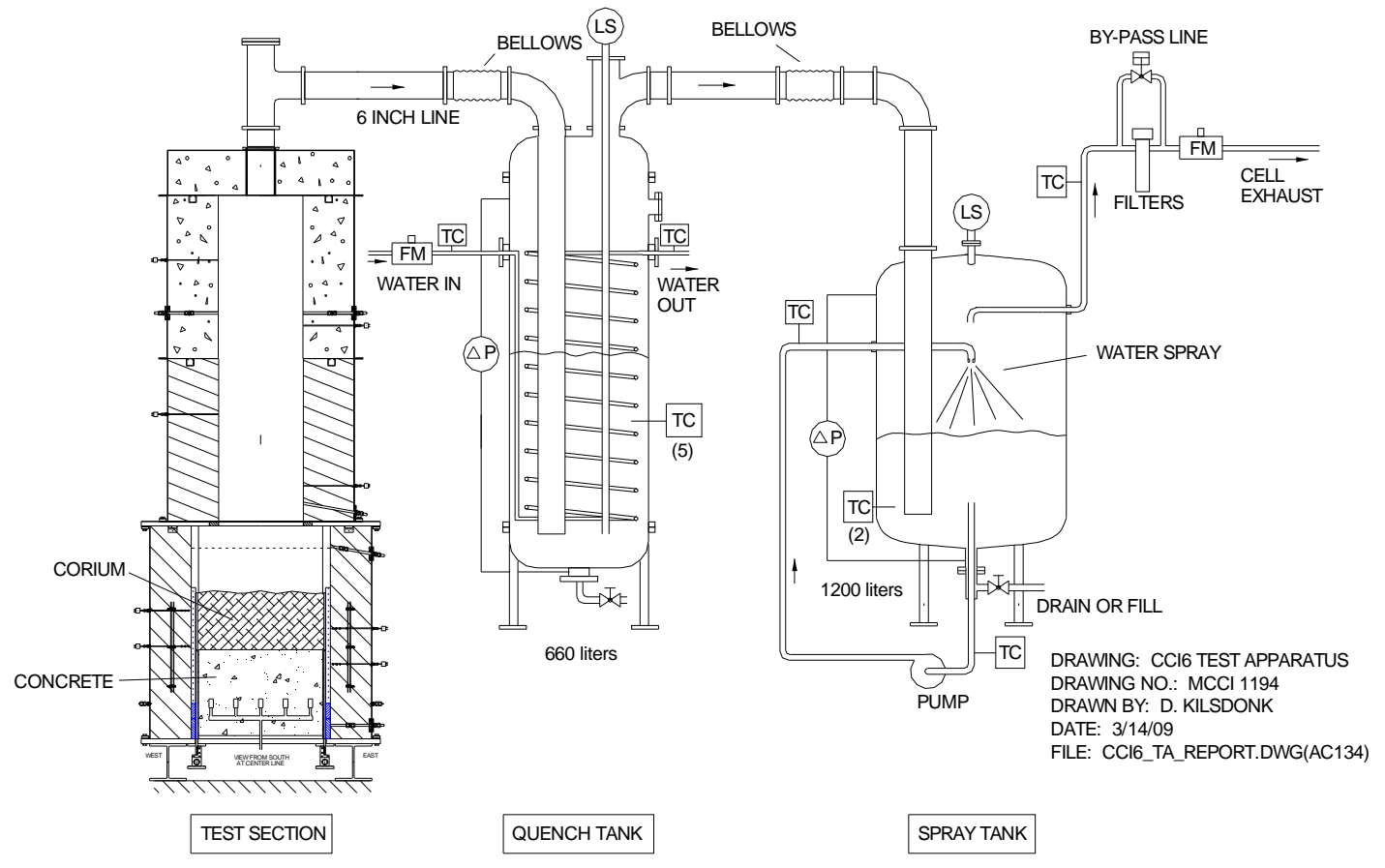

Figure 2-1. Schematic of CCI-6 Test Facility. 
As shown in Figures 52 and 5-3, the basemat and sidewall designs were also modified to include an array of 45 concrete nozzles that were arranged on a $14 \mathrm{~cm}$ lateral pitch. Twenty five of the nozzles were configured in the basemat, while ten nozzles were configured in each of the two concrete sidewalls. The nozzle design details are shown in Figure 5-4. The nozzles were all located at a depth of $27.5 \mathrm{~cm}$ below the initial concrete basemat surface elevation. The nozzles were sealed at the top with PVC pipe caps, and all were fed with water from a common header tank that provided a static net pressure of nominally $10 \mathrm{kPa}$ measured at the upper surface elevation of the nozzles. Once the corium melt reached the $27.5 \mathrm{~cm}$ axial ablation depth, the tops of the nozzles would be eroded through, thereby allowing passive water injection from below to begin the second phase of the experiment. At this point, the melt could be stabilized, or depending upon the extent of cooling, axial ablation could continue. If ablation continued, then the experiment would be terminated once the $32.5 \mathrm{~cm}$ axial erosion depth was reached.

As shown in Figures 5-

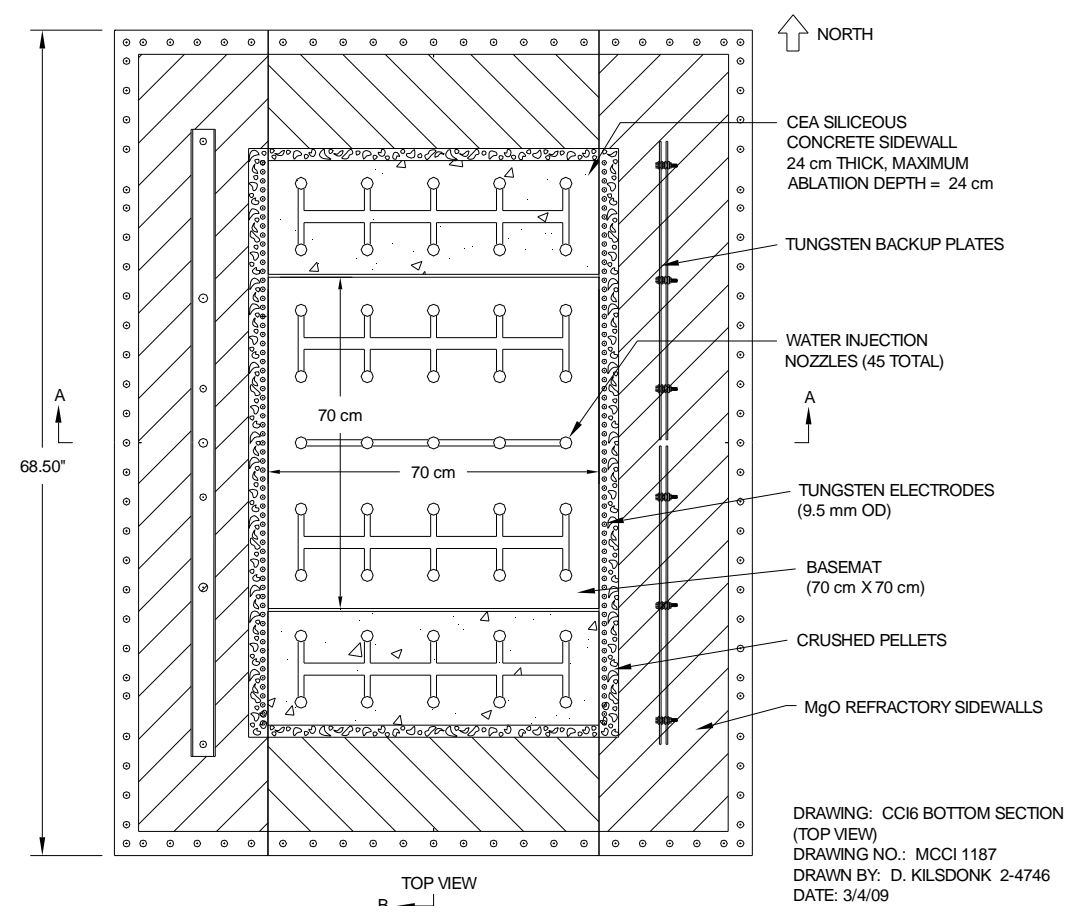

Figure 5-2. Top View of Lower Test Section.

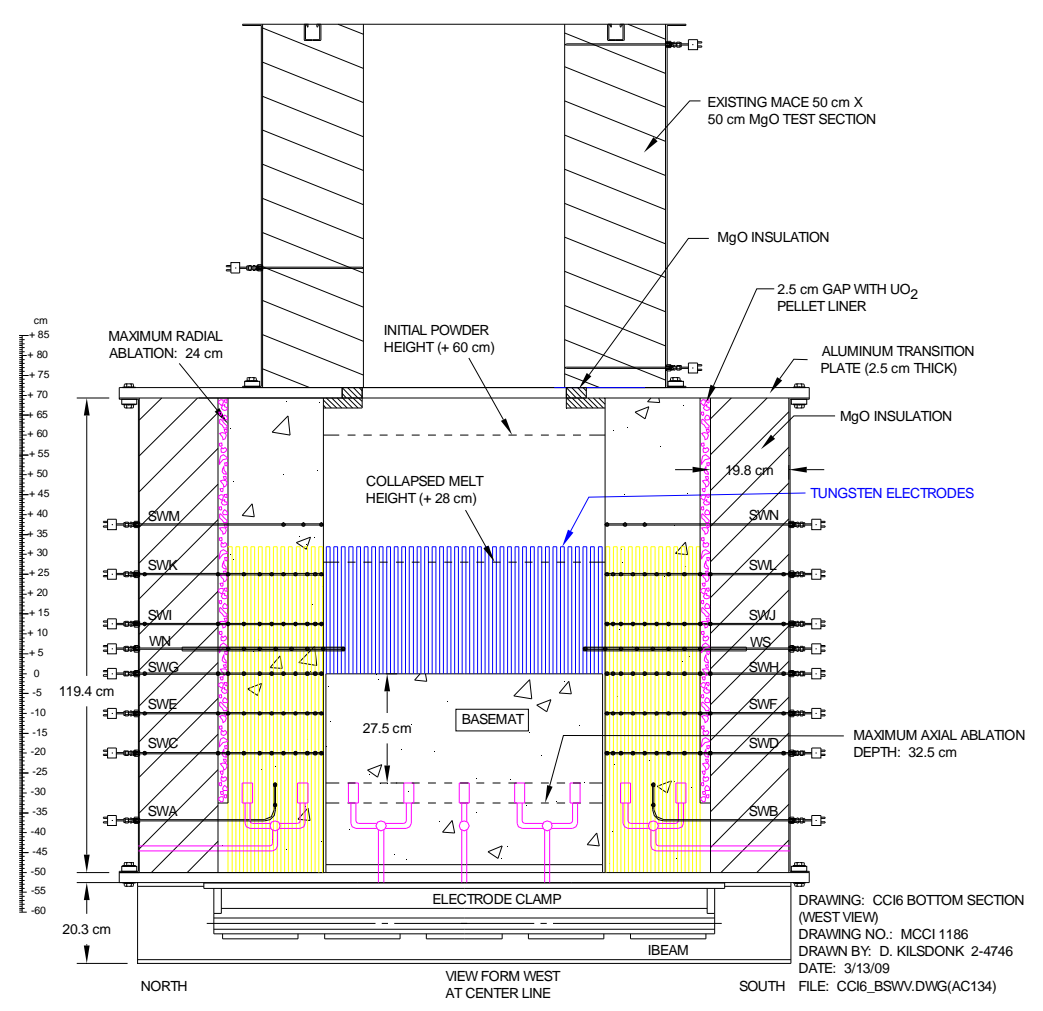

Figure 5-3. Side View of CCI-6 Lower Test Section.

2 and 5-3, the sidewalls of the lower test section were contained within a flanged steel form that was used to secure the unit to the balance of the existing test section components with an 
aluminum transition plate. The flanges allowed the lower sidewalls to be disassembled to reveal the solidified corium following the test. As previously noted, a layer of crushed $\mathrm{UO}_{2}$ pellets and $\mathrm{U}_{3} \mathrm{O}_{8}$ powder was used to protect the interior surface of the $\mathrm{MgO}$ sidewalls against thermochemical attack by the corium. For the electrode sidewalls, molybdenum and tungsten plates were embedded in the $\mathrm{MgO}$ to stop erosion in case the $\mathrm{UO}_{2} / \mathrm{U}_{3} \mathrm{O}_{8}$ protection layer failed. Multijunction Type $\mathrm{K}$ and Type $\mathrm{C}$ thermocouple assemblies were cast within the sidewalls so that the time-dependent heat loss from the melt could be calculated from the local temperature gradient and the thermal conductivity of the $\mathrm{MgO}$.

The melt was produced through an exothermic chemical reaction yielding the target mass over a timescale of $~ 30$ seconds. After the chemical reaction, DEH simulating decay heat was applied through two banks of tungsten electrodes. As shown in Figure 5-2, the electrodes lined the interior surfaces of the two opposing $\mathrm{MgO}$ sidewalls. The electrodes were $9.5 \mathrm{~mm}$ in diameter and aligned in a row with a pitch of $1.9 \mathrm{~cm}$. They were attached by copper clamps and water-cooled buss bars to a $560 \mathrm{~kW}$ AC power supply. The electrodes spanned a total width of $120 \mathrm{~cm}$ on each sidewall of the lower section. At the start of the experiment, the electrical current was drawn through the center, $70 \mathrm{~cm}$-wide section of electrodes that were in direct contact with the melt. As the test progressed and the concrete sidewalls were eroded, additional electrodes would be exposed to the corium. Current would be drawn through these newly exposed heating elements, thereby maintaining a uniform internal heat pattern in the melt over the course of the experiment. With the overall electrode span of $120 \mathrm{~cm}$, the entire $24 \mathrm{~cm}$ of lateral sidewall erosion could be accommodated on both sides of the test section while ensuring that the entire melt cross-sectional area was in contact with the electrodes.

A few minutes after the melt was formed, ablation of the concrete basemat and sidewalls would commence. As shown in Figure $5-1$ a $15 \mathrm{~cm}$ diameter gas line was used to vent the helium cover gas and the various gas species arising from the core-concrete interaction into two adjacent quench tanks that were partially filled with water. In the early initial phase of the experiment when the cavity was dry, the tanks served to cool the off-gases and filter aerosols generated from the core-concrete interaction. After the cavity was flooded, the tanks served to condense the steam and, based on the measured condensation rate, provide data on the corium cooling rate. In either case, the helium covergas and non-condensables $\left(\mathrm{CO}, \mathrm{CO}_{2}\right.$, and $\left.\mathrm{H}_{2}\right)$ passed through the tanks and were vented through an off gas system that included a demister and filters. The gases were eventually exhausted through the containment ventilation system and a series of high efficiency filters before finally being released from the building stack.

Soon after concrete erosion began, the cavity was flooded using an instrumented water supply system. During this stage of the test, the water entered the test section through two weirs located in the opposing (non-electrode) sidewalls of the top test section. The supply tank was pressurized and water was injected using gas pressure as the driving force to push water through the interconnected piping to the test section weirs. Makeup water was periodically added to maintain the water level in the test section at nominally $25 \pm 5 \mathrm{~cm}$. This was an increased scale test, and so the system was set up to recycle water from the quench system overflow tanks to the water supply tank as the test progressed. 
As concrete erosion proceeded, the point would eventually be reached at which the porous concrete nozzles in the basemat would open by ablation. When the axial ablation depth reached a predefined level, isolation valves that separated the nozzle header tank from the nozzles would be opened in preparation for water injection from below. The total head included that required to offset the melt hydrostatic head, which was estimated as $\sim 23.6 \mathrm{kPa}$. Thus, the header tank was configured in the test cell to provide a static water height of $3.45 \mathrm{~m}$ to the nozzles. The plenum of the header tank was attached by a pressure equilibration line to the test section plenum to ensure that the proper head was maintained as the test section plenum pressure fluctuated. As the quench process progressed, makeup water to the header tank would be provided automatically by a water supply line that included a float switch so that the net head would be maintained in the range of $10 \pm 0.1 \mathrm{kPad}$.

After a specified time with water present in the cavity, the option was provided to break the crust formed at the melt-water interface with an insertable crust lance to obtain data on the crust breach cooling mechanism. As for the CCI tests (see Section 4), the lance was made from $2.54 \mathrm{~cm}$ diameter, 304 stainless steel rod with a pointed tip. The driving force for the lance was simply a $450 \mathrm{~kg}$ dead weight that was remotely lowered with the crane during the test. The lance was equipped with a load cell to measure applied load and a displacement transducer to measure lance tip elevation in the test section.

As shown in Table 5-1, the composition of the CCI-6 concrete basemat and sidewalls was specified to be of the siliceous type. The sand and aggregate for the mix were supplied by CEA as an in-kind contribution to the program. The chemical composition for this concrete is provided in Table 5-2. This composition is based on analysis of a specimen taken from the CCI6 concrete archive sample that was produced during pouring of the test section sidewalls and basemat. The concrete density was calculated to be $2341 \mathrm{~kg} / \mathrm{m}^{3}$ based on the measured mass and volume of the archive sample. Instrumentation locations within the sidewalls and basemat are described below.

The corium oxide phase composition for CCI-6 was specified to be a fully oxidized core melt containing $6 \mathrm{wt} \%$ calcined concrete as an initial constituent. The melt composition at start of the interaction with the concrete basemat is shown in Table 5-3. The compositions of the 
concrete additives were consistent with the siliceous concrete used for the sidewalls and basemat for the test. Aside from lowering the melting point of the mixtures [61], the additives were incorporated to account for concrete erosion that is expected to occur during the corium spreading phase following breach of the Reactor Pressure Vessel (RPV) [62].

The CCI-6 facility was instrumented to monitor and guide experiment operation and to $\log$ data for subsequent evaluation. Principal parameters that were monitored during the course of the test included the power supply voltage, current, and gross input power to the melt; melt temperature and temperatures within the concrete basemat and sidewalls; crust lance position and applied load; supply water flow rate to the test section weirs as well as to the concrete nozzles; water volume and temperature within the test apparatus, and water volume and temperature within the quench system tanks. Other key data recorded by the DAS included temperatures within test section structural sidewalls, off gas temperature and flow rate, and pressures at various locations around the system. Measurement uncertainties for all instruments are provided in [63].

The concrete sidewall instrumentation locations for CCI-6 are shown in Figure 5-3, while a plan view of the basemat thermocouple layout is provided in Figure 5-4. Both the basemat and sidewalls were instrumented with multijunction Type $\mathrm{K}$ thermocouple assemblies to determine the 2$\mathrm{D}$ ablation profile as a function of time. In addition, multiple Type C thermocouple assemblies that were protected by tungsten thermowells were mounted vertically within the basemats and horizontally through the concrete sidewalls. The purpose of these instruments was to provide data on the axial and lateral melt temperature distributions versus time. Other significant test instrumentation included a stationary (lid mounted) video camera for observing physical characteristics of the core-

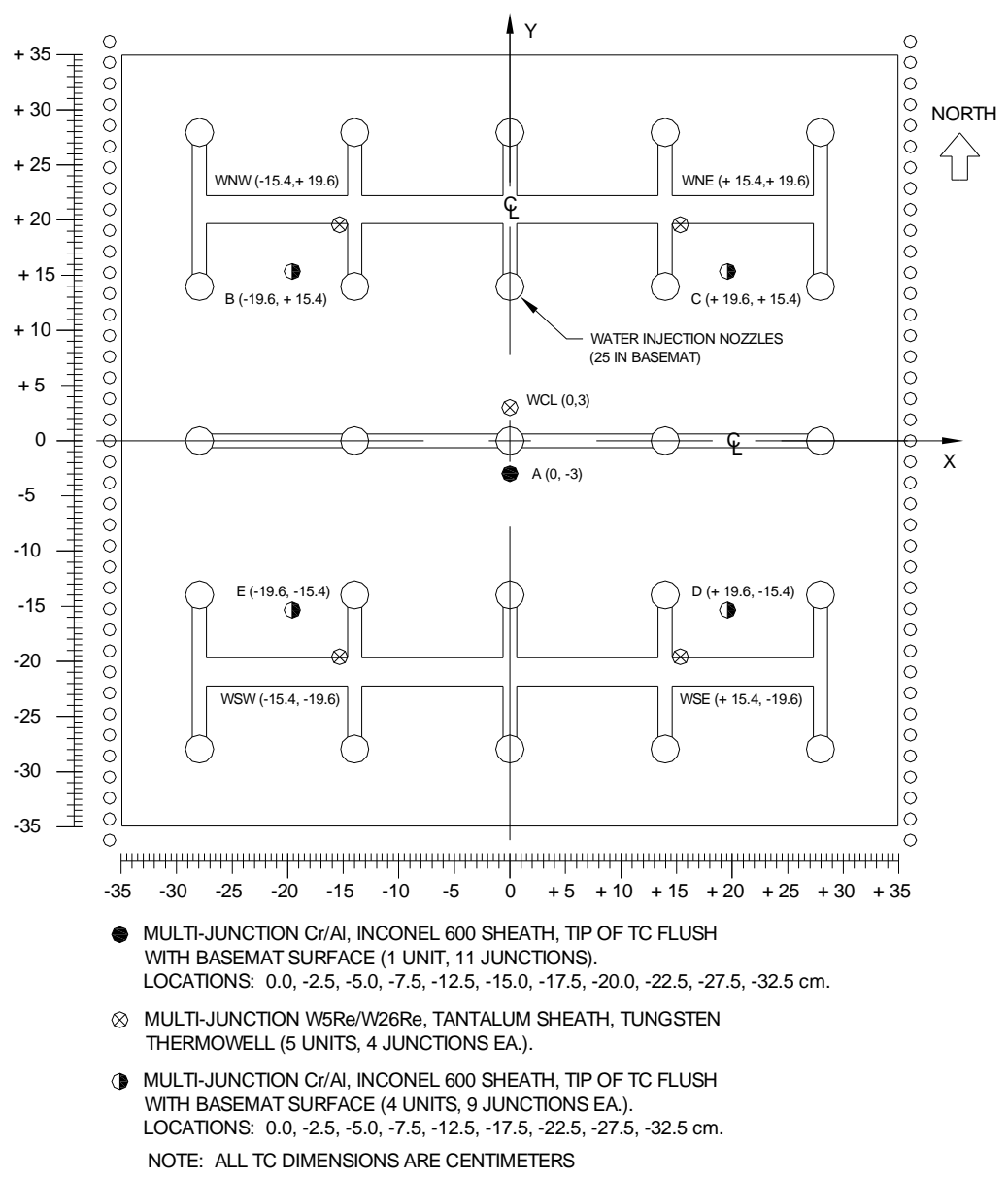

Figure 5-4. Plan View of CCI-6 Basemat Instrumentation. concrete interaction. 


\subsection{Results and Discussion}

Key thermalhydraulic results from the test included the DEH input power and the corresponding melt temperatures, lateral and axial concrete erosion rates, information on crust strength and morphology provided by the crust lance, and finally the debris water heat flux. The input power, ablation rate, and debris-water heat flux data are provided in Figures 5-5 through 5-7, respectively, while melt temperature data measured near the test section centerline and the two concrete walls are shown in Figure 5-8.

Unlike previous CCI tests, the operating procedure for CCI- 6 called for early cavity flooding soon after cavity ablation was established (see Table 5-1). In actuality, water was added $\sim 40$ seconds after the melt pool was formed, as opposed to after cavity ablation was initiated (see Table 5-1). ${ }^{6} \quad$ Thus, the initial cooling behavior was indicative of a corium melt pool containing 6 wt $\%$ siliceous concrete interacting with a concrete crucible in which the concrete surfaces were protected by insulating crusts. Despite the relatively low heat transfer rate to the concrete through the crusts, the initial debris cooling rate was quite high (i.e., $5 \mathrm{MW} / \mathrm{m}^{2}$ ), and melt eruptions were observed over the first 3 minutes of the melt-water interaction (Figure 5-7). Although cavity ablation was not occurring during this interval, concrete heatup was nonetheless occurring which resulted in the release of concrete decomposition gases. The gas release in turn caused melt eruptions. Due to the low concrete content of the corium the crust

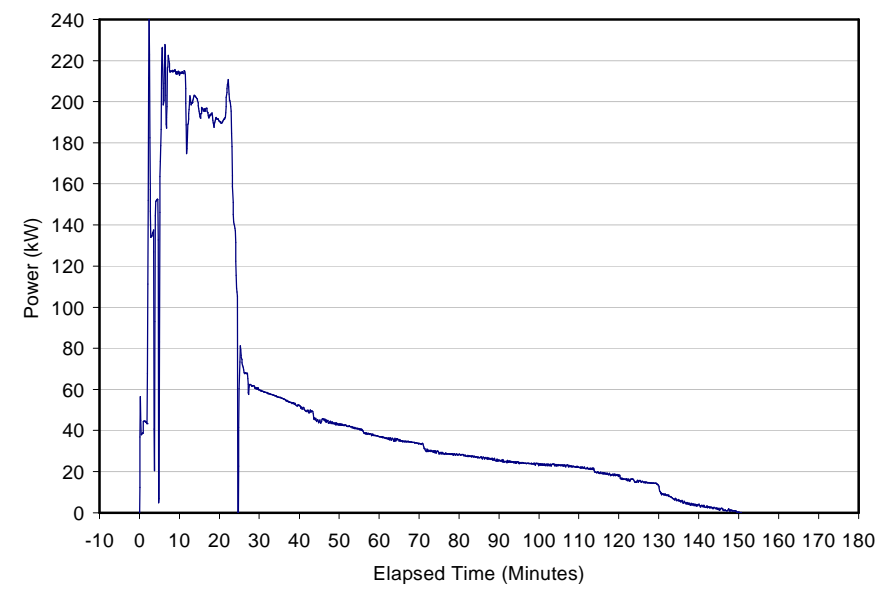

Figure 5-5. CCI-6 DEH Input Power.

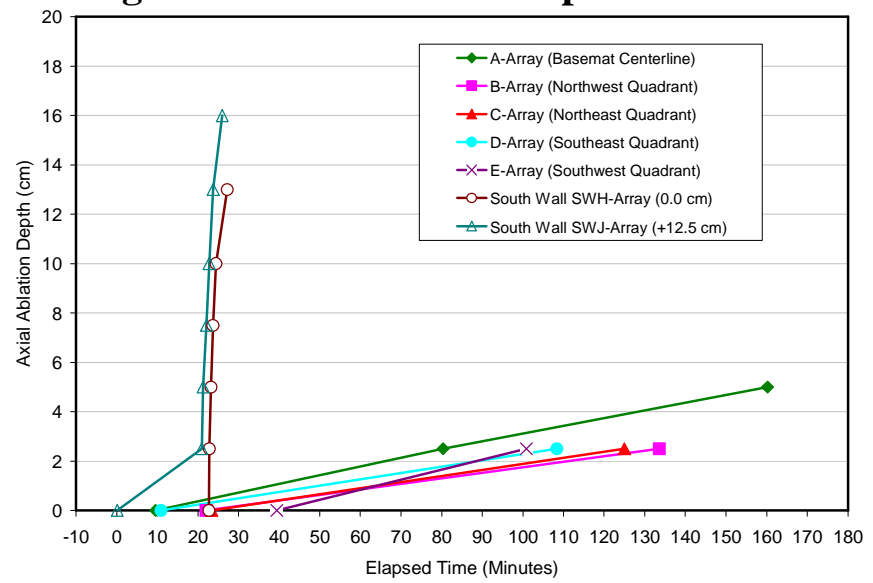

Figure 5-6. CCI-6 Axial and Radial Ablation Depth Data vs. Time.

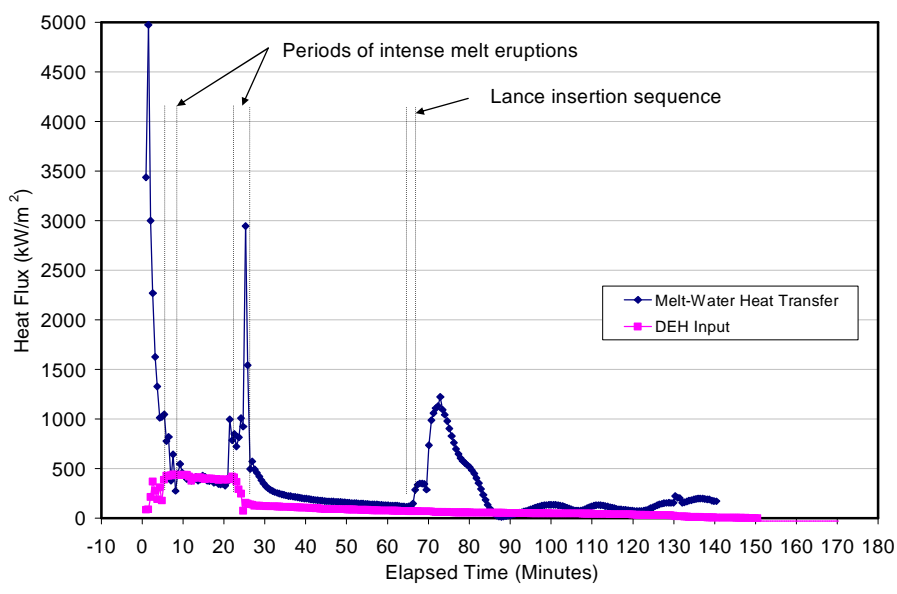

Figure 5-7. CCI-6 Top Flooding Debris-Water Heat Flux.

${ }^{6}$ Early addition was performed to reduce the temperature of the gas issuing into the cell through the failed test section main steamline [63]. This occurrence did not affect the fidelity of the test data, as sufficient instrumentation was available to provide the data required to calculate the debris-water steaming rate using other methods [63]. 
dryout limit was fairly high $\left(>200 \mathrm{~kW} / \mathrm{m}^{2}\right.$ based on the SSWICS correlation [3]). Thus, water ingression into the fractured crust may have also contributed to the early high debris cooling rate.

After 10 minutes, onset of axial ablation began. Thereafter, axial ablation proceeded slowly but steadily at a rate of $\sim 2$ $\mathrm{cm} /$ hour over the balance of the test. The lance insertion data suggested that the concrete surface was covered by a $2-3 \mathrm{~cm}$ thick crust at $\sim 60$ minutes into the test sequence, which may explain the slow but steady ablation behavior. The radial ablation characteristics were quite different from the axial case (Figure 5-6). The sidewall melt temperature thermocouple readings (Figure 5-8) showed that both walls were initially protected by corium crusts. However, at 21 minutes a rapid ablation burst was initiated on the south concrete wall, leading to an average ablation rate of $\sim 2.7 \mathrm{~cm} / \mathrm{min}$ as the ablation proceeded to a depth of $16 \mathrm{~cm}$ before stabilizing. Assuming that the ablation progression was driven by convective heat transfer from the melt, then the local heat flux to the concrete required to sustain this ablation rate is of the order of $2 \mathrm{MW} / \mathrm{m}^{2}$ [63]. Following this transient, additional sidewall ablation was terminated by water ingression at the core/concrete interface.

Data from the experiment further illustrated the local coupling between the cavity erosion behavior and the melt pool thermalhydraulics. In particular, melt temperature measurements indicate that the ablation transient in the south concrete wall was initiated at 21 minutes by failure of the crust that protected that surface during the early phase of the experiment. Over the next six minutes, melt temperatures near the

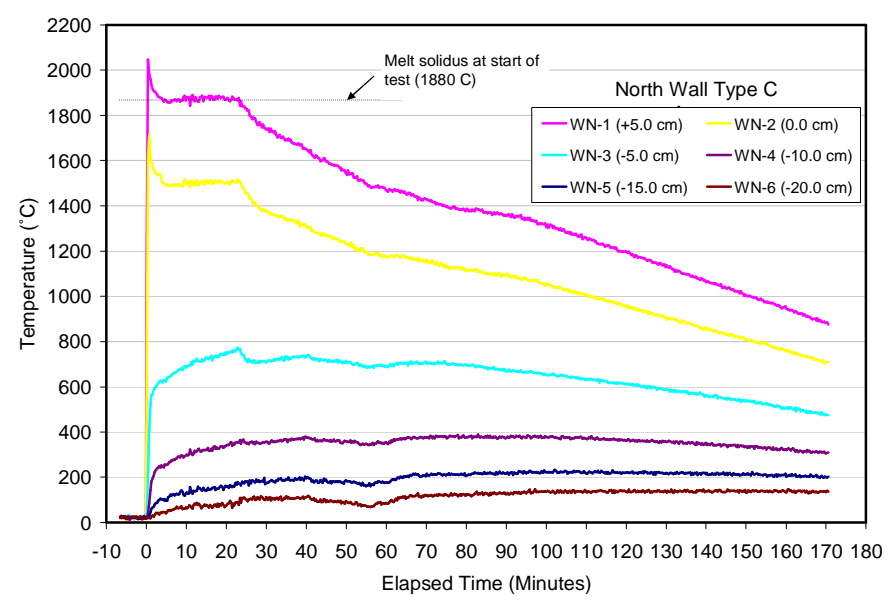

(a)

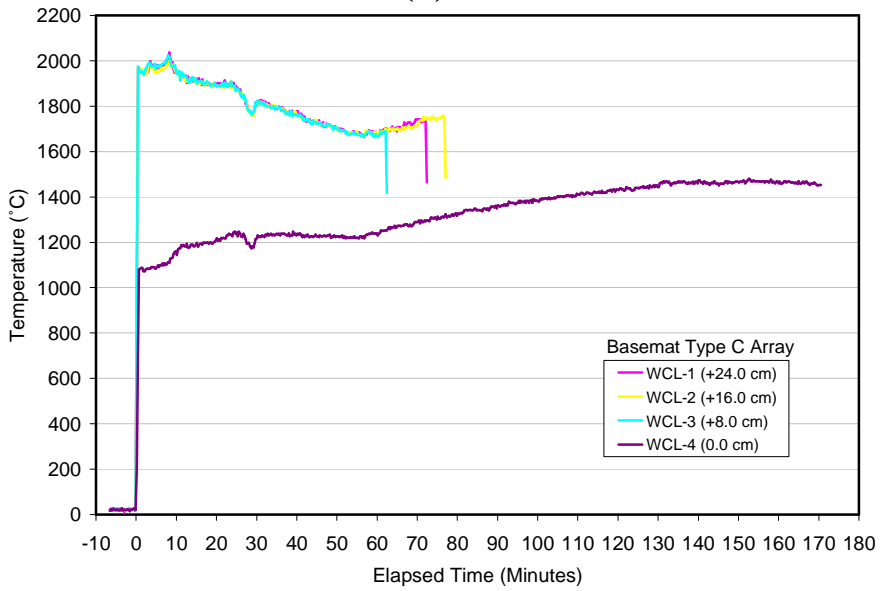

(b)

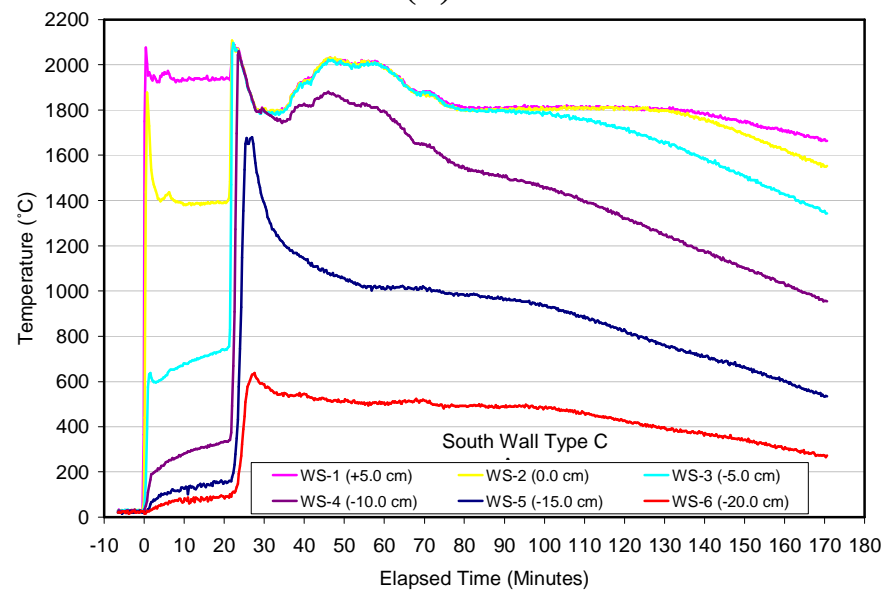

(c)

Figure 5-8. Melt Temperatures Measured (a) Radially Near North Concrete Wall, (b) Axially Near Test Section Centerline, and (c) Radially Near South Concrete Wall. (junction locations are relative to initial concrete surface locations). 
south wall dropped steadily until reaching a plateau at $\sim 27$ minutes. The plateau occurred at about the same time as the ablation transient in the wall terminated. One interpretation of this process would be that the sensible energy driving the ablation during this transient was provided by the melt fairly close to the south wall, as opposed to bulk energy extraction from the entire melt volume. In particular, given the measured melt temperature drop adjacent to the wall as well as the

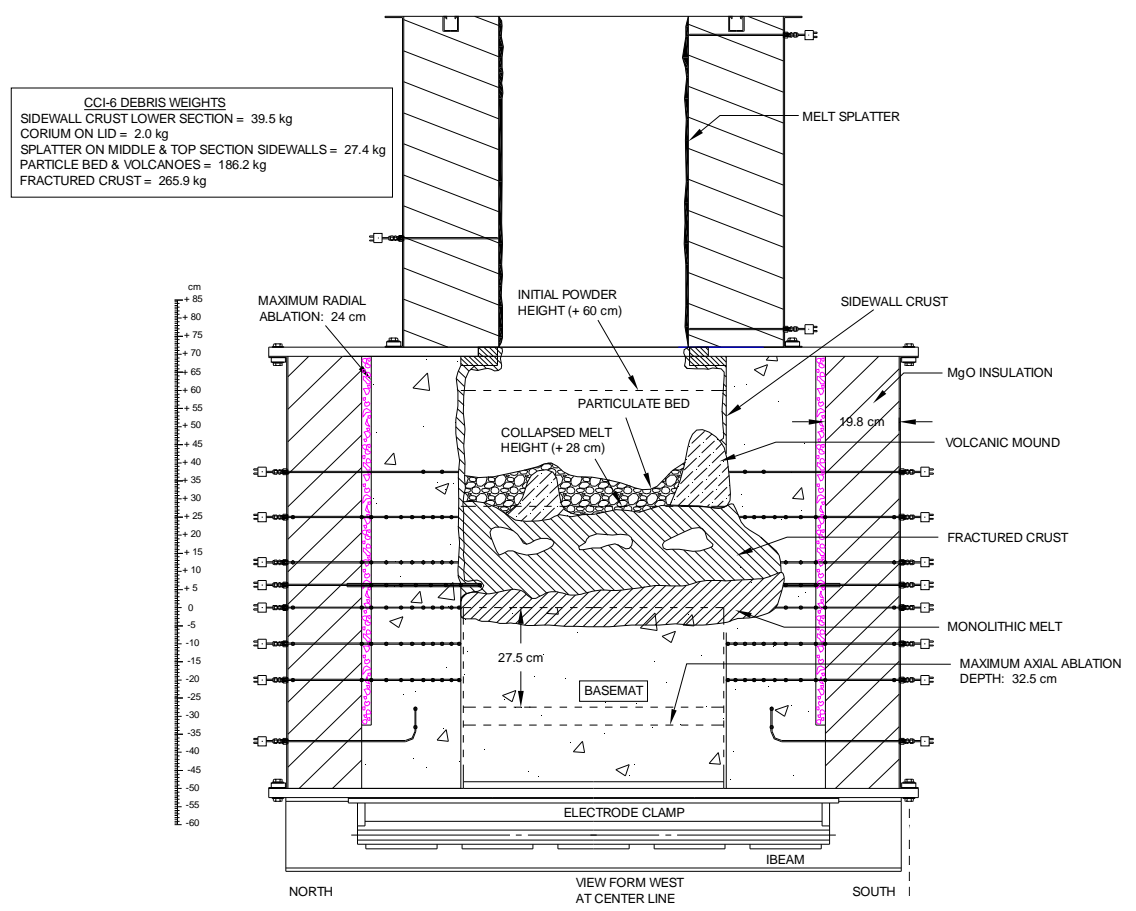

Figure 5-9. Rendering of CCI-6 Posttest Debris Configuration. known mass of eroded concrete, then a simple energy balance reveals that the energy required to erode the concrete would have been extracted from a melt mass of $\sim 340 \mathrm{~kg}$, which amounts to $38 \%$ of the initial melt mass used in the experiment. Another plausible explanation ${ }^{7}$ for the temperature transient near the wall is based on a cement paste liquefaction concept wherein the siliceous aggregate was only partially melted when the crust disappeared. This relatively cold material was then introduced into the melt pool once the crust failed, causing the temperature decrease. After the aggregate melted, the pool temperature was then able to rise again.

Following the transient, the concrete temperature data temperature indicates that additional ablation was minimal. The lack of bubble-induced convection within the melt from concrete decomposition resulted in large temperature gradients across the extent of the test section that ranged up to $500^{\circ} \mathrm{C}$ or more (Figure 5-8). The disparity was enhanced by the fact that the corium for this test contained a very low initial concrete content. Thus, the melt may have been quite stiff in the measured temperature range, and conduction within the debris would not have been negligible. Under these conditions, large temperature gradients developed. By the end of the experiment, temperatures varied from 700 to $1680^{\circ} \mathrm{C}$ across the extent of the debris.

Heat removal to overlying water over the course of the experiment was substantial; amounting to $\sim 1400 \mathrm{MJ}$ by the time power input was terminated at 150 minutes. This level of heat extraction can be compared with the $\sim 1080 \mathrm{MJ}$ initial energy content of the melt, as well as the $450 \mathrm{MJ}$ of heat input from $\mathrm{DEH}$ during the test. The large degree of heat removal to overlying water is also consistent with both the power supply response and the posttest debris morphology (Figure 5-9). In particular, the input power fell from $\sim 210 \mathrm{~kW}$ to $\sim 70 \mathrm{~kW}$ during

\footnotetext{
${ }^{7}$ M. Cranga and J.-M. Bonnet, IRSN, personal communication (e-mail) to M. T. Farmer, ANL, 28 September 2010.
} 
the rapid sidewall ablation phase. Since input power in constant voltage operation is inversely proportional to the size of the electrical conductor, this level of power reduction is consistent with the loss of $\sim 65 \%$ of the debris from the melt zone in the form of cooled core material. Furthermore, the posttest debris examinations indicated that over $50 \%$ of the debris had been quenched in the form of a coolable debris configuration by the end of the test (i.e., $186 \mathrm{~kg}$ particle bed from eruptions, as well as $266 \mathrm{~kg}$ fractured crust from water ingression); the morphology of this material is illustrated in Figure 5-10. Furthermore, the lance insertion sequence indicated that a loose debris structure had been formed by 60 minutes into the experiment sequence which is consistent with early, aggressive debris cooling. In terms of melt eruption characteristics, analysis of the data indicates that the melt entrainment coefficient averaged over the course of the test was $0.04 \%$. As noted by Bonnet and Seiler [64], this value is in the range where debris cooling and stabilization can be achieved on the basis of melt eruptions alone.

In summary, the CCI-6 was operationally successful, despite early melt through of the main steamline. The debris cooled exceptionally well, particularly in light of the fact that the test was conducted with siliceous concrete which has relatively low gas content. The debris-water heat flux, power supply response, and posttest debris morphology were all consistent with very good cooling. The question arises as to why this test cooled so well relative to previous tests conducted in the OECD/MCCI and MACE experiment programs. Differences between this experiment and those conducted previously include: i) increased scale, ii) early cavity flooding, iii) lowest initial concrete content in the melt (6 wt \%), and iv) crust anchoring did not occur that confounded coolability demonstration in the previous MACE experiment program. Finally, another difference between this test and virtually all tests conducted in the MACE program is that CCI-6 utilized a 2-D concrete crucible, as opposed to the 1-D configuration used in MACE. With respect to cooling mechanisms, the test also demonstrated that melt eruptions are viable for siliceous concrete, and that water ingression into fractured crust material is very effective for low concrete melts. Unfortunately, due to the relatively good cooling that was experienced early on, no data on bottom water injection cooling at large scale was obtained as the axial erosion depth realized in the test was limited to a few centimeters.

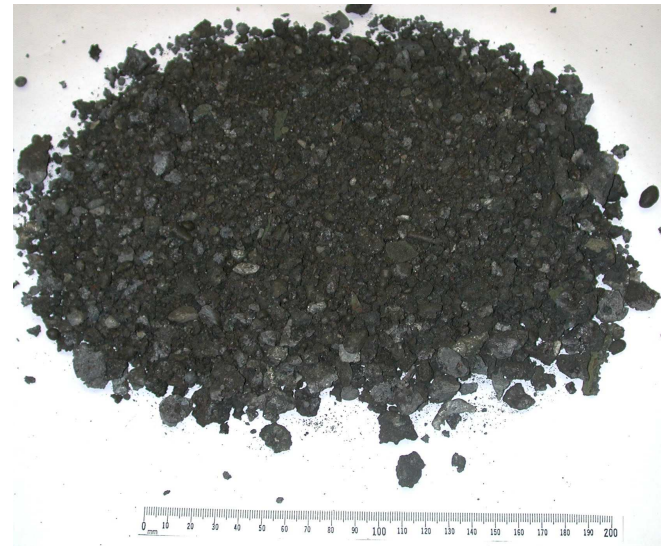

(a)

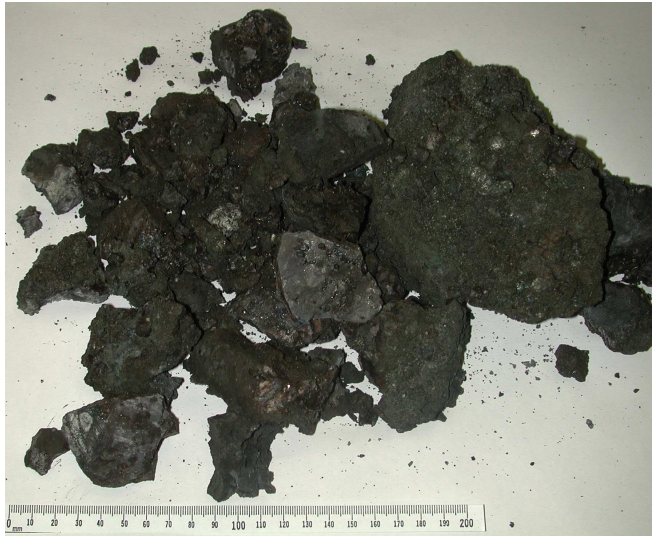

(b)

Figure 5-10. Photographs of (a) Particle Bed and (b) Fractured Crust Debris Regions. 


\subsection{SUMMARY AND CONCLUSIONS}

Based on the findings from previous MACE and OECD/MCCI programs, a broad workscope was defined for the follow-on MCCI-2 program. The workscope was divided into the following four categories:

1. Combined effect tests to investigate the interplay of different cooling mechanisms, and to provide data for model development and code assessment purposes.

2. Tests to investigate new design features to enhance coolability, applicable particularly to new reactor designs.

3. Tests to generate two-dimensional core-concrete interaction data.

4. Integral tests to validate severe accident codes.

In addition to the experimental work, an analysis task was defined to develop and validate coolability models to form the basis for extrapolating the experiment findings to plant conditions.

In Category 1, four separate effects tests were completed in the SSWICS test facility that was developed as part of the MCCI-1 program to investigate water ingression cooling under inert basemat conditions, as well as crust strength. The effect of gas sparging on the water ingression cooling was investigated in two tests (i.e. SSWICS-8 and SSWICS-11) by injecting argon through capillaries embedded within the basemat. Gases generated at the bottom of the melt rose up through the corium due to buoyancy and this had the potential to create melt porosity, which may supplement the fissures induced by thermal stress cracking and enhance water ingression cooling. The composition of both melts was $56 \% \mathrm{UO}_{2}, 23 \% \mathrm{ZrO}_{2}, 7 \% \mathrm{Cr}$, and $14 \%$ siliceous concrete, identical to that of SSWICS-6 in the first quench series. For SSWICS-8, the ends of the capillaries were flush with the surface of the basemat, i.e., at the level of the corium $/ \mathrm{MgO}$ interface at the bottom of the melt. The test data indicated that the sparging gases travelled around the melt rather than through it, and so the test was effectively a repeat of SSWICS-6 and could not provide an indication of the effects of sparging gases. It did, however, serve to demonstrate test repeatability as the cooling rates of SSWICS-6 and -8 are well matched. SSWICS-11 was a repeat of SSWICS-8 with capillaries extended $50 \mathrm{~mm}$ above the basemat to discourage gases from circumventing the melt. The modification proved successful and SSWICS-11 cooled considerably faster than either SSWICS-8 or -6 . Moreover, the morphology of the ingot was unusual, exhibiting a porous structure lacking in any of the previous ingots. The test indicated that the sparging gases can indeed markedly influence both the morphology and cooling rate of the corium.

The SSWICS-9 and SSWICS-10 tests were carried out to address the possibility that cutting ingots into thinner sections contributes to the existing crack structure and weakens samples before load testing. Ingots produced by the first seven tests in MCCI-1 were sectioned because, at a height of $15 \mathrm{~cm}$, they were too thick to fail in the desired mode when loaded with the apparatus designed to measure sample strength. This uncertainty was eliminated for the new tests by reducing the corium charge to $25 \mathrm{~kg}$ so that the quench process produced a $5 \mathrm{~cm}$ high ingot that could be load tested without first experiencing the sectioning process. Both SSWICS- 
9 and -10 quench tests successfully created the desired ingots, but only Ingot-10 was sturdy enough to survive removal from the quench test apparatus and placement into the loading apparatus. Ingot-9 broke apart upon removal from the basemat. The chemical composition of Ingot-10 was $61 \% \mathrm{UO}_{2}, 25 \% \mathrm{ZrO}_{2}, 6 \% \mathrm{Cr}$, and $8 \%$ siliceous concrete, identical to that of Ingot-2 in the first quench series. The measured strength of Ingots- 2 and -10 were $1.1 \pm 0.2 \mathrm{MPa}$ and 1.0 $\pm 0.3 \mathrm{MPa}$, respectively, effectively identical given the level of measurement uncertainty. Though only a single measurement of the strength of an uncut crust sample was obtained, it supports the notion that the cutting process did not unduly weaken the samples. Moreover, it is noted that Ingot-9 proved too fragile for loading in part because it did not bond to the $\mathrm{MgO}$ liner. All the samples suitable for loading, both cut and uncut, were supported in part by this outer ring of $\mathrm{MgO}$. This suggests that the $\mathrm{MgO}$ contributed to the effective strength of the ingots and that the measurements are conservative.

In Category 2, one large scale water-cooled basemat integral effect test was conducted to provide data on the cold-crucible method for melt stabilization, and two separate effect tests were carried out to provide data on the melt fragmentation method for melt stabilization. The specific objective of the Water-Cooled Basemat test (WCB-1) was to provide prototypic data on the transient evolution and stabilization of a core melt in a generic water-cooled core catcher design for advanced plant applications. The experiment approach was to incorporate a water-cooled basemat into the core-concrete interaction test apparatus used for the CCI tests. The basemat was composed of five parallel water channels that were instrumented to provide both local and global data on the plate heat transfer performance. The basemat was covered with a layer of sacrificial concrete that was ablated by the overlying melt at the start of the experiment. Eventually, the melt approached, and then was thermally stabilized at, the interface of the watercooled plate. The results from the test indicate that the up-down power split was heavily biased upwards to the overlying water pool that was added on top the melt as the ablation front approached the plate. In general, the plate was successful in cooling and stabilizing the core melt, although several hot spots developed on the plate as the experiment progressed, and the input power was reduced on that basis. However, the hot spots were noted to form on the ribbing between coolant channels, and additional analysis is needed to determine if the hot spots are problematic, or indicative of the heat removal that would be expected from a ribbed plate design. Due to the longer timeframe associated with this type of test, Direct Electrical Heating (DEH) was used to simulate decay heat within the melt to provide sufficient time for the melt to come to thermal equilibrium over the plate.

The SSWICS-12 and SSWICS-13 tests were carried out in the SSWICS test facility to provide data on the melt fragmentation cooling mechanism. The objective of the first test was to evaluate the effect of pressure head on the debris cooling rate using a porous concrete nozzle design. The experiment approach was to install four nozzles into the inert $\mathrm{MgO}$ basemat of the SSWICS apparatus; each nozzle was fed by a different header tank, and the four tanks were positioned at different elevations in the test cell in order to vary the water head to each nozzle. The test section was divided into four quadrants using a tungsten cruciform, with one nozzle in each quadrant. This design basically allowed four tests to be conducted simultaneously. The objective of the second test was to examine the influence of concurrent noncondensable (i.e., $\mathrm{N}_{2}$ ) gas injection on the local debris cooling rate, since the presence of non-condensable gas during 
melt-water interaction is postulated to suppress the possibility of an energetic interaction. For this test, four stainless steel tube nozzles were incorporated into the basemat; two were fed with water only, while the other two were fed with a gas-water mixture. A tungsten cruciform was used for this test to separate the test section into two sectors; the first side contained the waterfed nozzles, while the second contained the water-gas mixture nozzles. All four nozzles were fed with the same driving pressure. This approach thus allowed two tests to be conducted simultaneously. The results of both of these experiments confirmed that melt cooling by bottom water injection is an effective method for quenching the core melt. The results of SSWICS-12 showed that the water head on the nozzles had no discernable effect on the debris quenching rate in the range that was investigated (viz. 0.05-0.2 bar). All four porous concrete nozzles that were used in this test opened upon melt contact and provided a pathway for water to enter the melt. For SSWICS-13, the concurrent gas injection was found to have a negligible impact on the average debris quenching rate relative to that measured for pure water. In this test, three of the four nozzles opened upon melt contact, while the fourth opened briefly and then plugged for the balance of the test. The nozzle that plugged was intended to inject the water-gas mixture.

Tests CCI-1 through CCI-3 conducted as part of the MCCI-1 program principally addressed the effect of concrete type on 2-D cavity erosion behavior and late phase debris coolability. In Category 3, two additional tests were conducted in order to expand the parameter space addressed in the series. In particular, Test CCI-4 examined the influence of core melt composition on cavity erosion behavior and coolability. The specific objectives were to: i) increase the metal content of the melt to the highest practical level to more accurately mock up a prototypic BWR core melt composition at the time of vessel failure, and ii) modify the apparatus design to increase the duration of the dry core-concrete interaction phase. Conversely, Test CCI5 focused on examining the influence of melt pool aspect ratio on the radial/axial power split under dry cavity conditions. The specific objective was to increase the test section aspect ratio (i.e., test section width/melt depth) to the greatest extent possible to more accurately mock up prototypic conditions.

In terms of meeting program objectives, both tests CCI-4 and CCI-5 provided valuable data on 2-D cavity erosion behavior. However, neither test unfortunately provided debris coolability data that would have augmented the information gathered as part of the MCCI-1 program. For test CCI-4, the cavity was flooded but direct melt-water contact was precluded by the presence of a large mantle crust that formed in the upper regions of the test section due to extensive melt foaming that occurred over the course of the experiment. For CCI-5, the cavity was not flooded due to plugging of the main gas line for the apparatus. Thus, the following conclusions focus on core-concrete interaction behavior as opposed to debris coolability. The reader is referred to the MCCI-1 program final report for conclusions that were drawn regarding debris coolability under late flooding conditions based on MCCI-1 test results. However, valuable information regarding coolability under early flooding conditions was obtained as part of the CCI-6 experiment that is summarized below.

In terms of the findings from the CCI test series, all tests showed the overall trend of decreasing melt temperature as ablation progressed, which was due to a heat sink effect as relatively cool concrete slag was introduced into the melt, as well as the increasing heat transfer 
surface area as the melts expanded into the concrete crucibles. The reduction in melt temperature may have further reflected the evolution of the pool boundary freezing temperature that decreased as additional concrete was eroded into the melt over the course of the tests.

All tests also showed evidence of initial crust formation on the concrete basemat and sidewalls that resulted in an incubation period in which the ablation rates were very low and the melt temperature was relatively stable. These results are consistent with the TURC tests conducted at Sandia with in-vessel [i.e., $(\mathrm{U}, \mathrm{Zr}) \mathrm{O}_{2-\mathrm{x}}$ ] melts that were poured into concrete crucibles and allowed to cool with no further heating. The duration of the incubation period appeared to be inversely proportional to concrete gas content, which suggests that crust failure may be driven in part by the mechanical forces that arise from the production of decomposition gases at the core-concrete interface. Crust formation was stochastic, with some surfaces exhibiting initial crust formation while other surfaces did not.

Early initial exothermic oxidation of cladding for a partially oxidized melt caused a rapid transient increase in melt temperature of $\sim 100^{\circ} \mathrm{C}$, but once the cladding was oxidized, both the melt temperature and overall cavity ablation behavior approached that observed under fully oxidized conditions.

Long-term ablation behavior was found to be closely linked to concrete type. Lateral and axial ablation rates for the LCS concrete tests were virtually indistinguishable. Thus, the lateral/axial heat flux ratio for this concrete type was $\sim 1$. The relatively uniform power split for the LCS concrete tests can be contrasted with the results of the three tests conducted with siliceous concrete. For test CCI-1, the ablation was highly non-uniform, with most of the ablation concentrated in the North sidewall of the test apparatus. Crust stability may have played a major role in determining the ablation progression for this experiment; i.e., the data suggests that after the crust failed on the North concrete sidewall, the input power was predominately dissipated through ablation of this sidewall, while crusts continued to protect the basemat and south sidewall surfaces during the balance of the interaction.

In contrast to Test CCI-1, Test CCI-3 exhibited fairly symmetrical behavior insofar as the progression of lateral ablation is concerned. However, unlike Test CCI-2, the lateral ablation was highly pronounced in comparison to axial ablation. The same conclusion was drawn based on the CCI-5 test results; this experiment was conducted in an increased span test section with one ablating concrete wall. Long term lateral ablation in both CCI-3 and CCI-5 averaged $\sim 10$ $\mathrm{cm} / \mathrm{hr}$, while axial rates were in the range of $2-2.5 \mathrm{~cm} / \mathrm{hr}$. On this basis, the lateral/axial surface heat flux ratio for the siliceous tests was $\sim 4$, which is significantly higher than the near-unity ratio deduced for LCS concrete tests. The relatively close agreement in long-term ablation behavior for tests CCI-3 and CCI-5 indicate that aspect ratio has little influence on ablation characteristics. This observation lends credibility to the measured power split for siliceous concrete insofar as extrapolating the results to plant conditions. Between the two concrete types, possible explanations for differences in the erosion behavior are chemical composition and concrete gas content. A third possible explanation was revealed during posttest examinations. In particular, the core-concrete interface for the siliceous concrete tests consisted of a region where the core oxide had locally displaced the cement that bonded the aggregate. Conversely, the 
ablation front for the LCS tests consisted of a powdery interface in which the core and concrete oxides were clearly separated. Variations in the interface characteristics may have influenced the ablation behavior for the two concrete types.

In terms of the chemical analysis results obtained as part of the test series, the corium in the central region of the test section was generally found to have a slightly higher concentration of core oxides in comparison to that adjacent to the ablating concrete sidewalls. Conversely, core oxides were found to be slightly concentrated near the concrete basemat in comparison to that found in the bulk of the corium for some tests. For all siliceous concrete tests, two zones appeared to be present: a heavy monolithic oxide phase immediately over the basemat that was enriched in core oxides, with a second overlying porous, light oxide phase that was enriched in concrete oxides.

The objectives of the Category 4 CCI-6 test were to: 1) carry out a large scale integraleffect test to provide data on core debris coolability under early top flooding conditions, and if the corium did not quench during this initial interaction, 2) provide additional data on coolability under bottom flooding conditions wherein water would be injected into the melt through nozzles cast in the basemat. The overall experiment approach taken to meet these objectives was to: 1 ) enlarge the test section to minimize scaling distortions, and 2) incorporate an array of water injection nozzles into the core-concrete interaction test apparatus to inject water from below. Specifically, the test section was enlarged to incorporate a $70 \mathrm{~cm} \mathrm{x} 70 \mathrm{~cm}$ basemat, and the initial melt depth was increased to $28 \mathrm{~cm}$ (900 kg melt mass). The thermite was redesigned to reduce the amount of concrete initially present (i.e., $6 \mathrm{wt} \%$ ) to better mockup early cavity conditions. Water was intended to be added to the cavity as soon as ablation began. The basemat was redesigned to accommodate an array of water injection nozzles to quench the melt from below if the melt was not quenched earlier and ablation proceeded to $27 \mathrm{~cm}$.

The experiment was operationally successful, despite early melt through of the main steamline. The debris cooled exceptionally well, particularly in light of the fact that the test was conducted with siliceous concrete which has relatively low gas content. The debris-water heat flux, power supply response, and posttest debris morphology were all consistent with very good cooling. The question arises as to why this test cooled so well relative to previous tests conducted in the OECD/MCCI and MACE experiment programs. Differences between this experiment and those conducted previously include: i) increased scale, ii) early cavity flooding, iii) lowest initial concrete content in the melt (6 wt \%), and iv) no anchored crust occurred that confounded coolability demonstration in the MACE experiment program. Finally, another difference between this test and virtually all tests conducted in the MACE program is that CCI-6 utilized a 2-D concrete crucible, as opposed to the 1-D apparatus used in MACE.

With respect to cooling mechanisms, the test also demonstrated that melt eruptions are viable for siliceous concrete, and that water ingression into fractured crust material is very effective for low concrete melts. Unfortunately, due to the relatively good cooling that was experienced early on, no data on bottom water injection cooling at large scale was obtained. 
In terms of the applicability to plant conditions, these tests have provided information that will contribute to the database for reducing modeling uncertainties related to two-dimensional molten core-concrete interaction under both wet and dry cavity conditions. However, note that in real plant accident sequences, a significant melt metal fraction may be present that may result in a stratified pool configuration. This type of pool structure was not evaluated in this program. Thus, additional analysis and testing may be required with melts containing a significant metal fraction to further reduce phenomenological uncertainties related to core-concrete interaction, and to evaluate the effects of melt metal content on debris coolability. 


\subsection{REFERENCES}

1. M. T. Farmer, S. Lomperski, D. J. Kilsdonk, and R. W. Aeschlimann, "OECD MCCI Project Final Report,” OECD/MCCI-2005-TR06 (2006).

2. S. Lomperski, M. T. Farmer, R. W. Aeschlimann, and D.J. Kilsdonk, "Small-Scale Water Ingression and Crust Strength Tests (SSWICS) Final Report: Category 1 Test Results," OECD/MCCI-2010-TR01 (2010).

3. S. Lomperski, M. T. Farmer, D.J. Kilsdonk, and R. W. Aeschlimann, "Small-Scale Water Ingression and Crust Strength Tests (SSWICS) SSWICS Final Report: Thermal Hydraulic Results," OECD/MCCI-2005-TR03 (2005).

4. S. Lomperski, M. T. Farmer, D. J. Kilsdonk, and R. W. Aeschlimann, "Project Small-Scale Water Ingression and Crust Strength Tests (SSWICS) SSWICS Final Report: Crust Strength Measurements," OECD/MCCI-2005-TR02 (2005).

5. M. T. Farmer, S. Lomperski, R. W. Aeschlimann, and D. J. Kilsdonk, "Category 2 Coolability Engineering Enhancement Tests: Final Report," OECD/MCCI-2010-TR02 (2010).

6. M. T. Farmer, R. W. Aeschlimann, D. J. Kilsdonk, and S. Lomperski, "Category 3 Tests to Generate 2-D Core-Concrete Interaction Data: Final Report," OECD/MCCI-2010-TR06 (2010).

7. D. H. Thompson, M. T. Farmer, J. K. Fink, D. R. Armstrong, and B. W. Spencer, "ACE Phase C Final Report: Volume I - MCCI Thermalhydraulic Results," ACE-TR-C42 Volume I (1997).

8. M.T. Farmer, D. J. Kilsdonk, R. W. Aeschlimann, and S. Lomperski, "Category 4 Integral Test to Validate Severe Accident Codes: Final Report," OECD/MCCI-2010-TR05 (2010).

9. B. R. Sehgal, "Stabilization and Termination of Severe Accidents in LWRs," Nuclear Eng. Design Vol. 236, p. 1941 (2006).

10. A. Jasiulevicius and B. R. Sehgal, "COMECO Experiments on Molten Pool Coolability Enhancement in the BWR Lower Head with CRGTs," Proceedings NURETH-10, Seoul, Korea, October 5-9, 2003.

11. A. K. Nayak, B. R. Sehgal, and A. V. Stepanyan, "Quenching Behavior of a VolumetricallyHeated Particulate Bed with Non-Condensible Gas Addition from Bottom," $42^{\text {nd }}$ European Two-Phase Flow Group Meeting, Genova, Switzerland, June 23-25, 2004. 
12. A. K. Nayak, A. V. Stepanyan, and B. R. Sehgal, "An Experimental Study of Debris Bed Quenching in a Radially-Stratified Porous Bed," Proceedings NURETH-11, Avignon, France, October 2-6, 2005.

13. S. Lomperski and M. T. Farmer, "Experimental Evaluation of the Water Ingression Mechanism for Corium Cooling,” Nuclear Eng. Design, Vol. 237, p. 905 (2006).

14. S. Lomperski and M. T. Farmer, "Corium Crust Strength Measurements," Nuclear Eng. Design, Vol. 239, p. 2551 (2009).

15. M. T. Farmer, D. J. Kilsdonk, and R. W. Aeschlimann, "Corium Coolability under Ex-Vessel Accident Conditions for LWRs," Nuclear Eng. Technology, Vol. 41, p. 575 (2009).

16. K. R. Robb and M. L. Corradini, "Ex-Vessel Corium Coolability Sensitivity Study with the CORQUENCH Code," Proceedings NURETH-13, Kanazawa, Japan, September 27-October $2,2009$.

17. T.G. Theofanous, C. Liu, S. Addition, S. Angelini, O. Kymäläinen, and T. Salmassi "InVessel Coolability and Retention of a Core Melt," Nucl. Eng. Design, Vol. 169, p. 1 (1997).

18. T.N. Dinh, J.P. Tu, and T.G. Theofanous, "Two-Phase Natural Circulation Flow in AP-1000 In-Vessel Retention - Related ULPU-V Facility Experiments," Proceedings ICAPP '04, Pittsburgh, PA USA, June 13-17, 2004.

19. M. Fischer and H. Henning, "EPR ${ }^{\mathrm{TM}}$ Engineered Features for the Mitigation of Severe Accidents,” Proceedings ICAPP '09, Tokyo, Japan, May 10-14, 2009.

20. M. Fischer, O. Herbst, and H. Schmidt, "Demonstration of Heat Removing Capabilities of the EPR Core Catcher,” Nucl. Eng. Design, Vol. 235, p. 1189 (2005).

21. V.B. Khabensky, V.S. Granovsky, S.V. Bechta, and V.V. Gusarov, "Severe Accident Management Concept of the VVER-1000 and the Justification of Corium Retention in a Crucible-Type Core Catcher," Nucl. Eng. Technology, Vol. 41, p. 622 (2009).

22. H. Alsmeyer, M. Farmer, F. Ferderer, B. Spencer, and. W. Tromm, "The COMET-Concept for Cooling of Ex-Vessel Corium Melts," Proceedings ICONE-6, San Diego, CA USA, May 10-14, 1998.

23. H. Alsmeyer et al., "Ex-Vessel Core Melt Stabilization Research (ECOSTAR)," Nucl. Eng. Design, Vol. 235, p. 271 (2005).

24. C. Journeau and H. Alsmeyer, "Validation of the COMET Bottom-Flooding Core-Catcher with Prototypic Corium,” Proceedings ICAPP '06, Reno, Nevada USA, June 6-8, 2006. 
25. M. J. Konovalikhin and B. R. Sehgal, "Investigation of Volumetrically Heated Debris Bed Quenching," Proceedings ICONE-9, Nice, France, April 8-12, 2001.

26. K. Nayak, B. R. Sehgal, and A. V. Stepanyan, "An Experimental Study on Quenching of a Radially-Stratified Heated Porous Bed,” Nucl. Eng. Design, Vol. 236, p. 2189 (2006).

27. D. A. Powers, D. A. Dahlgren, J. F. Muir, and W. D. Murfin, "Exploratory Study of Molten Core Material/Concrete Interactions July 1975 - March 1977," SAND77-2042 (1978).

28. D. A. Powers and F. E. Arellano, "Large-Scale, Transient Tests of the Interaction of Molten Steel with Concrete," NUREG/CR-2282 (1982).

29. E. R. Copus, R. E. Blose, J. E. Brockmann, R. D. Gomez and D. A. Lucero, "Core-Concrete Interactions using Molten Steel with Zirconium on a Basaltic Basemat: The SURC-4 Experiment," NUREG/CR-4994 (1989).

30. E. R. Copus, R. E. Blose, J. E. Brockmann, R. D. Gomez and D. A. Lucero, "Experimental Results of Core-Concrete Interactions Using Molten Steel with Zirconium," NUREG/CR4794 (1990).

31. W. W. Tarbell, D. R. Bradley, R. E. Blose, J. W. Ross, and D. W. Gilbert, "Sustained Concrete Attack by Low-Temperature, Fragmented Core Debris," NUREG/CR-3024 (1987).

32. H. Alsmeyer, "BETA Experiments in Verification of the WECHSL Code: Experimental Results on the Melt-Concrete Interaction," Nucl. Eng. and Design, Vol. 103, p. 115 (1987).

33. H. Alsmeyer, "BETA Experiments on Zirconium Oxidation and Aerosol Release During Molten Corium/Concrete Interaction," $2^{\text {nd }}$ CSNI Specialists Meeting on Core DebrisConcrete Interactions, OECD/NEA/CSNI R(92)10, Karlsruhe, Germany, April 1992.

34. T. Sevón, T. Kinnunen, J. Virta, S. Holmström, P. H. Pankakoski, P. Koskinen, and T. Kekki, HECLA Experiments on Melt-Concrete Interactions: Final Report, VTT Research Report VTT-R-08013-09 (2009).

35. D. H. Thompson, et al., "Thermal-hydraulic Aspects of the Large-Scale Integral MCCI Tests in the ACE program," $2^{\text {nd }}$ CSNI Specialists Meeting on Core Debris-Concrete Interactions, OECD/NEA/CSNI R(92)10, Karlsruhe, Germany, April 1992.

36. J. K. Fink et al., "Aerosol and Melt Chemistry in the ACE Molten Core-Concrete Interaction Experiments," High Temperature and Materials Science, Vol. $\underline{33}$, p. 51 (1995).

37. J. E. Gronager, A. J. Suo-Anttila, and J. E. Brockman, "TURC2 and 3: Large Scale $\mathrm{UO}_{2} / \mathrm{ZrO}_{2} / \mathrm{Zr}$ Melt-Concrete Interaction Experiments and Analysis," NUREG/CR-4521 (1986). 
38. E. R. Copus, "Sustained Uranium Dioxide/Concrete Interaction Tests: The SURC Test Series," $2^{\text {nd }}$ CSNI Specialists Meeting on Core Debris-Concrete Interactions, OECD/NEA/CSNI R(92)10, Karlsruhe, Germany, April 1992.

39. E. R. Copus, R. E. Blose, J. E. Brockmann, R. B. Simpson, and D. A. Lucero, "CoreConcrete Interactions Using Molten Urania with Zirconium on a Limestone-Common Sand Concrete Basemat - The SURC-1 Experiment," NUREG/CR-5443 (1992).

40. E. R. Copus, R. E. Blose, J. E. Brockmann, R. B. Simpson, and D. A. Lucero, “CoreConcrete Interactions Using Molten Urania with Zirconium on a Basaltic Basemat - The SURC-2 Experiment," NUREG/CR-5564 (1992).

41. C. Journeau, P. Piluso, J.-F. Haquet, S. Saretta, E. Boccaccio, and J.-M. Bonnet, "OxideMetal Corium-Concrete Interaction Test in the VULCANO Facility," Proceedings ICAPP '07, Nice, France, May 13-18, 2007.

42. C. Journeau, P. Piluso, J.-F. Haquet, E. Boccaccio, V. Saldo, J.-M. Bonnet, S. Malaval, L. Carenini, and L. Brissonneau, "Two-dimensional Interaction of Oxidic Corium with Concretes: The VULCANO VB Test Series," Annals of Nuclear Energy, Vol. 36, p. 1597 (2009).

43. M. T. Farmer, S. Lomperski, D. Kilsdonk, R. W. Aeschlimann, and S. Basu, "A Summary of Findings from the Melt Coolability and Concrete Interaction (MCCI) Program," Proceedings ICAPP '07, Nice, France, May 13-18, 2007.

44. T. G. Theofanous, C. Liu, and W. W. Yuen, "Coolability and Quench of Corium-Concrete Interactions by Top-Flooding," MACE-TR-D14 (1998).

45. R. E. Blose, J. E. Gronager, A. J. Suo-Anttila, and J. E. Brockman, "SWISS: Sustained Heated Metallic Melt/Concrete Interactions With Overlying Water Pools," NUREG/CR-4727 (1987).

46. R. E. Blose, D. A. Powers, E. R. Copus, J. E. Brockmann, R. B. Simpson, and D. A. Lucero, "Core-Concrete Interactions with Overlying Water Pools - The WETCOR-1 Test," NUREG/CR-5907 (1993).

47. G. Sdouz, R. Mayrhofer, H. Alsmeyer, T. Cron, B. Fluhrer, J. Foit, G. Messemer, A. Miassoedov, S. Schmidt-Stiefel, and T. Wenz, "The COMET-L2 Experiment on Long-Term MCCI with Steel Melt," FZKA 7214 (2006).

48. H. Alsmeyer, T. Cron, B. Fluhrer, G. Messemer, A. Miassoedov, S. Schmidt-Stiefel, and T. Wenz, "The COMET-L3 Experiment on Long-Term Melt-Concrete Interaction and Cooling by Surface Flooding," FZKA 7244 (2007). 
49. H. Nagasaka, M. Kato, I. Sakaki, Y. Cherepnin, Y. Vasilyev, A. Kolodeshnikov, V. Zhdanov, and V. Zuev, "COTELS Project (1): Overview of Project to Study FCI and MCCI During a Severe Accident," OECD Workshop on Ex-Vessel Debris Coolability, Karlsruhe, Germany, November 15-18, 1999.

50. H. Nagasaka, I. Sakaki, M. Kato, Y. Vasilyev, A. Kolodeshnikov, and V. Zhdanov, "COTELS Project (3): Ex-vessel Debris Cooling Tests," OECD Workshop on Ex-Vessel Debris Coolability, Karlsruhe, Germany, November 15-18, 1999.

51. M. T. Farmer, B. W. Spencer, D. J. Kilsdonk, and R. W. Aeschlimann, "Results of MACE Corium Coolability Experiments M0 and M1b," Proceedings of ICONE-8, Baltimore, MD, April 2-6, 2000.

52. B. R. Sehgal, "Light Water Reactor (LWR) Safety," Nucl. Eng. Technology, Vol. $\underline{38}$, p. 1 (2006).

53. R. J. Roark and W. C. Young, Formulas for Stress and Strain, McGraw-Hill, Inc., New York, Chapter 10 (1975).

54. A. G. Evans and R. W. Davidge, "The Strength and Fracture of Stoichiometric

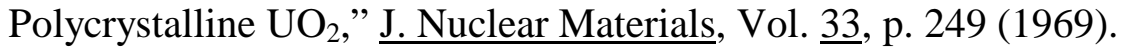

55. S. Mindess and J. F. Young, Concrete, Prentice-Hall, Inc., Englewood Cliffs, Chapter 15 (1981).

56. M. T. Farmer, D. J. Kilsdonk, and R. W. Aeschlimann, "MSET-1 Test Data Report," EPRI/MACE-TR-D18 (2002).

57. S. Lomperski, M. T. Farmer, D. J. Kilsdonk, and R. W. Aeschlimann, "Small-Scale Water Ingression and Crust Strength Tests (SSWICS); SSWICS-8 Test Data Report: Thermalhydraulic Results," OECD/MCCI-2007-TR02 (2007).

58. M. T. Farmer, D. J. Kilsdonk, S. Lomperski, and R. W. Aeschlimann, "Category 2 Coolability Engineering Enhancement Tests: Water-Cooled Basemat Test 1 (WCB-1) Test Plan," OECD/MCCI-2008-TR04 (2008).

59. M. T. Farmer, R. W. Aeschlimann, D. J. Kilsdonk, and, S. Lomperski, "2-D Core Concrete Interaction (CCI) Tests: CCI-4 Final Report," Rev.0, OECD/MCCI-2007-TR06, November, 2007.

60. M. T. Farmer, D. J. Kilsdonk, S. Lomperski, and R. W. Aeschlimann, "CCI-5 Data Report," OECD/MCCI-2009-TR06, November 2009.

61. M. F. Roche, et al., "Solidus and Liquidus Temperatures of Core-Concrete Mixtures," U.S. Nuclear Regulatory Commission Report NUREG/CR-6032, 1993. 
62. J. J. Sienicki and B. W. Spencer, "The Jet Impingement Stage of Molten Core-Concrete Interactions," OECD CSNI Specialist Meeting on Core Debris/Concrete Interactions, Electric Power Research Institute, Palo Alto, CA, September 3-5, 1986.

63. M. T. Farmer, D. J. Kilsdonk, R. W. Aeschlimann, and S. Lomperski, "Category 4 Integral Test to Validate Severe Accident Codes: Core-Concrete Interaction Test Six (CCI-6) Data Report," OECD/MCCI-2010-TR04, June 2010.

64. J. M. Bonnet and J. M. Seiler, "Coolability of Corium Spread Onto Concrete Under Water, the PERCOLA Model," $2^{\text {nd }}$ CSNI Specialists Meeting on Core Debris-Concrete Interactions, OECD/NEA/CSNI R(92)10, Karlsruhe, Germany, April 1992. 
OECD/MCCI-2010-TR06, Rev. 1

APPENDIX A: BIBLIOGRAPHY OF MCCI-2 PROJECT REPORTS

\begin{tabular}{|c|c|c|c|c|}
\hline$\#$ & Report \# & \multicolumn{2}{|c|}{ Revision Status } & Author and Title \\
\hline 1 & 2006-TR01 & $\begin{array}{l}\text { Rev. } 0 \\
\text { Rev. } 1\end{array}$ & $\begin{array}{l}12 / 06 \\
02 / 07\end{array}$ & $\begin{array}{l}\text { S. Lomperski, M. T. Farmer, D. J. Kilsdonk, and R. W. } \\
\text { Aeschlimann, Small-Scale Water Ingression and Crust } \\
\text { Strength Tests (SSWICS); SSWICS-8 Design Report. }\end{array}$ \\
\hline 2 & 2007-TR01 & $\begin{array}{l}\text { Rev. } 0 \\
\text { Rev. } 1\end{array}$ & $\begin{array}{l}02 / 07 \\
07 / 08\end{array}$ & M. T. Farmer, CORQUENCH 3.0 User's Guide \\
\hline 3 & 2007-TR02 & $\begin{array}{l}\text { Rev. } 0 \\
\text { Rev. } 1 \\
\text { Rev. } 2\end{array}$ & $\begin{array}{l}02 / 07 \\
03 / 07 \\
04 / 07\end{array}$ & $\begin{array}{l}\text { S. Lomperski, M. T. Farmer, D. J. Kilsdonk, and R. W. } \\
\text { Aeschlimann, Small-Scale Water Ingression and Crust } \\
\text { Strength Tests (SSWICS); SSWICS-8 Test Data Report: } \\
\text { Thermalhydraulic Results. }\end{array}$ \\
\hline 4 & 2007-TR03 & Rev. 0 & $02 / 07$ & $\begin{array}{l}\text { M. T. Farmer, D. J. Kilsdonk, S. Lomperski, and R. W. } \\
\text { Aeschlimann, OECD MCCI Project 2-D Core Concrete } \\
\text { Interaction (CCI) Tests: CCI-4 Test Plan. }\end{array}$ \\
\hline 5 & 2007-TR04 & Rev. 0 & $06 / 07$ & $\begin{array}{l}\text { M. T. Farmer, R. W. Aeschlimann, D. J. Kilsdonk, and S. } \\
\text { Lomperski, OECD MCCI Project 2-D Core Concrete } \\
\text { Interaction (CCI) Tests: CCI-4 Quick Look Data Report. }\end{array}$ \\
\hline 6 & 2007-TR05 & Rev. 0 & $11 / 07$ & $\begin{array}{l}\text { S. Lomperski, M. T. Farmer, D. J. Kilsdonk, and R. W. } \\
\text { Aeschlimann, Small-Scale Water Ingression and Crust } \\
\text { Strength Tests (SSWICS); SSWICS-9 \& } 10 \text { Design Report. }\end{array}$ \\
\hline 7 & 2007-TR06 & $\begin{array}{l}\text { Rev.0 } \\
\text { Rev. } 1\end{array}$ & $\begin{array}{l}10 / 07 \\
11 / 10\end{array}$ & $\begin{array}{l}\text { M. T. Farmer, R. W. Aeschlimann, D. J. Kilsdonk, and S. } \\
\text { Lomperski, OECD MCCI Project 2-D Core Concrete } \\
\text { Interaction (CCI) Tests: CCI-4 Final Data Report. }\end{array}$ \\
\hline 8 & 2008-TR01 & Rev. 0 & $02 / 08$ & $\begin{array}{l}\text { S. Lomperski, M. T. Farmer, D. J. Kilsdonk, and R. W. } \\
\text { Aeschlimann, Small-Scale Water Ingression and Crust } \\
\text { Strength Tests (SSWICS); SSWICS-9 Test Data Report: } \\
\text { Thermalhydraulic Results. }\end{array}$ \\
\hline 9 & 2008-TR02 & $\begin{array}{l}\text { Rev. } 0 \\
\text { Rev. } 1\end{array}$ & $\begin{array}{l}03 / 08 \\
03 / 08\end{array}$ & $\begin{array}{l}\text { S. Lomperski, M. T. Farmer, D. J. Kilsdonk, and R. W. } \\
\text { Aeschlimann, Small-Scale Water Ingression and Crust } \\
\text { Strength Tests (SSWICS); SSWICS-10 Test Data Report: } \\
\text { Thermalhydraulic Results. }\end{array}$ \\
\hline 10 & 2008-TR03 & $\begin{array}{l}\text { Rev. } 0 \\
\text { Rev. } 1\end{array}$ & $\begin{array}{l}03 / 08 \\
05 / 08\end{array}$ & $\begin{array}{l}\text { M. T. Farmer, D. J. Kilsdonk, S. Lomperski, and R. W. } \\
\text { Aeschlimann, 2-D Core Concrete Interaction (CCI) Tests: } \\
\text { CCI-5 Test Plan }\end{array}$ \\
\hline
\end{tabular}


OECD/MCCI-2010-TR06, Rev. 1

\begin{tabular}{|c|c|c|c|c|}
\hline \# & Report \# & \multicolumn{2}{|c|}{ Revision Status } & Author and Title \\
\hline 11 & 2008-TR04 & $\begin{array}{l}\text { Rev. } 0 \\
\text { Rev. } 1 \\
\text { Rev. } 2\end{array}$ & $\begin{array}{l}04 / 08 \\
05 / 08 \\
06 / 08\end{array}$ & $\begin{array}{l}\text { M. T. Farmer, D. J. Kilsdonk, S. Lomperski, and R. W. } \\
\text { Aeschlimann, Category } 2 \text { Coolability Engineering } \\
\text { Enhancement Tests: Water-Cooled Basemat Test } 1 \text { (WCB-1) } \\
\text { Test Plan }\end{array}$ \\
\hline 12 & 2008-TR05 & Rev. 0 & 08/08 & $\begin{array}{l}\text { S. Lomperski, M. T. Farmer, D. J. Kilsdonk, and R. W. } \\
\text { Aeschlimann, Small-Scale Water Ingression and Crust } \\
\text { Strength Tests (SSWICS); SSWICS-11 Design Report. }\end{array}$ \\
\hline 13 & 2008-TR06 & $\begin{array}{l}\text { Rev. } 0 \\
\text { Rev. } 1\end{array}$ & $\begin{array}{l}03 / 09 \\
03 / 09\end{array}$ & $\begin{array}{l}\text { S. Lomperski, M. T. Farmer, D. J. Kilsdonk, and R. W. } \\
\text { Aeschlimann, Small-Scale Water Ingression and Crust } \\
\text { Strength Tests (SSWICS); SSWICS-12 Design Report. }\end{array}$ \\
\hline 14 & 2008-TR07 & Rev. 0 & $11 / 08$ & $\begin{array}{l}\text { M. T. Farmer, D. J. Kilsdonk, S. Lomperski, and R. W. } \\
\text { Aeschlimann, CCI-5 Quick Look Data Report }\end{array}$ \\
\hline 15 & 2009-TR01 & $\begin{array}{l}\text { Rev. } 0 \\
\text { Rev. } 1 \\
\text { Rev. } 2 \\
\text { Rev. } 3\end{array}$ & $\begin{array}{l}01 / 09 \\
03 / 09 \\
09 / 09 \\
06 / 10\end{array}$ & $\begin{array}{l}\text { S. Lomperski, M. T. Farmer, D. J. Kilsdonk, and R. W. } \\
\text { Aeschlimann, Small-Scale Water Ingression and Crust } \\
\text { Strength Tests (SSWICS); SSWICS-11 Test Data Report: } \\
\text { Thermalhydraulic Results. }\end{array}$ \\
\hline 16 & 2009-TR02 & $\begin{array}{l}\text { Rev.0 } \\
\text { Rev. } 1 \\
\text { Rev. } 2 \\
\text { Rev. } 3\end{array}$ & $\begin{array}{l}03 / 09 \\
06 / 09 \\
08 / 09 \\
11 / 10\end{array}$ & $\begin{array}{l}\text { M. T. Farmer, D. J. Kilsdonk, S. Lomperski, and R. W. } \\
\text { Aeschlimann, Category } 4 \text { Integral Test to Validate Severe } \\
\text { Accident Codes: Core-Concrete Interaction Test Six (CCI- } \\
\text { 6) Test Plan }\end{array}$ \\
\hline 17 & 2009-TR03 & $\begin{array}{l}\text { Rev. } 0 \\
\text { Rev. } 1\end{array}$ & $\begin{array}{l}08 / 09 \\
11 / 09\end{array}$ & $\begin{array}{l}\text { S. Lomperski, M. T. Farmer, D. J. Kilsdonk, and R. W. } \\
\text { Aeschlimann, Small-Scale Water Ingression and Crust } \\
\text { Strength Tests (SSWICS); SSWICS-13 Design Report. }\end{array}$ \\
\hline 18 & 2009-TR04 & $\begin{array}{l}\text { Rev. } 1 \\
\text { Rev. } 2\end{array}$ & $\begin{array}{l}08 / 20 / 09 \\
09 / 14 / 09\end{array}$ & $\begin{array}{l}\text { S. Lomperski, M. T. Farmer, D. J. Kilsdonk, and R. W. } \\
\text { Aeschlimann, Small-Scale Water Ingression and Crust } \\
\text { Strength Tests (SSWICS); SSWICS-12 Test Data Report: } \\
\text { Thermalhydraulic Results. }\end{array}$ \\
\hline 19 & 2009-TR05 & Rev. 0 & $11 / 09$ & $\begin{array}{l}\text { M. T. Farmer, R. W. Aeschlimann, D. J. Kilsdonk, and S. } \\
\text { Lomperski, OECD MCCI Project Engineering } \\
\text { Enhancement Tests: Water-Cooled Basemat Test } 1 \text { (WCB-1) } \\
\text { Data Report }\end{array}$ \\
\hline 20 & 2009-TR06 & $\begin{array}{l}\text { Rev. } 0 \\
\text { Rev. } 1\end{array}$ & $\begin{array}{l}11 / 09 \\
11 / 10\end{array}$ & $\begin{array}{l}\text { M. T. Farmer, D. J. Kilsdonk, S. Lomperski, and R. W. } \\
\text { Aeschlimann, OECD MCCI Project } 2-D \text { Core concrete } \\
\text { Interaction (CCI) Tests: CCI-5 Data Report }\end{array}$ \\
\hline
\end{tabular}


OECD/MCCI-2010-TR06, Rev. 1

\begin{tabular}{|c|c|c|c|c|}
\hline$\#$ & Report \# & \multicolumn{2}{|c|}{ Revision Status } & Author and Title \\
\hline 21 & 2009-TR07 & Rev. 0 & $12 / 09$ & $\begin{array}{l}\text { S. Lomperski, M. T. Farmer, D. J. Kilsdonk, and R. W. } \\
\text { Aeschlimann, Small-Scale Water Ingression and Crust } \\
\text { Strength Tests (SSWICS); SSWICS-13 Test Data Report: } \\
\text { Thermalhydraulic Results. }\end{array}$ \\
\hline 22 & 2010-TR01 & $\begin{array}{l}\text { Rev. } 0 \\
\text { Rev. } 1\end{array}$ & $\begin{array}{l}02 / 10 \\
11 / 10\end{array}$ & $\begin{array}{l}\text { S. Lomperski, M. T. Farmer, R. W. Aeschlimann, and D. J. } \\
\text { Kilsdonk, Small-Scale Water Ingression and Crust Strength } \\
\text { Tests (SSWICS); Final Report Category } 1 \text { Test Results. }\end{array}$ \\
\hline 23 & 2010-TR02 & $\begin{array}{l}\text { Rev. } 0 \\
\text { Rev. } 1\end{array}$ & $\begin{array}{l}02 / 10 \\
11 / 10\end{array}$ & $\begin{array}{l}\text { M. T. Farmer, S. Lomperski, R. W. Aeschlimann, and D. J. } \\
\text { Kilsdonk, Category } 2 \text { Coolability Engineering } \\
\text { Enhancement Tests: Final Report }\end{array}$ \\
\hline 24 & 2010-TR03 & $\begin{array}{l}\text { Rev. } 0 \\
\text { Rev. } 1\end{array}$ & $\begin{array}{l}03 / 10 \\
11 / 10\end{array}$ & $\begin{array}{l}\text { M. T. Farmer, The CORQUENCH Code for Modeling of } \\
\text { Ex-Vessel Corium Coolability under Top Flooding } \\
\text { Conditions, Code Manual-Version3.03 }\end{array}$ \\
\hline 25 & 2010-TR04 & $\begin{array}{l}\text { Rev. } 0 \\
\text { Rev. } 1 \\
\text { Rev. } 1\end{array}$ & $\begin{array}{l}06 / 10 \\
08 / 10 \\
11 / 10\end{array}$ & $\begin{array}{l}\text { M. T. Farmer, D. J. Kilsdonk, R. W. Aeschlimann, and S. } \\
\text { Lomperski, Category } 4 \text { Integral Test to Validate Severe } \\
\text { Accident Codes: Core-Concrete Interaction Test Six (CCI- } \\
\text { 6) Final Report }\end{array}$ \\
\hline 26 & 2010-TR05 & $\begin{array}{l}\text { Rev. } 0 \\
\text { Rev. } 1\end{array}$ & $\begin{array}{l}07 / 10 \\
11 / 10\end{array}$ & $\begin{array}{l}\text { M.T. Farmer, D. J. Kilsdonk, R. W. Aeschlimann, and S. } \\
\text { Lomperski, Category } 4 \text { Integral Test to Validate Severe } \\
\text { Accident Codes: Final Report }\end{array}$ \\
\hline 27 & 2010-TR06 & $\begin{array}{l}\text { Rev. } 0 \\
\text { Rev. } 1\end{array}$ & $\begin{array}{l}08 / 10 \\
11 / 10\end{array}$ & $\begin{array}{l}\text { M. T. Farmer, R. W. Aeschlimann, D. J. Kilsdonk, and S. } \\
\text { Lomperski, Category } 3 \text { Tests to Generate 2-D Core- } \\
\text { Concrete Interaction Data: Final Report }\end{array}$ \\
\hline 28 & 2010-TR07 & $\begin{array}{l}\text { Rev. } 0 \\
\text { Rev. } 1\end{array}$ & $\begin{array}{l}11 / 10 \\
11 / 10\end{array}$ & $\begin{array}{l}\text { M. T. Farmer, S. Lomperski, D. J. Kilsdonk, and R. W. } \\
\text { Aeschlimann, and D. J. Kilsdonk, OECD MCCI-2 Project } \\
\text { Final Report }\end{array}$ \\
\hline
\end{tabular}

